On particulate characterization in a heavy-duty Diesel engine by time-resolved laser-induced incandescence

Sublimation

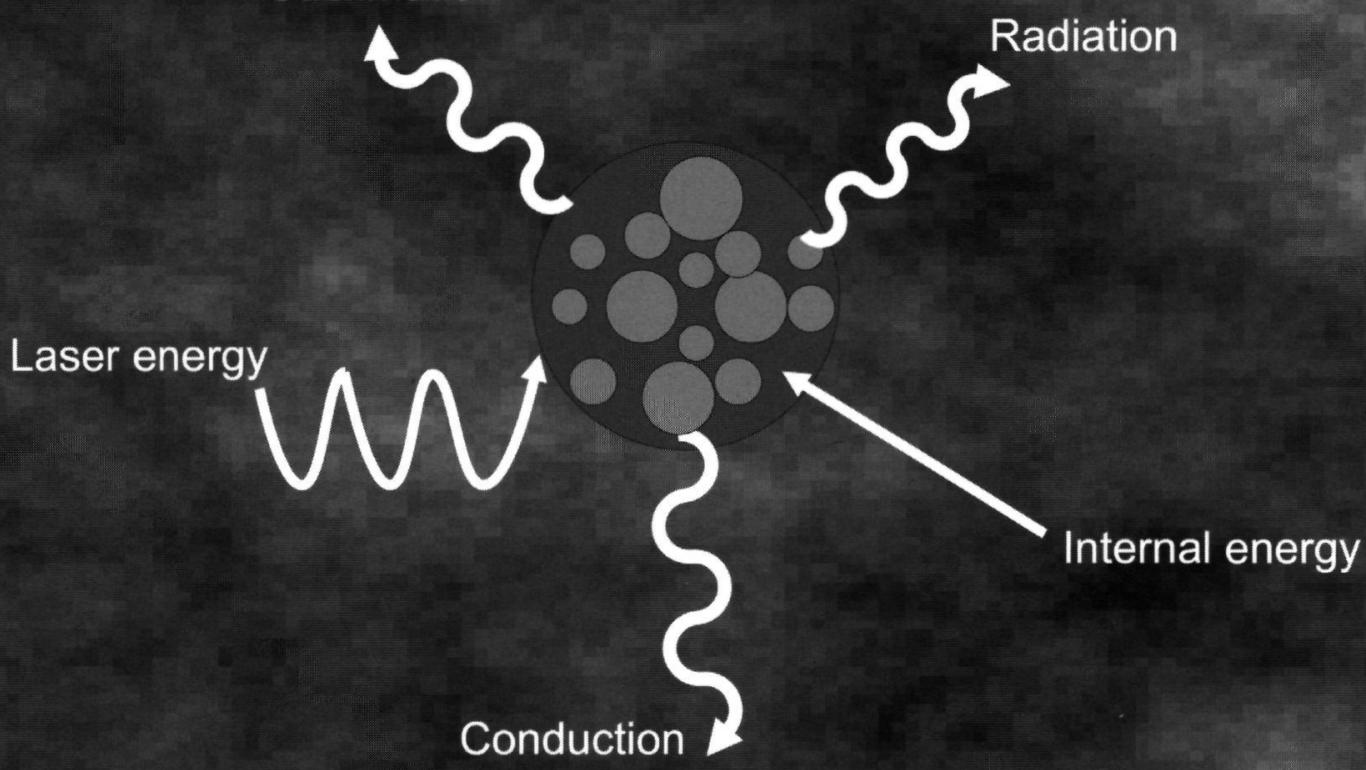

Bas Bougie 

ON PARTICULATE CHARACTERIZATION IN A HEAVY-DUTY DIESEL ENGINE BY TIME-RESOLVED LASER-INDUCED INCANDESCENCE 
On particulate characterization in a heavy-duty Diesel engine by time-resolved laser-induced incandescence

Bas Bougie

Thesis Radboud University Nijmegen - Illustrated

With references - With summary in Dutch

ISBN 978-90-9022431-2

Subject headings: combustion diagnostics / particulate characterization

Diesel engine / Diesel sprays / laser spectroscopy / imaging

Copyright (C) Bas Bougie (2007). 


\section{ON PARTICULATE CHARACTERIZATION IN A HEAVY-DUTY DIESEL ENGINE BY TIME-RESOLVED LASER-INDUCED INCANDESCENCE}

EEN WETENSCHAPPELIJKE PROEVE OP HET GEBIED VAN DE

NATUURWETENSCHAPPEN. WISKUNDE EN INFORMATICA

\section{PROEFSCHRIFT}

TER VERKRIJGING VAN DE GRAAD VAN DOCTOR

AAN DE RADBOUD UNIVERSITEIT NIJMEGEN.

OP GEZAG VAN DE RECTOR MIAGNIFICUS

PROF. MIR. S.C.J.J. KORTMANN.

VOLGENS BESLUIT VAN HET COLLEGE VAN DECANEN

IN HET OPENBAAR TE VERDEDIGEN

OP MIAANDAG 3 DECEMBER 2007.

OM 13.30 UUR PRECIES

DOOR

HENRICUS JOHANNA THEODORUS BOUGIE

GEBOREN OP 30 JUNI 1976

TE SITTARD 
PROMOTORES:

PROF. DR. J.J. TER MEULEN

PROF. DR. IR. R.S.G. BAERT

TECHNISCHE UNIVERSITEIT EINDHOVEN

COPROMOTORES:

DR. N.J. DAM

DR. T. GERBER

PAUL SCHERRER INSTITUT. VILLIGEN, ZWITSERLAND

MANUSCRIPTCOMMISSIE: PROF, DR. W.L. MEERTS

DR. T. DREIER

UNIVERSITÄT DUISBURG-ESSEN, DUITSLAND

PROF. DR. C. MOUNAÏM-ROUSSELLE POLYTECH. ORLÉANS.

FRANKRIJK

\section{Radboud University Nijmegen}
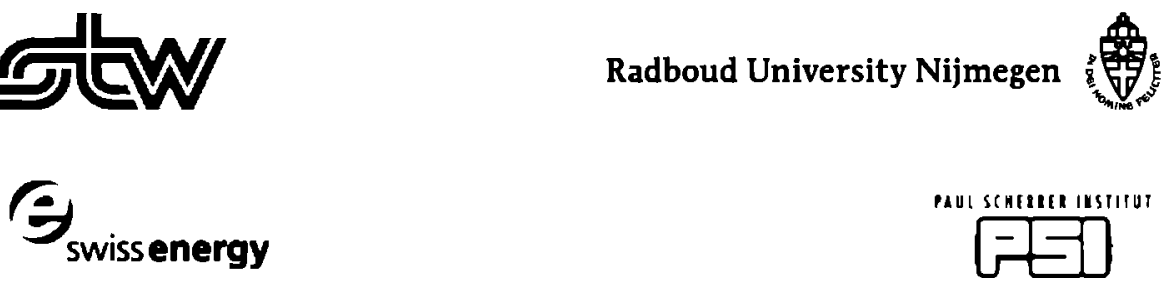

This research was financially supported by the Dutch Technology Foundation STW (project EWE.5125) and the Swiss Federal Officc of Encrgy (project 27509). 


\section{Contents}

1 Introduction 1

1.1 The Diesel engine and the environment . . . . . . . . . . . . 1

1.2 Diesel combustion process . . . . . . . . . . . . 3

1.3 Soot formation . . . . . . . . . . . . . . . . 4

1.4 Laser-induced incandescence . . . . . . . . . . . . . . . 4

1.5 Thesis setup . . . . . . . . . . . . . . 7

2 Diagnostics 13

2.1 Combustion systems . . . . . . . . . . . . . . . . . 13

2.1.1 The high-pressure high-tomperature cell . . . . . . . . . 13

2.1.2 The heavy-duty Diesel engine . . . . . . . . . . . 15

2.2 Diagnostic techniques . . . . . . . . . . . . . . . . . 17

2.2 .1 Shadowgraphy . . . . . . . . . . . . . 17

2.2 .2 Two-color pyrometry . . . . . . . . . . . . . . . . 18

2.2 .3 Laser-induced incandescence . . . . . . . . . . . . . . 19

$\begin{array}{ll}\text { 2.2.4 Practical issues of laser-induccd incandescence } & 21\end{array}$

3 TR-LII Model $\quad 31$

3.1 The Mclton model . . . . . . . . . . . . . . . . . . . 31

3.2 Comparison between several models 33

3.2 .1 Change in internal encrgy . . . . . . . . . . . . . 34

3.2.2 Absorption of laser encrgy . . . . . . . . . . . . . . . . 34

3.2 .3 Conductive cooling . . . . . . . . . . . . . . . . 34

3.2 .4 Vaporative/sublimative cooling . . . . . . . . . . . 36

3.2 .5 Radiation . . . . . . . . . . . . . . . . . 38

$\begin{array}{lll}3.3 & \text { Cooling model applicd in this study } & 38\end{array}$

3.3 .1 Interpolation functions . . . . . . . . . . . . . . . 39

$\begin{array}{llr}4 & \text { HTDZ experiments } & \mathbf{4 7}\end{array}$

4.1 Introduction . . . . . . . . . . . . . . . . 48

4.2 Measurement techniques . . . . . . . . . . . . . . . . 49

4.2.1 Experimental Setup $\quad 49$ 
4.3 Results and discussion . . . . . . . . . . . . . . . . . 51

4.3.1 Non-reacting spray injection . . . . . . . . . . . . 51

4.3 .2 Reacting sprays . . . . . . . . . . . . . 56

4.4 Conclusions and outlook . . . . . . . . . . . . . . . . . . . 59

5 Mono-disperse analysis $\quad \mathbf{6 7}$

5.1 Introduction . . . . . . . . . . . . . . . . . 67

5.2 Measurement and data analysis . . . . . . . . . . . 67 67

5.3 Results and discussion . . . . . . . . . . . . . . . . . . . . . . . . 69

6 Particulate characterization $\quad \mathbf{7 5}$

6.1 Introduction . . . . . . . . . . . . . . 76

6.2 Theory . . . . . . . . . . . . . . . . . 77

6.3 Experimental setup . . . . . . . . . . . . . . . . . . . 79

6.4 Results and discussion . . . . . . . . . . . . . . 81

6.4 .1 Detection system time responsc . . . . . . . . . 82

6.4 .2 Deconvolution . . . . . . . . . . . . . . . 82

$\begin{array}{lll}\text { 6.4.3 Initial Temperature } & 85\end{array}$

$6.4 .4 \quad \chi^{2}$-error landscape . . . . . . . . . . . . . . . 86

6.4.5 Crank angle dependent measurements . . . . . . . . . . 89

6.5 Summary and Conclusions . . . . . . . . . . . . . . . . . . 92

$\begin{array}{llr}7 & \text { Line pump measurements } & 97\end{array}$

7.1 Introduction . . . . . . . . . . . . . . . . . . . 97

7.2 TR-LII . . . . . . . . . . . . . . . . . . . . . . . . . . . . . 98

7.3 Experimental setup . . . . . . . . . . . . . . . . . . . . . . . 99

7.4 Results and discussion . . . . . . . . . . . . . . . . . . . . 102

7.5 Conclusions . . . . . . . . . . . . . . . . . . . 106

8 TR-LII at high injection pressure $\quad 111$

8.1 Introduction . . . . . . . . . . . . . . . . . . 111

8.2 Experimental setup . . . . . . . . . . . . . . . . . . . 112

8.3 Results and discussion . . . . . . . . . . . . . . . . . 112

8.4 Conclusions . . . . . . . . . . . . . . . . . 114

9 Conclusions and outlook 119

$\begin{array}{lr}\text { Appendices } & 122\end{array}$

$\begin{array}{lr}\text { A Annealing and oxidation } & 123\end{array}$

A.1 Annealing . . . . . . . . . . . . . . . . . . . . 123

A.2 Oxidation . . . . . . . . . . . . . . . . 125 
$\begin{array}{ll}\text { C Hyperbolic behavior } & 135\end{array}$

$\begin{array}{lr}\text { Summary } & 145\end{array}$

$\begin{array}{lr}\text { Samenvatting } & 147\end{array}$

$\begin{array}{lr}\text { Acknowledgments } & 148\end{array}$

$\begin{array}{ll}\text { About the author } & 151\end{array}$ 


\section{Chapter 1}

\section{Introduction}

\subsection{The Diesel engine and the environment}

In a Diesel engine a combustible mixture is heated up by compression until ignition tempcrature is reached. There is no spark plug. The fuel ignites as soon as the air to fuel ratio, the pressure and the temperature are in an appropriate range. This type of engine is named after Rudolf Diesel, who developed the first compression ignition engine in 1892. The Diesel engine is still the most efficient internal combustion engine present on the market nowadays. Dicscl engines are more efficient than sparkignition engines, as the maximal pressure which can be built up in the cylinders of a Diesel engine is bigger than that allowable in a gasoline (Otto) engine. Due to this higher efficiency a smaller amount of fuel is needed to obtain a comparable power [1]. As a consequence less greenhousc gas $\left(\mathrm{CO}_{2}\right)$ is produced during the Diesel combustion cycle compared to the Otto cycle.

However, in addition to $\mathrm{CO}_{2}$ other products emanating from the combustion process are harmful, like NO and soot [1]. Consequently, there is a strong necd to improve the combustion process. NO contributes to the formation of acid rain (e.g. [2]) and to the destruction of ozone (e.g. [3]). There are scveral pathways leading to the formation of NO [4-6]. The thermal NO formation mechanism, proposed by Zeldovich [4] takes place at high temperatures $(>1800 \mathrm{~K})$ and is generally considered as the most important $\mathrm{NO}$ formation process in the Diesel engine.

The creation of soot takes place in flames at the location where the fuel/air mixture is too fuel-rich [7]. Although during the last fiftecn years the pollution by fine particles and dust has been reduced significantly. there is an increasing need for further reduction [8]. because it has severe health cffects [10] and it contributes to global warming [9]. The major source of fine particles created by humans is the plentitude of Diesel engines used in terrestrial and maritime traffic. Legislation by the European Union is aiming at the reduction of both fine particles and $\mathrm{NO}_{\mathbf{x}}$ emitted from Diesel engines in terrestrial and maritime traffic. 
Since soot is formed primarily at relatively low $(1300 \mathrm{~K})$ and $\mathrm{NO}$ at higher $(1800 \mathrm{~K})$ temperatures, there is an antagonistic relation between the soot and $\mathrm{NO}_{\mathrm{x}}$ formation. $\mathrm{A} \mathrm{NO}_{\mathrm{x}} /$ particulates trade off is illustrated in Fig. 1.1. It can be seen that reducing the $\mathrm{NO}_{\mathrm{x}}$ formation is accompanied by an increase of the particulates production and vice versa. It is the challenge to break it [11].

The aim of the work described in this thesis is to measure in-situ the soot particle size distribution in a realistic Diesel engine, which has not been done up to now. The outcome of the measurements can be used by modelers to develop new models and to verify existing models, describing the soot formation is a Diesel engine. This may lead to a better understanding of the combustion process enabling the development of an improved engine design. Two ways of particle reduction could

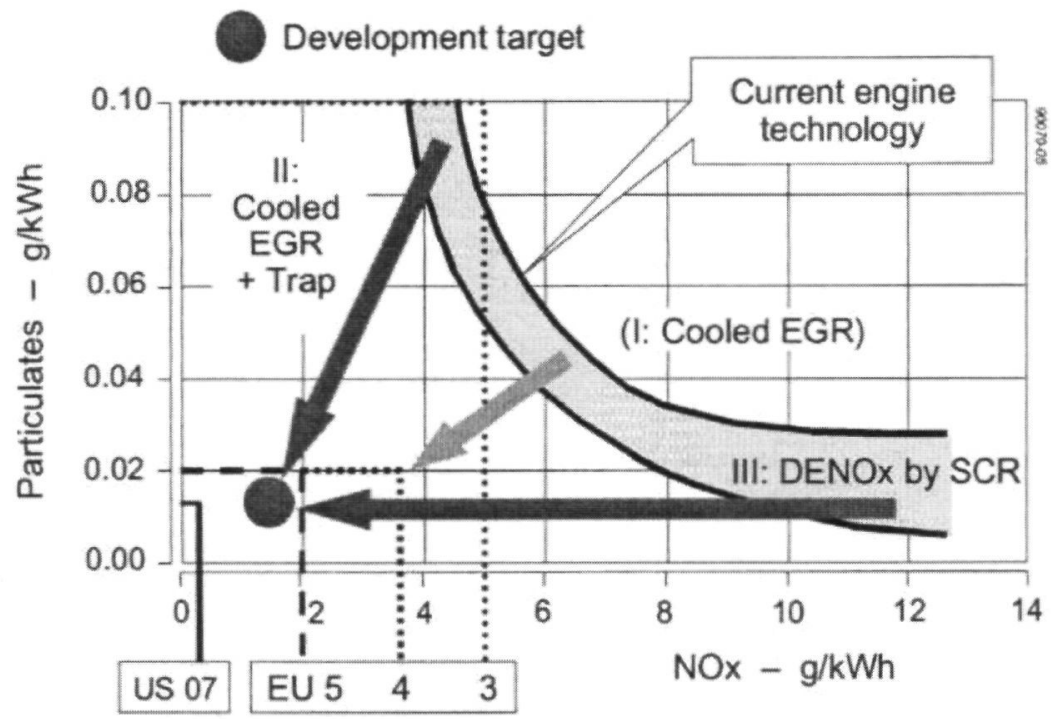

Figure 1.1: Trade off between the formation of $\mathrm{NO}_{\mathrm{x}}$ and soot in a heavy-duty Diesel engine. More production of $\mathrm{NO}_{\mathrm{x}}$ or soot, as the timing of the fuel injection is advanced or retarded, successively. The development targets for the European Union are indicated in the graph as well [11]. The EURO 5 emission standards are set to enter into force in the year 2009. The indicated "current engine technology "was the status in 2001. EGR: Exhaust gas recirculation; part of the exhaust gases are introduced at the inlet again. DENOx by SCR: Selective catalytic reduction of $\mathrm{NO}_{\mathrm{x}}$; a process where a gaseous or liquid reductant (most commonly ammonia or urea) is added to the exhaust gas stream and is absorbed onto a catalyst. The reductant reacts with $\mathrm{NO}_{\mathrm{x}}$ in the exhaust gas to form $\mathrm{H}_{2} \mathrm{O}$ and $\mathrm{N}_{2}$. Reprinted with permission from SAE 2001-01-0186 (C) 2001 SAE International 
be considered: The first one is trapping of the created particles before they are emitted from the exhaust, and the second one is the production of less particles in the engine. Trapping particles of the exhaust stream can be performed with carefully designed particle filters. Such filters, however. increase the fucl consumption and the costs and cannot prevent the smallest (and probably most harmful) particulates to pass through. The best solution of the soot problem has to be sought at the source, by for instance improved injection strategies and a higher injection pressure. Also the introduction of a swirl in the airflow could contribute to an improved combustion behavior. The latter two strategies contribute to a faster spray breakup and conscquently to a longer effective combustion time and a reduced emission of soot particles.

\subsection{Diesel combustion process}

The combustion process in a Diesel engine proceeds according to a very complex system of both physical and chemical mechanisms. Many physico-chemical parameters influcnce the combustion process, like pressurc, tempcrature, the flow field, composition of the fuel, composition of the intake air, etc. [12].

In a Diescl engine the whole process starts with the high-pressure injection of liquid fuel through one or several small orifices (nozzles), and the breakup and vaporisation of the ensuing jet. At the start of injection - very close to the nozzle a dense liquid core exists which penetrates with a high speed into the combustion chamber. Cavitation can occur in the nozzle when the local pressure of the moving fluid is lower than the vapor pressure. This phenomenon is supposed to play an important role during the first stage of the spray breakup (e.g. [13]), although the momentum transfer between the relatively quiescent air and the moving Diescl fuel is thought to be more responsible for this phenomenon $[13,14]$. Simultaneously, the spray penetration speed decreases. The breakup does not take place at one single location. but progresses actually over a trajectory [15]. After a certain time the fucl spray is broken up into small droplets. The definition of this so-called breakup time is subject to debate. Arai [16] defines the breakup time as the time needed for the penetration distance to change from a linear dependence of the time to a square-root dependence. The distance between the position of the spray tip at the breakup time and the exit hole of the nozzle is called the breakup length (See also Chapter 4). The mixing process is enhanced by turbulence which is caused by the high pressure at which the fuel is injected into the combustion chamber and the swirl of the air which is present in modern engines [1]. Because of the high temperature, present in the combustion chamber. the fuel parcels evaporate. For the initialization of the combustion process the temperature should be high enough. because this is one of the important physical parameters in the start-up of the combustion process [1]. The air-fuel-ratio should be in the range between 0.7 and about $1.3[1]$. If it is lower. then the mixture cannot ignite because it is too fucl-lean and if it is higher then it cannot ignite because it is too fuel-rich. If these conditions have been fulfilled. 
auto-ignition of the mixture can take place.

At this point the chemical composition of the fuel starts to play its role in the combustion process. The autoignition bchavior of a fuel (relative to two standard fuels) is globally characterized by the so-called cetane number [1]. After autoignition, which can occur simultaneously at several locations in the combustion chamber, the flame(s) will propagate through the combustion chamber, consuming fuel vapor and air on its (their) way. The production of soot. of course, is tightly linked to the details of this whole fucl combustion process.

\subsection{Soot formation}

The soot formation process has not been fully understood yet [7]. Recently, Xi and Zhong [19] have published a review about soot formation in Diesel combustion systems. The formation process of soot has been studied by a combination of experiments and simulations. Figure 1.2 shows the current understanding of the soot formation process. Soot is composed of heavy polycyclic aromatic hydrocarbons (PAHs), and its formation proceeds according to a complex mechanism [19]. The first step in the soot formation process is the formation of benzene rings from $\mathrm{C}_{2} \mathrm{H}_{2}$ and by addition of $\mathrm{C}_{2}$ and $\mathrm{C}_{3}$. It is, however, believed that different pathways lead to the formation of the first benzene ring in low or high temperature environments (Fig. 1.3). Molecular precursors of soot are thought to have a typical mass of 5001000 a.m.u. Miller et al. [20.21] believe that the formation of benzene takes place by concatenation of $\mathrm{C}_{3} \mathrm{H}_{3}$.

The sccond step in the soot formation process is formed by nucleation or inception of particles from these heavy PAH molecules [19]. In this step the PAH molecules are formed into nascent soot with a typical mass of about 2000 a.m.u. These particles have a diameter of about $1.5 \mathrm{~nm}$. During the third step gas phase moleculcs adsorb to the surface of the soot which make the soot particles grow. During the fourth step. particles stick together by particle-particle collisions. This causes the number of particles to decline, but the size of the particles grows. forming an agglomerate of soot particles. The fifth step in the soot formation process of Miller et al. is the change in morphological structure of soot. During this step. the small particles undergo a restructuring process. during which the amorphous soot is dehydrogenated and the soot is formed into a more graphitic ball-shaped structure. the so-called primary particle. During the sixth and last step soot is oxidizing and the particle size is decreasing again. The oxidation rate is dependent on the sizc of the primary particles.

\subsection{Laser-induced incandescence}

Optical diagnostics offer a great potential to gain information about combustion processes in a non-intrusive way. Many laser-based techniques have been developed 


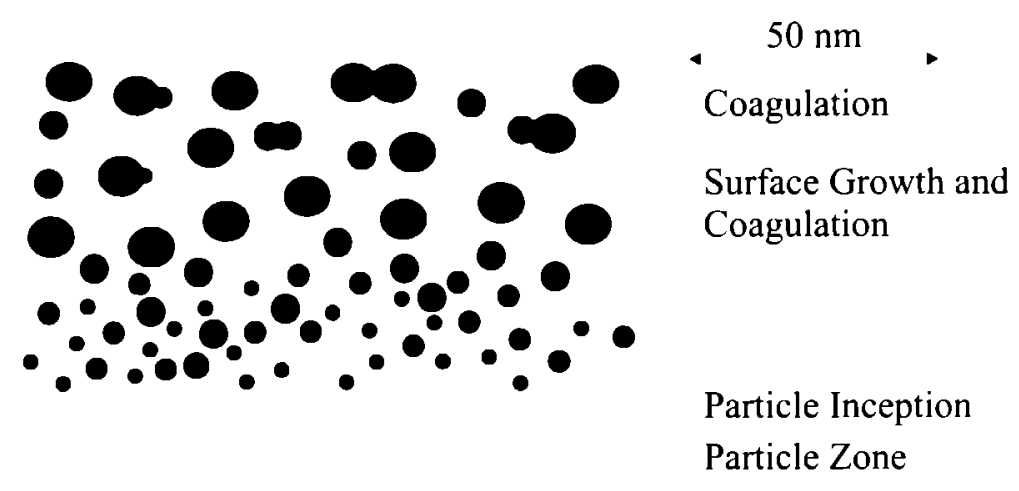

Ð્ટ<smiles>c1cc2ccc3cccc4ccc(c1)c2c34</smiles><smiles></smiles><smiles>c1ccc2c(c1)ccc1ccccc12</smiles><smiles>C#Cc1ccccc1</smiles><smiles>C#CC#CCCCCC</smiles><smiles>c1ccc2ccccc2c1</smiles>

Molecular Zone

Fuel and Oxidizer (premixed)

Figure 1.2: Schematics of the current understanding of the soot formation process (Reprinted from [7]. Witl kind permission of Springer Science and Business Media)

to investigate the combustion process in situ [24]. The only measurement technique which. at least in principle. is able to measure in situ both the soot volume fraction and the particle radius is laser-induced incandesecnece (LII). LII was first obscrved as an undesired side-effect during Raman measurements by Eckbreth [25].

In LII a high-cnergy laser pulse is applicd which heats up the soot particles, so that 


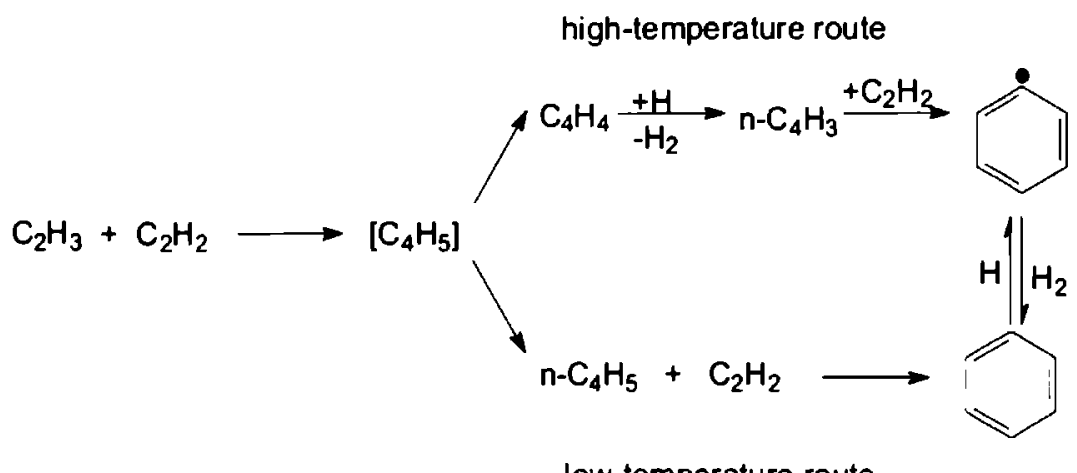

low-temperature route

Figure 1.3: In the low temperature regime and in the high temperature regime the formation process of the first benzene ring may take place along a different reaction pathway. Reprinted with permission from Xi ct al. [19]

these start to glow. The intensity of the resulting radiation (the "LII-signal") is a measure for the soot volume fraction in the measurement volume [26]. The decay rate of the LII signal is a measure for the soot particle size [27]. Consequently, LII has the potential to measure both the soot volume fraction and the particle size simultaneously. which makes it a very powerful technique.

The first LII measurements in a Diesel engine were performed by Dec and coworkers [28]. They performed measurements in a six cylinder direct-injection Diesel engine. Using the frequency-doubled output of a Nd:YAG laser $(\lambda=532 \mathrm{~nm})$ they showed the potential of getting a qualitative view about the soot volume fraction development in Diesel sprays, but experienced that the influence of the extinction of the laser light by the Diesel fuel was significant. In a subsequent paper Dec [18] combined natural flame luminosity measurements, LII, and clastic light scattering in order to reduce the influence of cycle-to-cycle fluctuations in the combustion process. The conclusions were that for his engine settings there was a clear separation between the region where liquid fuel is present and the soot-loaded regions.

Later on Dec and Espcy [29] performed laser-induced fluorescence (LIF), clastic light scattering and LII experiments simultaneously in order to discriminate between the liquid fucl phase, the vapor fuel phase and the soot-loaded regions. They found no proof that the soot was only present around the periphery of the fuel spray. In another paper [30] Dec and Espey described results from combincd natural cmission, LII and elastic light scattering measurements. Their conclusions were that the smallest soot particles can be found in the periphery of the spray and the bigger ones in the core of the fuel spray.

Kock et al. [31] were the first to publish in-cylinder measurements of particle sizes in a 2-stroke light-duty Dicscl engine. In early stages of the combustion cycle, they observed a growth of particles, followed by a decay of the particle size later on. 
However, the in-cylinder pressure varies over a broad range and the model that was implemented in that paper, did not consider the correct pressure regime. Recontly, they published a paper in which they considered the correct pressure regime [32] and a similar trend was observed.

\subsection{Thesis setup}

The present thesis is divided in two parts. One part of the experiments has been performed in an optically accessible high-temperature, high-pressurc cell, located at the Paul Scherrer Institute and the other part has been performed in an optically accessible engine, located at the Radboud University Nijmegen. Chapter 2 gives an introduction in the used experimental setups and the applied measurement techniques. Chapter 3 gives a more elaborate view on several LII models which have been published in literature and describes the model, used in this dissertation to analyze the measurements. In Chapter 4 the results of measurements performed in the constant volume combustion high-temperature, high-pressure cell (HTDZ) are described. Combinations of shadowgraphy, elastic light scattering. chemiluminescence and lascr-induced incandescence have been performed in order to investigatc the influence of the spray formation on the ignition process and the successive soot development. Chapter 5 describes the results of soot particle size measurements which have been performed in the cylinder of a 4-stroke heavy-duty Diesel engine, based on the assumption of a mono-disperse particle size distribution. In Chapter 6 the experimental approach is described more elaborately as well as the method for the data analysis of the particle size. Chapter 7 describes the results for several engine loads when the measurement cylinder is equipped with an in-line pump system, under the assumption of a poly-dispersed particle size distribution. Finally, chapter 8 describes the results of the particle size measurements, the measurement cylinder being equipped with a common-rail system. The common-rail injection system enables the operation at a higher, more constant injection pressure, with a much more flexible timing than is possible with a line pump. 


\section{Bibliography}

[1] R. van Basshuysen and F. Schäfcr (2002): Handbuch Verbrennungsmotor. Friedr. Vieweg \& Sohn Verlagsgeseelschafft mbH, Braunschweig/Wiesbaden. $1^{\text {st }}$ edition.

[2] Y. Jin. M.C. Veiga and C. Kennes (2005): Bioprocesses for the removal of nitrogen oxides from polluted air. J. Chem. Technol. Biotechnol. 80 (5). 483494.

[3] P.J. Crutzen (1970): Influence of nitrogen oxides on atmospheric ozone content. Quart. J. Roy. Met. Soc. 96 (408), 320.

[4] Y.B. Zeldovich (1946): The formation of nitrogen in combustion and explosions. Acta Physiochimica 21, 577-628.

[5] C.P. Fenimore (1972): Formation of nitric oxide from fuel nitrogen in ethylenc flames. Combust. Flame 19 (2), 289-296.

[6] J. Wolfrum (1972): Bildung von Stickstoffoxiden bei der Verbrennung. ChemieIngenieur-Technik 44 (10), 656-659.

[7] H. Bockhorn (1994): Soot Formation in Combustion. Springer Verlag.

[8] N.D. van Egmond and R.D. Woittiez (2005): Fijn stof nader bekeken. De stand van zaken in het dossier fijn stof. Milieu en Natuur Planburcau.

[9] J. Hansen and L. Nazarenko (2004): Soot climate forcing via snow and ice albedos. PNAS 101 (2), 423-428.

[10] I.M. Kennedy (2007): The health effects of combustion-generated aerosols. In: Proc. Comb. Inst. 31 (2), 2757-2770.

[11] F.X. Moser. T. Sams and W. Cartellieri (2001): Impact of future exhaust gas emission legislation on the heavy-duty truck engine. SAE Tech. Pap. Scries 2001-01-0186.

[12] H. Hiroyasu (1985): Diesel engine combustion and its modeling. In: COMODIA, 53-75. 
[13] C. Soteriou, R. Andrews and M. Smith (1995): Direct injection Diesel sprays and the effect of cavitation and hydraulic flip on atomization. SAE Tech. Pap. Scries 950080 .

[14] L.C. Ganippa, S. Andersson and J. Chomiak (2003): Combustion characteristics of Diesel sprays from cquivalent nozzles with sharp and rounded inlet geometrics. Combust. Sci. and Tech. 175, 1015-1032.

[15] R.D. Reitz (1978): Atomization and other breakup regimes of a liquid jet. $\mathrm{PhD}$ Thesis Princeton University, U.S.A.

[16] M. Arai, M. Tabata, H. Hiroyasu, M. Shimizu (1984): Disintegrating process and spray characterization of fuel jet injected by a a Diesel nozzle. SAE Tech. Pap. Series 840275 .

[17] P.F. Flynn. R.P. Durrett. G.L. Hunter, A.O. zur Loye, O.C. Akinyemi. J.E. Dec and C.K. Westbrook (1999): Diesel combustion: An integrated vicw combining laser diagnostics, chemical kinetics, and empirical validation. SAE Tech. Pap. Series 1999-01-0509.

[18] J.E. Dec (1992): Soot distribution in a D.I. Diesel engine using 2-D imaging of laser-induced incandescence. elastic scattering and flame luminosity. SAE Tech. Pap. Series 920115.

[19] J. Xi and B.-J. Zhong (2006): Soot in Diesel Combustion. Chem. Eng. Technol. $29(6)$. 665-673.

[20] J.A. Miller, R.J. Kee and C.K. Westbrook (1990): Chemical kinetics and Combustion modeling. Ann. Rev. Phys. Chem. 41. 345-387.

[21] J.A. Miller and C.F. Melius (1992): Kinetic and thermodynamic issues in the formation of aromatic compounds in flames of aliphatic fucls. Combust. Flame 91, 21-39.

[22] J. Hansen and L. Nazarenko (2003): Soot climate forcing via snow and ice albedos. Proc. Natl. Acad. Sci. USA 101 (2). 423-428.

[23] J. Raloff (2003): Air Sickness. Science News 164 (5), 72-74.

[24] K. Kohsc-Höinghaus and J. Jeffreys eds. (2002): Applied Combustion Diagnostics. Taylor \& Francis Inc.

[25] A.C. Eckbreth: Effects of laser-modulated particle incandescence on Raman scattering diagnostics. J. Appl. Phys. 48 (11). 4473-4479.

[26] L.A. Melton (1984): Soot diagnostics based on laser heating. Appl. Opt. 23 (13). 2201-2208. 
[27] P. Roth and A.V. Filippov (1996): In situ ultrafinc particle sizing by a combination of pulsed laser heatup and particle thermal emission. J. Acr. Sc. 27 (1). 99-104.

[28] J.E. Dec, A.O. zur Loye and D.L. Sicbers (1991): Soot distribution in a D.I. Diesel engine using 2-D lascr-induced incandescence imaging. SAE Tech. Pap. Series 910224 .

[29] J.E. Dec and C. Espey (1992): Soot and fucl distributions in a D.I. Diescl engine via 2-D imaging. SAE Tech. Pap. Series 922307.

[30] J.E. Dec and C. Espcy (1995): Ignition and early soot formation in a DI Diescl engine using multiple 2D-imaging diagnostics. SAE Tech. Pap. Serics 950456.

[31] B.F. Kock. Th. Eckhardt, P. Roth (2002): In-cylinder sizing of Diesel particles by time-resolved laser-induced incandescence (TR-LII). In: Proc. Combust. Inst. 29, 2775-2781.

[32] B.F. Kock, B. Tribalet, C. Schulz and P. Roth (2006): Two-color time-resolved LII applied to soot particle sizing in the cylinder of a Diesel engine. Combust Flame 147 (1-2), 79-92. 


\section{Chapter 2}

\section{Diagnostics}

\subsection{Combustion systems}

\subsubsection{The high-pressure high-temperature cell}

An optically accessible constant volume combustion cell has been used to measurc simultaneously different phenomena which play a role in the Diescl combustion process, but under more controlled conditions than in a reciprocating enginc. It is important to measure simultaneously as many phenomena as possible because turbulence plays an important role during combustion in a Diesel engine. where. in practice, a combustion event cannot be reproduced in detail from cycle to cycle. The setup described below has a constant volume without turbulence but facilitates the investigation of different phenomena simultaneously.

Figure 2.1 depicts an outline of the facility around the constant volume combustion cell. The combustion cell has a height of $110 \mathrm{~mm}$ and an internal diameter $40 \mathrm{~mm}$. It is made of high-strength stainless steel. and is optically accessible via four sapphire windows of $40 \mathrm{~mm}$ diameter clear aperture in cach side wall. The cell is equipped with gas intake and exhaust valves and a common rail fuel injector. This allows the observation of transient liquid fuel injection/combustion events over a broad rangc of initial gas pressures (up to $8 \mathrm{MPa}$ ) and temperatures (up to $850 \mathrm{~K}$ ) [1-3]. Valve timings and fuel injection characteristics (pressure, duration, and timing in case of split injection) can be varied within ranges typical for intcrnal combustion cngines. and optical access does not suffer from complications imposed by a moving piston. The cell can be loaded with compressed gas mixtures. e.g. $\mathrm{N}_{2}$ or air, which are pre-heated and pressurized in a $12 \ell$ autoclave system connected to the inlet port via a pneumatic valve. The autoclave system consists of 3 bottles with a volume of $4 \ell$ cach.

The whole device is heated electrically by several heating cartridges (cell body: $4 \times 2 \mathrm{~kW}$, connecting gas supply tube: $6 \times 800 \mathrm{~W}$ ) and heating wires (autoclave). By the heating cartridges alone the cell body can be heated up to $750 \mathrm{~K}$. For 


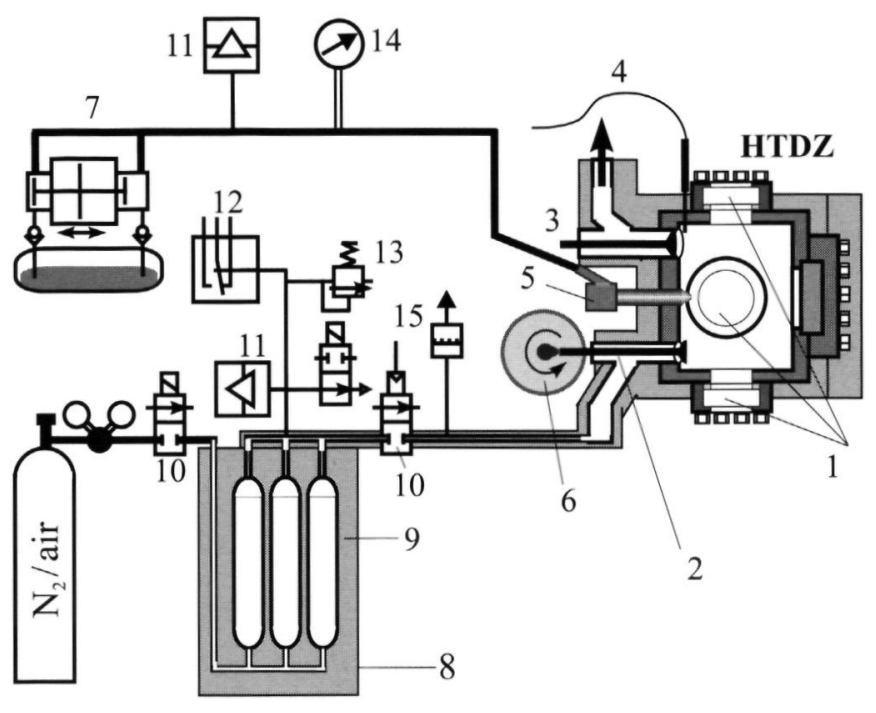

1. Sapphire windows

2. Inlet valve

3. Outlet valve

4. Thermocouple

5. Needle-lift sensor

6. Fly-wheel+cam shaft

7. Fuel pump

8. Autoclave

9. Thermal insulation

10. Magnetic valve

11. Pressure sensor

12. Pressure switch

13. Pressure relief

14. Manometer

15. Rupture disk

Figure 2.1: Sketch of the test facility employed, including high-temperature highpressure optical cell (HTDZ) and gas/fuel supply system.

measurements at higher initial gas temperatures $(800 \mathrm{~K})$ additional heat release is provided through pre-combustion. For these measurements a pilot fuel injection (nozzle opening time: $4 \mathrm{~ms}$ ) occurs $20 \mathrm{~ms}$ before the main injection event $(3 \mathrm{~ms}$ duration).

Gases are introduced via a cam-shaft driven valve in the inlet port and exhausted through a pneumatically operated valve, thus simulating a Diesel engine combustion cycle without piston movement. A low-aromatic Diesel fuel (DEA TT 1420) was introduced through a single hole, mini-sac type nozzle (length-to-diameter ratio: 4, hole diameter: $150 \mu \mathrm{m}$ ) by a fuel injector (Ganser crs, Winterthur) with electronic valve timing control. The fuel is pressurized with a pneumatically operated piston pump (Heilmeier \& Weinlein, München), which allows injection pressures up to $150 \mathrm{MPa}$. A fast pressure sensor (Kistler, mod. 6061B) and a thermocouple (Ni/CrNi, $100 \mu \mathrm{m}$ diameter) are installed close to the fuel injection nozzle in the combustion chamber to record the physical changes in the gas mixture.

Depending on the choice of initial parameters, the fully computer-controlled operation of a complete experimental cycle (autoclave gas fill, opening of connecting valve for inlet port fill, inlet valve actuation, fuel injection, exhaust valve opening) takes 2-4 s. The injection/combustion cycle is only initiated if the continuously measured temperature and pressure readings from all relevant parts (cell, nozzle and autoclave) are within preset limits and safe operating ranges. 


\subsubsection{The heavy-duty Diesel engine}

A 4-stroke 6-cylinder heavy-duty Diesel engine has been modified in order to provide optical access. The original configuration of the engine was of the WS type of DAF make with a total displacement volume of $11.6 \ell$. The engine is split into two blocks of three cylinders each. The first block (cylinder 1-3) has been modified for the experiments. the other block (cylinder 4-6) is still in its original configuration and is in fact the driving engine during the experiments. Cylinder 1 is the measurement cylinder and the fuel injectors of cylinders 2 and 3 have been removed. The pistons of the latter cylinders have becn transpierced in order to prevent compression of the air. The engine load can be varied by means of a break. The boost pressure and the amount of fuel which is injected into the engine can be adjustcd for each engine load, accordingly.

A schematic picture of the measurement cylinder (cylinder 1) is depicted in Fig. 2.2. The original combustion chamber has been removed and on top of the original cylinder an elongated cylinder with the combustion chamber of a production type XF95 DAF engine has been constructed. One of the exhaust valves of the system has been replaced by a quartz window with a diameter of $28 \mathrm{~mm}$ and a thickness of $50 \mathrm{~mm}$ ('top window'). The piston bowl is provided with a quartz window with a diameter of $74 \mathrm{~mm}$ and a thickness of $49 \mathrm{~mm}$, which gives full optical access to the combustion chamber from the bottom of the extended cylinder. With a mirror under an angle of $45^{\circ}$, which can be inserted in the interior of the moving piston through broad slots in the piston and liner walls, the combustion chamber contents can be monitored from outside. At three sides of the combustion chamber a $47 \mathrm{~mm}$ thick quartz window with outer dimension $57 \times 32 \mathrm{~mm}^{2}$, and inner dimension $48 \times 23 \mathrm{~mm}^{2}$ and $47 \mathrm{~mm}$ thick) can be mounted. Only the side window closest to the top window has been mounted during the measurements presented in this thesis. At the side of this window a slot has been machined in the rim of the piston bowl, in order to improve the optical access close to top-dead center. (Top-dead center (TDC) is the moment when the piston is in its uppermost position [4].)

The engine is thermostatted by a closed water heating system, and the inlet air is heated elcctrically. Fresh air is introduced into the measurement cylinder at a temperature of $313 \mathrm{~K}$. The boost pressure of the inlet air can be varied. dependent on the engine load. The measurement cylinder is fired only once per 35 cycles, by means of its own dedicated fuel injection system. This has been done to prevent overheating since this piston runs without lubricants in order to reduce window fouling. A rider ring and a piston ring prevent wear of the piston, because of the absence of lubricants. The measurement cylinder can be equipped with two different injection systcms, each with its own injector: an in-line pump injection system constructed by Bosch. and a common-rail injection system. which has been constructed in house. Both injectors have 8 holes and contain a needle lift sensor. The injectors are rotatable, so that the spray position can be varied relative to a probe location that is fixed in space. The in-line pump system is equipped with an injector, constructed by Bosch and a needle-lift sensor (MUB). The common- 
a

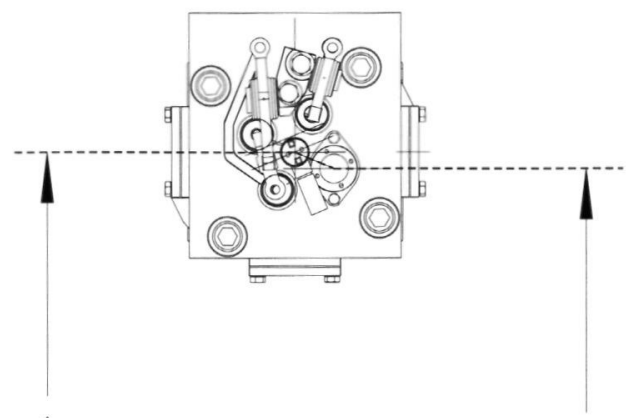

A

A

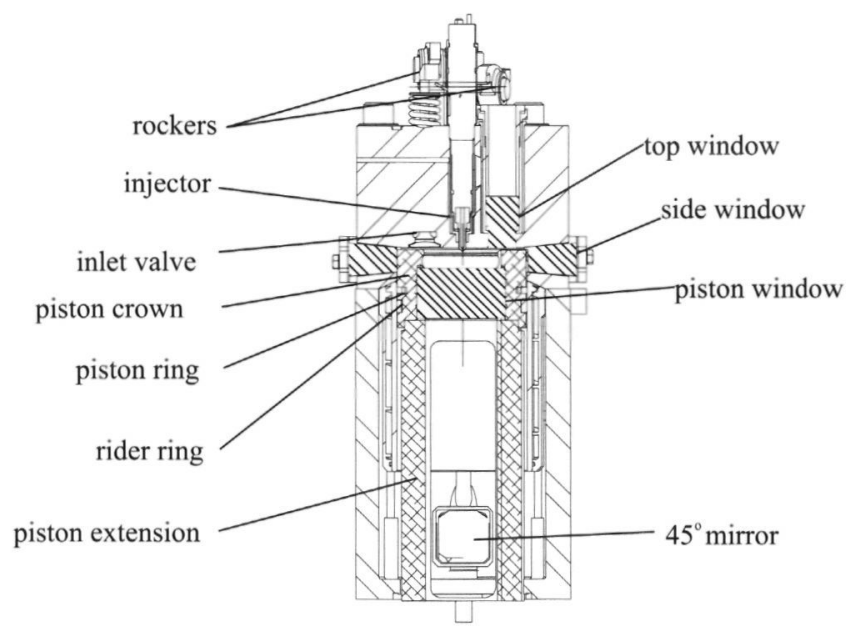

A-A

Figure 2.2: Top view (a) and vertical cut-through (b) of the measurement cylinder. The latter one is not in one plane, but along the line A-A in the top-view.

rail injection system is provided with a Bosch injector (type CR12.8.1-injector B2sample) as well, in combination with a needle displacement sensor (type: U05, constructed by Micro-Epsilon). The needle lift sensor measures the position of the fuel injector needle: it gives an accurate measure for the start and duration of the fuel injection.

A pressure sensor (AVL QHC32) can be installed at the location of the top window in order to monitor the pressure transients during the combustion cycle. With the used optical arrangements (Chapter 6) it is not possible to measure the pressure 


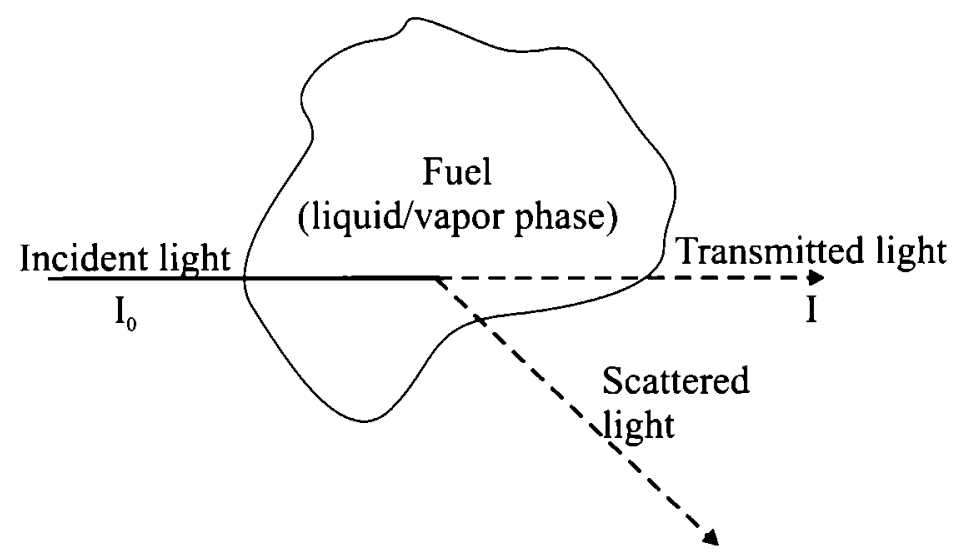

Figurc 2.3: A schematic picture of the principle of shadowgraphy. The transmitted light is dependent on the composition of the medium.

curves simultaneously with the optical measurements.

In all the expcriments discussed in this dissertation, the engine was run on regular city Diesel fuel at a speed of 1430 rcvolutions per minute, resulting in $116 \mu$ s per degree crank angle. A more detailed description of the construction of cylinder 1 and the other cylinders can be found in the dissertation of Van den Boom [5].

\subsection{Diagnostic techniques}

This section gives an introduction to the used measurement techniques and explains the physical principles on which they are based.

\subsubsection{Shadowgraphy}

The spray breakup process can be investigated with shadowgraphy $[3,6,7]$. Shadowgraphy is a non-intrusive optical line-of-sight visualization technique. The principle of shadowgraphy is explained in Fig. 2.3. A Xenon flash-lamp with intensity $I_{0}$ illuminates the flow from the back side and the intensity $I$ of the light transmitted through the spray is photographed [7].

Due to the presence of a medium between the light source and the detector there will be a decrease in intensity of the light, which is dependent on the composition of the medium. Two processes contribute to the decrease in intensity of the light

- The light is absorbed by the medium:

- The light is scattered by the medium. 
In a fucl spray two phases are present simultaneously and the scattering or absorption efficiency is dependent on the size of the fucl droplets, relative to the wavelength and on the differences in optical density of the specics in the cross-section [8]. This makes that extinction of the light can be uscd to extract qualitative information about the position of the fucl spray and/or droplets.

\subsubsection{Two-color pyrometry}

The light emission from soot particle exhibits a black-body spectrum. in a fair approximation [9]. As a conscquence. the broad-band spectral radiance spectrum $U_{b b}$ is determined by Planck's radiation law

$$
U_{b b}\left(\lambda_{d c t} . T\right)=\frac{8 \pi h c}{\lambda_{d e t}^{5}} \frac{1}{\exp \left(\frac{h c}{\lambda_{d e t} k_{B} T}\right)-1}
$$

in which $h$ is Planck's constant. $c$ is the speed of light. $\lambda_{d c t}$ is the detection wavelength. $k_{B}$ is Boltzmann's constant and $T$ is the temperature. Figure 2.4 shows the cmission spectrum of black-body radiators for different tempcratures. The influence of the temperature is visible in both the absolute intensity of the emission and the shape of the spectrum. Consequently, the intensity ratio of the emission at two wavelengths contains information about the tempcrature of the soot particles [10]. This is the principle of the two-color pyrometry method.

However, there are some complexities in the measurement technique. which result in uncertainties in the measured temperature. Soot is in fact not a black-body radiator. but a gray-body radiator. which means that there is an additional correction factor to the cmissivity. dependent on the detcetion wavelength $\lambda_{\text {det }}$. Therefore, a correction for the measured spectral radiance $U_{m}$ has to be made for the emissivity $\varepsilon\left(\lambda_{d c t}\right)$ of the soot [11]:

$$
U_{m}=\varepsilon\left(\lambda_{d e t}\right) U_{b b} .
$$

Taking two different detection wavelengths $\lambda_{1}$ and $\lambda_{2}$ the ratio of the emissivities can be described with [11]

$$
\frac{\varepsilon_{1}}{\varepsilon_{2}} \times \frac{\lambda_{2}}{\lambda_{1}} .
$$

One can calibrate the two-color pyrometry detection system in the following way. For a black-body radiator with temperature $T_{b b}$ and emission spectrum $U_{b b}$, the light intensity $I_{L}$. corrected for the wavelength dependence of the detection system $\tau_{L}(\lambda)$ and the emissivity $\varepsilon\left(\lambda . T_{b b}\right)$. is given by

$$
I_{L}\left(\lambda_{d c t} . T_{b b}\right)=\tau_{L}\left(\lambda_{d e t}\right) U_{b b}\left(\lambda . T_{b b}\right) \varepsilon\left(\lambda_{d e t} . T_{b b}\right)
$$

This intensity is measured at two disjunct wavelengths and the ratio of the intensities is calculated. Consider now a soot particle at unknown temperature $T_{s}$. of 


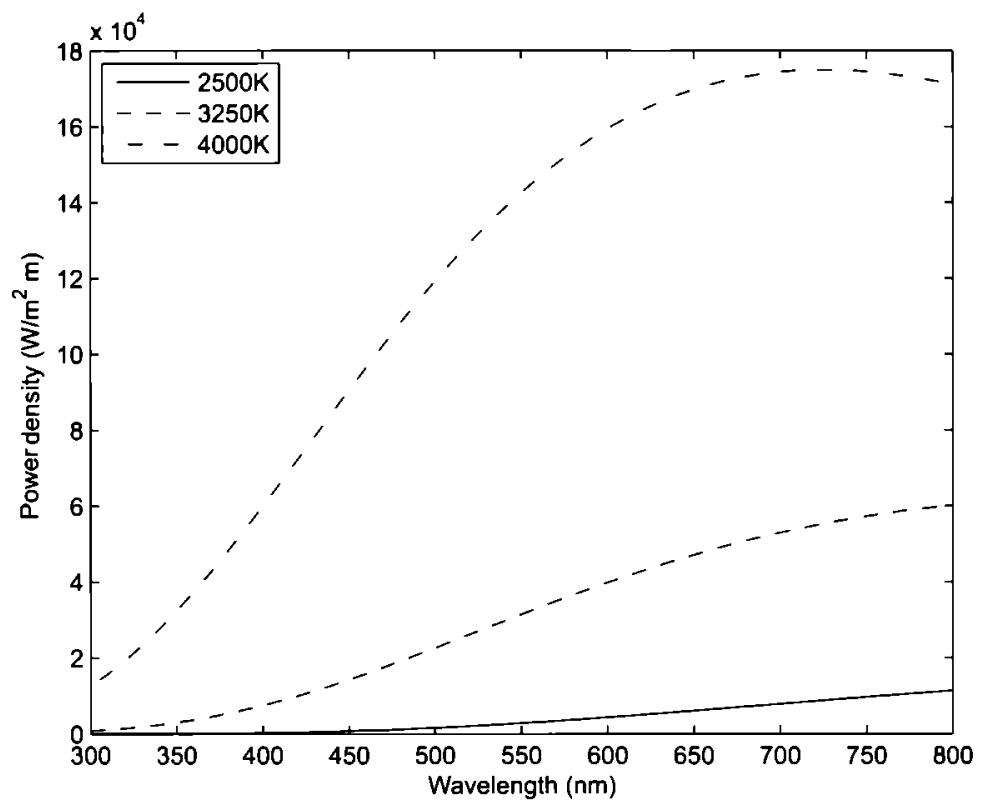

Figure 2.4: Planck`s spectrum for several temperatures.

which the intensity of the emitted radiation $U_{s}$ is measured at the same wavelcngths. Because the same detection system is used

$$
\frac{\tau_{L}\left(\lambda_{1}\right)}{\tau_{L}\left(\lambda_{2}\right)}=\frac{\tau_{s}\left(\lambda_{1}\right)}{\tau_{s}\left(\lambda_{2}\right)},
$$

which mcans that the influence of the detection system on the detected light cancels. Suppose that the measured intensity of the glowing soot is $U_{s}$, which is measured at the same wavelengths as well, the particle temperature can now be calculated by [11]

$$
T_{s}=\frac{h c}{k_{B}}\left(\frac{1}{\lambda_{2}}-\frac{1}{\lambda_{1}}\right) \times\left\{\ln \left[\frac{U_{s}\left(\lambda_{1}, T\right)}{U_{s}\left(\lambda_{2} \cdot T\right)} \frac{U_{b b}\left(\lambda_{2} \cdot T_{b b}\right)}{U_{b b}\left(\lambda_{1} \cdot T_{b b}\right)}\right]+\frac{h c}{k_{B} T_{b b}}\left(\frac{1}{\lambda_{2}}-\frac{1}{\lambda_{1}}\right)\right\}^{-1}
$$

\subsubsection{Laser-induced incandescence}

Laser-induced incandescence (LII) was first observed as an undesired side-effect in Raman scattering experiments by Eckbreth [9]. He found an unexpected background signal which he could not ascribe to Raman scattering. The signal was 
caused by glowing soot particles that had been heated by the laser beam used to induce Raman scattering. This radiation is called incandescence.

Melton [13] was the first who thought about the possibilities for soot diagnostics which were created by Eckbreth's finding. He quantitatively explained the incandescence intensity by a model in which soot particles were quickly heated up to their vaporization temperature by a short, high-energy laser pulse. Duc to the absorptive heating, the spontaneous (black- or gray-body) radiation of the soot particles increases in intensity, while its spectrum shifts to the blue. After the laser pulse the particles cool down again, at a rate which is dependent on their size: small particles cool down faster than larger ones. Prompt LII is the term for the incandescence which is emitted at the peak temperature. Mclton [13] showed that the intensity $S_{L I I}$ of the prompt LII signal, whon the soot particles are heated to their vaporisation tempcraturc, can be written as

$$
S_{L I I} \propto N_{p} r_{p}^{3+154 / \lambda_{\text {det }},}
$$

in which $r_{p}$ is the particle radius (assuming a mono-disperse spherical size distribution). $N_{p}$ is the particle density and $\lambda_{d e t}$ is the detection wavelength (in nm). It can be seen that the intensity of the LII signal measured at long detection wavelengths, is almost proportional to the volume fraction of the soot in the probe volume. The details of the transient spectral changes depend on particle density, as well as on the particle size distribution. This dependence is the basis of the diagnostic value of Laser-Induced Incandescence (LII).

Basically, LII is based on the internal energy balance of soot particles

$$
\frac{d}{d t} E_{\imath n t}=\dot{Q}_{\imath n}-\dot{Q}_{o u t}
$$

in which $Q_{\imath n}$ is the energy absorbed by the soot particles and $Q_{o u t}$ is the energy which is emitted or relcased by the particles. The energy absorbed by the particles $\left(Q_{i n}\right)$ is originating from the laser irradiation. The energy transfer process between the heated soot particles and the environment $\left(Q_{\text {out }}\right)$ is governed by scveral processes. The cooling processes cause a decay of the LII intensity: The temperature difference between the laser-heated soot particles and the environment gradually decreases, until the particles reach the ambient temperature.

For spherical particles, Melton [13] showed that the cooling behavior is dependent on the size of the particles. Basically. it is dependent on the surface-to-volume ratio of the soot particles. This decay process can be monitored via the time dependence of the LII intensity, and this measuring technique is called Time-Resolved LII (TR-LII). The slope of the TR-LII curves incorporates information about the temperature change of the particles as a function of time and consequently, about the primary particle size. Assuming a physical model for the cooling behavior of the particles, a modeled curve can be fitted to the measured TR-LII curve. By adjusting the fitting parameters the particle size can be found which best reproduces the TR-LII measurements. The Melton model includes cooling terms for conduction, vaporisation and radiation in the encrgy balance. In Sect. 3.1 an outline of 
the Melton model will be given This model serves as a basis for many TR-LII measurements which have been performed later

Roth and Filippov [14] showed that it is possible by a numerical analysis of the TR-LII curve to get detailed information about the particle size distribution As long as the particles are not heated up to tempcratures which are above the vaporisation temperature (about $4000 \mathrm{~K}$ ) the decay-rate is only determined by matcrial properties They claimed that it is possible to calculate unambiguously the particle size distribution, from this information

In addition to Melton s model many different other models have been developed to analyze the TR-LII signal in order to extract information about the particle size distribution It turned out that the soot particle size distribution that is obtained from the analysis of TR-LII measurements is strongly dependent on the assumed physical model [15] About the (interpretation of the) heat transfer constants and functions some debate is still going on [15] With respect to the heat balance most models include particle cooling by conduction, sublimation/vaporisation and radiation In practice, the heat loss rate is usually dominated by conduction, and as a result the decay time of TR-LII signals is strongly influcnced by the pressure (see Chapter 3) the higher the pressure the shorter the decay time of the TR LII signal [16] Especially at higher pressures, such as those in an internal combustion engine this poses severe demands on the detection equipment, because the decay time of the LII signal typically gets shorter than $20 \mathrm{~ns}$ In case of the engine environment, it turns out that explicitly accounting for the response time of the measurement system is crucial in the analysis of the data (sce Chapter 5)

\subsubsection{Practical issues of laser-induced incandescence}

This section will treat some considerations which are important in the experimental approach of LII and in the analysis and interpretation of the measurcments

\section{Particle size distribution}

Soot particle inception and soot growth are very complex processes, involving many chemical reactions, which have not becn completely understood yet [18] Many physical parameters also influence the soot formation and growth processes, like local temperature and pressure and the composition of the environment Primary soot formation processes dommated by codgulation result in a log-normal soot particle size distribution [19] This distribution is defined as

$$
P\left(r_{p}\right)=\frac{1}{r_{p} \sigma_{m} \sqrt{2 \pi}} \exp \left(-\frac{\left(\ln r_{p}-\ln r_{m}\right)^{2}}{2 \sigma_{m}^{2}}\right)
$$

in which $r_{m}$ is the mcan particle radius and $\sigma_{m}$ is the geometric width of the distribution Transmission Electron Microscopy (TEM) measurements on soot in the exhaust of a Diesel engine have shown that the primary particle size distribution 
of soot which is formed during the Diesel combustion process can be considered to be log-normal distributed as well [12]. Therefore, the assumption is made that the in-situ particle size is log-normal distributed as well.

\section{Morphology}

The decay rate of the LII intensity is mainly governed by the specific surface of the particles, which is defined as the free surface of soot per unit volume of soot particles. This is dependent on the primary particle size [15]. However, agglomeration of the primary soot particles can play a role. Two extreme cases of agglomeration are illustrated in Fig. 2.5. The effective heat exchange surface in Fig. 2.5a is much smaller than the effective heat exchange surface in Fig. 2.5b. Consequently, the particles will cool down faster in case $b$ than in case $a$. Kock et al. showed that particles that are point-wise connected cool down as individual primary particles [20]. Liu et al. [21] demonstrated recently that the aggregate structure has influence on the particle cooling behavior. A compact particle, consisting of a number of fractals (small sub-chains of particles in a bigger agglomerate) has the same cooling behavior as a bigger spherical primary particle. In the cooling model which they introduced, the fractal size is taken into account. The model, which is used in this dissertation, does not consider the fractal size, and the assumption is made that the primary particles are spherical, and point-wise connected in agglomerates (see Chapter 3).
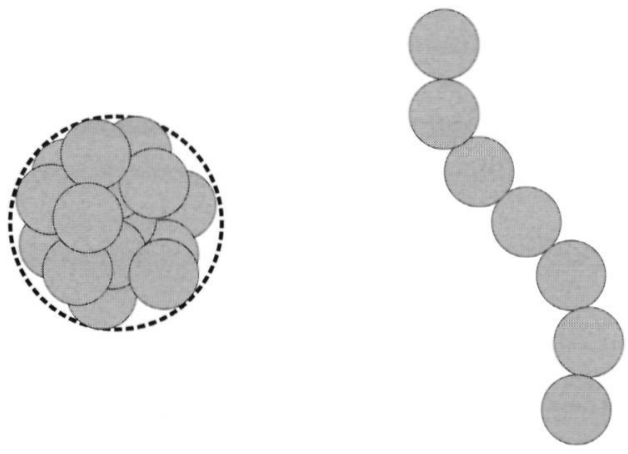

a

$\mathrm{b}$

Figure 2.5: A cartoon of two extreme cases of particle agglomeration: a. Particles are agglomerated in a compact form. The effective cooling area is approximately equal to the surrounding dashed sphere. b. Particles are chain-wise connected. Kock et al. [20] showed that the effective cooling area is equal to the total area of the individual particles in the latter case. 


\section{Excitation wavelength}

Melton [13] showed for three excitation wavelengths (220 nm. $270 \mathrm{~nm}, 532 \mathrm{~nm})$ that the shorter the excitation wavelength is the smaller the particles are. which absorb laser energy most efficiently. Using a laser at a wavelength of 220 nm. particles with a radius of about $30 \mathrm{~nm}$ absorb the laser cnergy most efficiently. Using a laser with a wavelength of $270 \mathrm{~nm}$ particles with a radius of $40 \mathrm{~nm}$ absorb the laser energy most efficiently. For the $532 \mathrm{~nm}$ excitation wavelength. the particles absorb the heat energy with an efficiency which is nearly independent of their size. Therefore Melton concluded that $532 \mathrm{~nm}$ is the best excitation wavelength for LII.

In principle, it is possible to heat soot particles at any laser wavelength, because soot is a gray absorber. For this rcason, the convenient, commercially available Nd:YAG laser is often used in LII experiments. using either the fundamental wavelength $(\lambda=1064 \mathrm{~nm})$ or its second harmonic $(\lambda=532 \mathrm{~nm})$. Other wavelengths. in the UV spectral range, have been used as wcll [22 26]. There are, howcver, scveral reasons to choose $1064 \mathrm{~nm}$ as cxcitation wavelength in LII experiments. First of all. excitation of the LII signal with UV light can result in photodissociation. reducing the particle size [27]. Furthermore, there is a number of other reasons why it is preferablc to excite LII with $1064 \mathrm{~nm}$ instead of $532 \mathrm{~nm}$ :

- Interference with other cmissions: at longer excitation wavelengths less smaller fragments $\left(C_{2}\right)$ are produced. Swan band emission. $\left(C_{2} d^{3} \Pi_{g} \rightarrow a^{3} \Pi_{u}\right)$. has been reported to interfere with LII [28]. OH and O-emission have been observed to interfere with LII when $532 \mathrm{~nm}$ was chosen as excitation wavelength [29]. Howcver, $\mathrm{C}_{2}$ emission can also be observed when $1064 \mathrm{~nm}$ is chosen as excitation wavelength, especially during high-fluence LII with beam profiles containing hot spots [29].

- Laser-induced fluorescence (LIF) of polycyclic aromatic hydrocarbons (PAH) can occur with LII excitation at visible or UV wavclengths [22 26]. PAHs are common soot precursors in flames [18], and their fluorescence cxtends over a large range in the visible. Delhay et al. [30] showed that with incrcasing laser fluence the contribution of PAH interference increases and can be up to $80 \%$ of the LII intensity at $532 \mathrm{~nm}$ excitation. The PAH fluorescence is shortlived at elevated temperatures and occurs predominantly during the laser pulse $[23,24]$. It should be noted though, that this is exactly the moment. when prompt LII is measured.

- Elastic light scattering becomes more prominent in sooty flames if a shorter excitation wavelength is chosen. because particles are then closer to the Mic scattering regime [8]. If $532 \mathrm{~nm}$ is chosen as the excitation wavelength. the elastically scattered light might not be completely blocked by the detection optics. causing an interference with the LII signal during the laser pulse. If $1064 \mathrm{~nm}$ is chosen as excitation wavelength. the detectors are often not sensitive for the excitation radiation. making it possible to measure prompt LII, without interference by elastic scattering. 
- If the particles satisfy the Rayleigh criterion, that is $\pi r_{p} / \lambda_{c x}<0.3$. then the Rayleigh-Debye-Gans/Polydisperse Fractal Aggregate (RDG/ PFA) theory can be applicd. This theory predicts that the absorption of radiation by an aggregate of primary particles is the same as the sum of the absorptions by the primary particles, and the peak particle temperature is independent of the particle size. because the absorption cross-section is linearly proportional to the radius of the particles [31].

\section{Laser fluence}

The maximum temperature which is reached during the heating process is dependent on the laser energy in combination with the properties of soot (Par. 3.1). Above a certain threshold. the tempcrature will not increase any further with increasing laser energy. because the soot has reached its vaporisation temperature. This limit is dependent on the excitation wavclength. The so-called plateau region is reached at $0.2 \mathrm{~J} / \mathrm{cm}^{2}$ for $532 \mathrm{~nm}[32,33]$. Van der Wal [34] and Allouis et al. [35] showed that using $1064 \mathrm{~nm}$ as excitation wavelength the plateau region starts at $0.3 \mathrm{~J} / \mathrm{cm}^{2}$. In order to influcnce the soot particle size not too much. the laser fluence should be kcpt bclow this level, because, obviously, vaporisation results in particle size reduction. However, in a high-pressure environment, the influence of sublimation/vaporisation on the cooling process of the laser-heated soot particles is not significant at fluences of about $0.25 \mathrm{~J} / \mathrm{cm}^{2}$ [40. 41].

The excitation laser can contribute to morphological changes of the particles as well. Using transmission electron microscopy on thermophoretically sampled soot Van der Wal and Jensen [42] found that a considerable change in the structure of the soot particles takes place due to the laser-heating process at energies of $0.3 \mathrm{~J} / \mathrm{cm} 2$. The layers of heated primary soot particles are compactly bound with each other, in this way decreasing the size of the effective cooling surface of the particles. At cnergies of $0.15 \mathrm{~J} / \mathrm{cm}^{2}$ no changes in particle morphology were observed.

\section{Vaporisation}

The sublimation/vaporisation of soot particles is a complex issue. One question is what kind of phase change will take place at such high tempcratures [15]. An additional difficulty is that different fragments are expected to be present from the soot particle in the high temperature range. Leider et al. [36] found that $\mathrm{C}_{3}$ is the dominant $\mathrm{C}$-species at high temperatures in the equilibrium state. Also, electronically excited $\mathrm{C}_{2}$ molecules have been observed. probably caused by laser ablation $[28,29]$. Larger molecules may be produced due to sublimation as well, but might not be visible by luminescence. This is probably due to collisional quenching if the molecules are produced in excited electronic states. or due to the fact that they are produced in the ground statc [37]. 


\section{Detection issues}

The incandescence spectrum is broad-band. As a result a broad detection wavelength range can be chosen. However. in order to discriminate the LII intensity from the natural flame luminosity, the spectrum should be recorded preferably around $400 \mathrm{~nm}$. Like pointed out before. care should be taken that the PAH fluorescence docs not interfere with the LII. Especially the beginning of the decay curve - the period during which the fluorescence of PAH's is present - is critical during the fitting procedure of the measured curve to the model. Also, interference with the Swan bands of $\mathrm{C}_{2}$ (i.c. at $473 \mathrm{~nm}, 516 \mathrm{~nm}$ and $563 \mathrm{~nm}$ ) should be avoided [15]. The decay-rate of the TR-LII signal is dependent on the temperature difference between the heated particles and the environment. For particles which are in the Rayleigh limit the heat-up temperature is independent of the particle size [14]. As the laser energy fluctuates from shot to shot, and the absorption of the laser light within the engine or flame varies from cycle to cycle [38], the lascr energy in the probe volume. and consequently the heat-up temperature of the particles varies from shot to shot as well. Therefore, it is necessary to measure the initial temperature of the heated particles in some way. Two-color pyrometry $(\S 2.2 .2)$ can be used to determine this tempcrature. In this case, the prompt LII is measured by two detectors in different wavelength ranges. For increased precision, these ranges should be chosen as far from each other as possible. limited in practice by the spectral width of the LII spectrum.

In the case of soot volume fraction measurements it is necessary to make a correction for the LII signal which is absorbed between the location of excitation and the location of the detector [33. 39]. In the case of TR-LII such a correction is not neccssary, because the shape of the transicnt is of importance. rather than its absolute strength.

\section{Soot material properties}

The values adopted for the material constants of soot vary a lot betwcen different models [15]. Differences in values for physical constants are reflected in the result of the fitting process. In general, properties of graphitic carbon are taken for the physical constants of soot (the density $\rho$ and the heat capacity $C_{s}$ ), but there does not appear an obvious rationale for this approach. The accommodation coefficient $\alpha_{T}$ is often used as a fit parameter in order to make the LII modeling agree with TR-LII curves, which have been measurcd on a known particle size distribution. However, the accommodation coefficient depends on the nature of both the gas and the particles [44]. In the model which we have used to analyze the measurements in this research, the accommodation coefficient is not prcsent. This is due to the fact that the measurements are analyzed in a different pressure rcgime, resulting in a different heat-transfer function. This makes that the importance about the correctness of the accommodation coefficient does not play a role in the present research (see Chapt. 3). 


\section{Bibliography}

[1] P. Obrecht, T. Gerber, A.P. Tzannis. B. Mischler, P.P. Radi, H.-M. Frey and P. Beaud (1998): High temperature, high pressure test cell for investigation of the Diescl engine cycle. In: Scientific report, Paul Scherrer Institute, Villigen, Switzerland: V, 56-57.

[2] G. Barroso, B. Schneider and K. Boulouchos (2003): An extensive parametric study on Diesel sprays simulation and verification with experimental data. SAE Tech. Pap. Series 2003-01-3230.

[3] B. Schneider (2003): Expcrimentelle Untersuchungen zur Spraystruktur in transienten verdampfenden und nicht verdampfenden Brennstoffstrahlen unter Hochdruk. PhD Thesis ETH Zürich, Switzerland.

[4] R. van Basshuysen and F. Schäfer (2002): Handbuch Verbrennungsmotor. Friedr. Vieweg \& Sohn Verlagsgeseelschafft mbH. Braunschweig/Wiesbaden. $1^{\text {st }}$ edition.

[5] H.L.G.J. van den Boom (2000): Laser Diagnostics in Diesel engines. PhD Thesis, Katholicke Universiteit Nijmegen.

[6] H. Schardin (1934): Das Tocplersche Schlierenverfahren. Forschungsheft 367. Beilage zu "Forschung auf dem Gebicte des Ingenieurswesens". 1-32.

[7] G.S. Settles (1964): Schlieren and Shadowgraph Techniqucs. Springer.

[8] M. Kerker (1969): The Scattering of Light and other Magnetic Properties. Academic, New York. U.S.A.

[9] A.C. Eckbreth (1977): Effects of laser-modulated particle incandescence on Raman scattering diagnostics. J. Appl. Phys. 48 (11), 4473-4479.

[10] H.C. Hottel and F.P. Broughton (1932): Determination of true tempcrature and total radiation from luminous gas flames. Ind. Eng. Chem. 4 (2), 170)-171.

[11] F. Cignoli. S. de Iuliis. V. Manta and G. Zizak (2001): Two-dimensional twowavelength emission technique for soot diagnostics. Appl. Opt. 40 (30). 53705380 . 
[12] B.F. Kock, B. Tribalet. C. Schulz and P. Roth (2006): Two-color time-resolved LII applied to soot particle sizing in the cylinder of a Diesel engine. Combust. Flame 147 (1-2). 79-92.

[13] L.A. Melton (1984): Soot diagnostics based on laser heating. Appl. Opt. 23 (13), 2201-2208.

[14] P. Roth and A.V. Filippov (1996): In situ ultrafine particle sizing by a combination of pulsed laser heatup and particle thermal emission. J. Aerosol Sci. 27 (1), 99-104.

[15] C. Schulz, B.F. Kock, M. Hofmann. H. Michelsen, S. Will, B. Bougie. R. Suntz and G. Smallwood (2006): Laser-induced incandescence: recent trends and current questions. Appl. Phys. B 83 (3). 333-354.

[16] M. Hofmann, W.G. Bessler, C. Schulz and H. Jander (2003): Laser-induced incandescence (LII) for soot diagnostics at high pressures. Appl. Opt. 42 (12). 2052-2062.

[17] B. Bougie, L.C. Ganippa. A.P. van Vliet, W.L. Mecrts, N.J. Dam and J.J. ter Meulen (2006): Laser-induced incandescence particle size measurcments in a heavy-duty Diesel enginc. Combust. Flame 145 (3), 635-637.

[18] H. Bockhorn (1994): Soot Formation in Combustion, Springer Verlag.

[19] W.C. Hinds (1982): Aerosol Technology: properties, bchavior and measurement of airborne particles, Wilcy, New York.

[20] B.F. Kock, C. Kayan, J. Knipping, H.R. Orthner and P. Roth (2005): Comparison of LII and TEM sizing during synthesis of iron particle chains. In: Proc. Combust Inst. 30, 1689-1697.

[21] L. Liu, G.J. Smallwood and D.R. Snelling (2005): Effects of primary particle diameter and aggregate size on the temperature of soot particles heated by pulsed lascrs. J. Quantum Spcctrosc. Radiat. Transf. 93 (1-3), 301-312.

[22] D.S. Coc and J.I. Steinfeld (1980): Fluorescence excitation and emission spectra of polycyclic aromatic hydrocarbons at flame temperatures. Chem. Phys. Let. 76 (3). 485-489.

[23] F. Ossler, T. Mctz and M. Aldén (2001): Pico-second laser-induced fluorescence from gas-phase polycyclic aromatic hydrocarbons at elevated temperatures. I. Cell measurcments. Appl. Phys. B 72 (4). 465-478.

[24] F. Ossler. T. Metz. and M. Aldén (2001): Pico-second laser-induced fluorescence from gas-phase polycyclic aromatic hydrocarbons at elevated temperatures. II. Flame-seeding measurcments. Appl. Phys. B 72 (4). 479-489. 
[25] A. Lcipertz. F. Ossler. and M. Aldén (2002): PAH and soot diagnostics by optical techniques. In Applicd Combustion Diagnostics. Taylor and Francis.

[26] C. Schoemaecker-Morcau, E. Therssen, X. Mercicr, J.F. Pauwels and P. Desgroux (2004): Two-color laser-induced incandescence and cavity ring-down spectroscopy for sensitive and quantitative imaging of soot and PAHs in flames. Appl. Phys. B 78 (3-4). 485-492.

[27] C.B. Stipc, J.H. Choi, D. Lucas, C.P. Koshland, and R.F. Sawycr (2004): Nanoparticle production by UV irradiation of combustion generated soot particles. J. Nanopart. Res. 6 (5), 467-477.

[28] P.-E. Bengtsson and M. Aldén (1995): Soot-visualization strategies using laser techniques, lascr-induced fluorescence in $\mathrm{C}_{2}$ from laser-vaporized soot and lascrinduced soot incandescence. Appl. Phys. B 60 (1), 51-59.

[29] R.L. Vander Wal and K.J. Weiland (1994): Laser-induccd incandescence: Development and characterization towards a measurement of soot-volume fraction. Appl. Phys. B 59 (4), 445-452.

[30] J. Delhay, Y. Bouvicr. E. Therssen. J.D. Black, and P. Desgroux (2005): 2D imaging of laser wing effects and of soot sublimation in laser-induced incandescence measurcments. Appl. Phys. B 81 (2-3), 181-186.

[31] T.L. Farias, M.G. Carvalho, Ü.Ö. Köylï, and G.M. Faeth (1995): Computational evaluation of approximate Rayleigh-Debye-Gans/fractal aggregate theory for the absorption and scattering propertics of soot. J. Heat Transf.,117 (1), 152-159.

[32] B. Axelsson, R. Collin and P.-E. Bengtsson (2000): Laser-induced incandescence for soot particle size measurements in premixed flat flames. Appl. Opt. 39 (21). 3683-3690.

[33] D.J. Bryce, N. Ladommatos and H. Zhao (2000): Quantitative investigation of soot distribution by laser-induced incandescence. Appl. Opt. 39 (27). 50125022 .

[34] R.L. Vanderwal (1996): Lascr-induced incandescence: detection issucs. Applied Optics 35 (33). 6548-6559.

[35] C. Allouis, A. d'Alessio. C. Noviello. and F. Beretta (2000): Time resolved laser induced incandescence for soot and cenospheres measurements in oil flames. Combust. Sci. Techn. 153, 51-63.

[36] H.R. Leider. O.H. Krikorian and D.A. Young (1973): Thermodynamic properties of carbon up to the critical point. Carbon $11(5), 555-563$. 
[37] P. Monchicourt (1991): Onset of carbon cluster formation inferred from light emission in a lascr-induced expansion. Phys. Rev. Lett. 66 (11). 1430-1433.

[38] K. Verbiezen, R.J.H. Klcin-Douwel. A.P. van Vliet, A.J. Donkerbroek, W.L. Meerts, N.J. Dam and J.J. ter Meulen (2006): Attenuation corrections for in-cylinder NO LIF measurements in a heavy-duty Diesel cngine. Appl. Phys. B 83 (1), 155-166.

[39] M.Y. Choi and K.A. Jensen (1998): Calibration and correction of laserinduced incandescence for soot volume fraction measurements. Combust. Flame $112(4), 485-491$.

[40] B. Bougie, L.C. Ganippa, A.P. van Vliet, N. Dam, W.L. Meerts and J.J. ter Meulen (2005): Soot charactcrization with laser-induced incandescence in a hcavy-duty Diesel enginc. In: Proc. European Combustion Meeting, paper 166.

[41] B.F. Kock and P. Roth (2003): Two-color TR-LII applied to in-cylinder Diesel particle sizing. In: Proc. Europcan Combustion Mecting 2003. paper 093.

[42] R.L. Vanderwal and K.A. Jensen (1998): Laser-induced incandescence: Excitation intensity. App. Opt. 37 (9). 1607-1616.

[43] R.L. Vander Wal, T.M. Ticich and A.B. Stephens (1998): Optical and microscopy investigations of soot structure alterations by laser-induced incandescence. Appl. Phys. B 67 (1), 115-123.

[44] B.J. McCoy and C.Y. Cha (1974): Transport phenomena in the rarefied gas transition regime. Chem. Eng. Sci. 29 (2), 381-388. 


\section{Chapter 3}

\section{The TR-LII model}

This chapter will explain details about TR-LII modeling, which is needed in order to extract particle size information out of the TR-LII measurements. Paragraph 3.1 describes the Melton model, because it is the basis of all TR-LII models. Paragraph 3.3.1 gives a comparison between several models, based on the Melton model and points out differences between them. Different cooling models lcad to dramatic differences in fitted particle size distributions. Since 2005, an international working group is collaborating, more intensively on a better description of the LII modeling. The model we used for the analysis of the in-cylinder TR-LII measurements is described as well. This model has been chosen because it can be used for a wide range of pressure conditions. Appendix A considers some cooling phenomena which are taken into account in the most elaborate model which is used in the LII community nowadays.

\subsection{The Melton model}

In this section the Melton model [1] is described in more detail because it is the basis of all existing LII models. Melton described the energy balance of spherical soot particles by

$$
\frac{d}{d t} E_{i n t}=\dot{q}_{a b s}-\dot{q}_{c o n d}-\dot{q}_{v a p}-\dot{q}_{r a d},
$$

in which the terms at the right hand side are successively the rate of absorbed laser energy, and the energy loss rates by conduction, vaporisation and radiation. It is schematically expressed in Fig. 3.1.

The internal energy. $E_{\text {int }}$. of a single, spherical soot particle with radius $r_{p}$ at a temperature $T_{p}$ is described by

$$
E_{\text {int }}=\frac{4}{3} \pi r_{p}^{3} \rho_{p} C_{p} T_{p}
$$




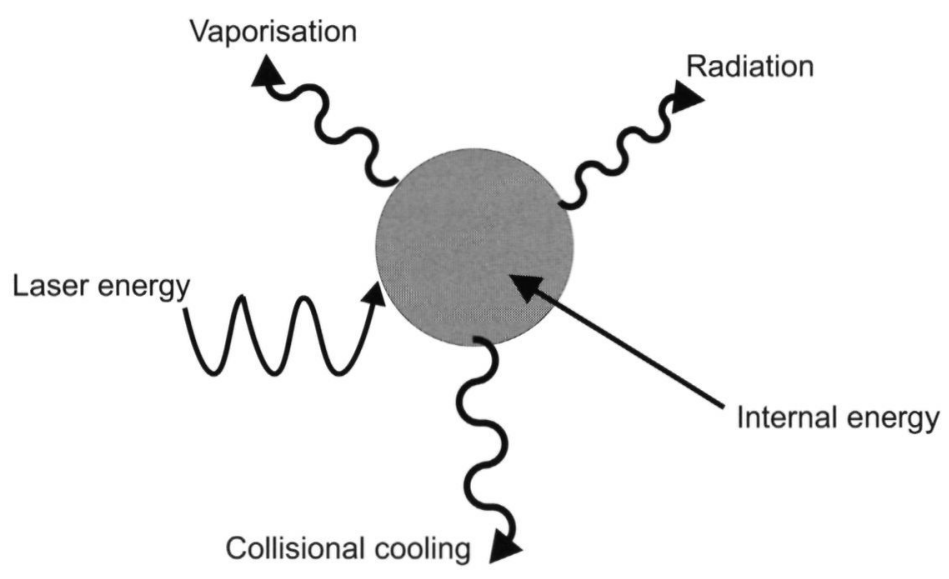

Figure 3.1: A cartoon of the model proposed by Melton [1] of laser-induced incandescence (LII): a high-energy laser pulse heats up a soot particle, after which the soot particle cools down by conduction, vaporisation and radiation.

in which $\rho_{p}$ is the density and $C_{p}$ the heat capacity of the soot particle. Melton assumed the values for graphitic carbon for these two parameters [7]. The absorption term is written as

$$
\dot{q}_{a b s}=Q_{a b s} \pi r_{p}^{2} \dot{q}_{l a s e r},
$$

in which $\dot{q}_{\text {laser }}$ is the laser fluence and $Q_{a b s}$ is the Mie absorption efficiency. The conduction cooling term is written as

$$
\dot{q}_{\text {cond }}=\frac{\lambda_{a}}{r_{p}} \frac{\left(T_{p}-T_{a}\right)\left(4 \pi r_{p}^{2}\right)}{1+G \cdot K n},
$$

in which $\lambda_{a}$ is the thermal conductivity of air, $T_{a}$ is the ambient temperature and $G$ is a geometry-dependent heat transfer factor, given by

$$
G=\frac{8 f}{\alpha_{T}}(\gamma+1)
$$

in which $f$ is the Eucken factor. This factor takes into account the transfer of energy between translational energy and internal energy [8]. $\alpha_{T}$ is the thermal accommodation coefficient giving the fraction of heat which is transferred during a collision between a soot particle and the environment [9]. Melton took the value 0.9 for the accommodation factor. $\gamma$ is the heat capacity ratio of the ambient gas defined as

$$
\gamma=\frac{C_{p}}{C_{v}}
$$

in which $C_{p}$ is the heat capacity at constant pressure and $C_{v}$ is the heat capacity at constant volume. Considering air as a diatomic ideal gas Melton took $\gamma=1.4$ [7]. 
The Knudsen number is a dimensionless number which gives the ratio between the mean free path $\lambda_{m f p}$ in a gas/vapor - which is dependent on the pressure and a characteristic length scale [10]. Mclton calculates a Knudsen number based on the particle diameter and the mean free path in the gas phase (air) $\lambda_{m f p, a}$ :

$$
K n \stackrel{\text { def }}{=} \frac{\lambda_{m f p a}}{2 r_{p}} .
$$

The heat loss rate by vaporization is given by the mass loss rate multiplied by the specific heat of vaporisation of carbon,

$$
\dot{q}_{v a p}=\Delta H_{v} \frac{d m_{p}}{d t}=\Delta H_{v} \rho_{p} 4 \pi r_{p}^{2} \frac{d r_{p}}{d t} .
$$

in which $\Delta H_{v}$ is the specific vaporisation heat per unit mass carbon. Invoking the continuity equation and assuming that there is no interaction between the vaporisation of soot and the ambient gas, it can be proved that

$$
\rho_{p} \frac{d r_{p}}{d t}=\rho_{v} c_{t v}
$$

in which $c_{t v}$ is the thermal velocity with which the vaporised carbon leaves the solid soot particle and $\rho_{v}$ is the density of vaporised soot, which is calculated with the idcal gas law in combination with the Clausius-Clapeyron cquation

$$
p(T)=p^{*} \exp \frac{\Delta H_{v}\left(T_{p}-T^{*}\right)}{R_{m} T_{p} T^{*}} .
$$

in which $\left(p^{*}, T^{*}\right)$ represents a rcference point in the phase diagram of carbon [11] and $R_{m}$ is the universal molar gas constant.

Assuming soot to be a black-body radiator, the net heat loss by radiation is given by the Stefan-Boltzmann law

$$
\dot{q}_{\text {rad }}=4 \pi r_{p}^{2} \sigma_{S B}\left(T_{p}^{4}-T_{a}^{4}\right)
$$

in which $\sigma_{S B}$ is the Stefan-Boltzmann constant.

\subsection{Comparison between several models}

This section comparcs several models, developed on basis of the Melton model. as they are used in the current analysis of TR-LII measurements (e.g. [4-6. 12-19]). The models calculate the change in internal energy as a function of the absorbed laser energy and treat conduction and sublimation or vaporisation of the soot as cooling mechanisms. Most of the models also treat the heat loss by radiation. but some don "t take this into account. because they (rightly) conclude that it is a cooling mechanism which is negligible in their experimental conditions. All the models assume that the primary particles have a spherical geometry and that the primary particles determine the cooling process. In the following sub-paragraphs some differences in the cooling energy change terms will be discussed. 


\subsubsection{Change in internal energy}

The change in internal energy in all models is given by

$$
\frac{d}{d t} E_{\imath n t}=\frac{d}{d t}\left(\frac{4}{3} \pi r_{p}^{3} \rho_{p} C_{p} T_{p}\right)
$$

All models assume that the material properties $\left(\rho_{p}\right.$ and $\left.C_{p}\right)$ for graphitic carbon can be applied to soot Most of the models assume that $C_{p}$ is independent of the temperature [12-19], but some, such as the model of Kock et al take a temperature dependent heat capacity, $C_{p}(T)$, because of the large temperature range which is present during the LII experiments [4-6] Michelsen [6], who considers annealing and melting of the soot particle as well, takes corresponding heat capacities and densities for the melted and the annealed fraction of the particles

$$
E_{\text {ınt }}=\rho_{p} C_{p}\left(1-X_{a n n}-X_{m e l t}\right)+\rho_{a n n} C_{a n n} X_{a n n}+\rho_{l} C_{l} X_{m e l t}
$$

In which $X_{a n n}$ is the fraction of the soot particle which has anneded, $X_{\text {melt }}$ the fraction of the soot particle which has melted, $\rho_{a n n}$ the density of anncaled soot, $\rho_{l}$ the density of liquid soot, $C_{a n n}$ the heat capacity of annealed soot and $C_{l}$ the heat capacity of liquid soot All densities and heat capacities are a function of temperature

\subsubsection{Absorption of laser energy}

All models assume that the absorption of laser energy can be described by

$$
q_{a b s}=\pi r_{p}^{2} Q_{a b s} q_{l a s e r}
$$

in which $q_{\text {laser }}$ is the laser fluence and $Q_{a b s}$ is the absorption efficiency of laser energy

\subsubsection{Conductive cooling}

The general equation for heat-losses by conduction looks like

$$
q_{\text {cond } f m}=4 \pi r_{p}^{2} h\left(T_{p}-T_{a}\right)
$$

in which $h$ is a general heat transfer coefficient There is no agreement between the models how to treat the heat transfer coefficient [2] For the free molecular regime Kock et al [4] and Roth and Filippov [12] describe the hedt losses by conduction, using the theory proposed by Williams and Loyalka [10] by

$$
q_{\text {cond } f m}=\alpha_{I} 4 \pi r_{p}^{2} \frac{1}{2} \rho_{a} c_{t a} \frac{T_{p}-T_{a}}{T_{a}}
$$


in which $\rho_{a}$ is the ambient density and $c_{t a}$ is the thermal volocity of the ambient gas, which is calculated with

$$
c_{t a}=\sqrt{\frac{R_{m} T_{a}}{2 M_{a}}}
$$

in which $M_{a}$ is the molar mass of the ambient enviromment. Roth and Filippov [12] assume that the thermal accommodation cocfficient $\alpha_{T}$ cquals 1 . Kock et al. [4] take a value of 0.3 for $\alpha_{T}$ in the free-molecular regime. For elevated pressures (in the transition regime) both use a Knudsen-number-dependent interpolation function betwecn the frec-molecular and continuum regimes based on the theory of Williams and Loyalka [10]

$$
\dot{q}_{c o n d, t r}=f\left(K n_{\mathrm{c}}\right) \cdot \dot{q}_{\mathrm{cond}, \mathrm{c}},
$$

in which $f\left(K n_{c}\right)$ is a Knudsen-number-dependent interpolation function. Filippov et al. [14] use the latter equation as the general expression for cooling by conduction. The expression for the conductive cooling in the continuum regime is defined as

$$
\dot{q}_{\text {cond }, c}=4 \pi r_{p} \lambda_{a}\left(T_{p}-T_{a}\right),
$$

in which $\lambda_{a}$ is the thermal conductivity and can be calculated with

$$
\lambda_{a}=\frac{1}{3} I_{a} c_{t a} C_{v} \frac{p_{a}}{R_{m} T_{a}},
$$

in which $I_{a}$ is the mean free path in the ambient environment. $K n_{\mathrm{r}}$ is calculated based on the mean free path of the gas in the ambient atmosphere, calculated from $[10]$

$$
\lambda_{m f p, a}=\frac{1}{\sqrt{2} \cdot \sigma_{\text {coll }}} \cdot \frac{k_{B} T_{a}}{p_{a}}=\frac{1}{\sqrt{2} \sigma_{\text {coll }} \rho_{a}},
$$

in which $\sigma_{\text {coll }}$ is the collision cross-section of the soot particles with the surrounding air. Details of the interpolation function are given in $\S 3.3 .1$.

The other models $[6.13,15-17,19]$ use the theory of McCoy and Cha [23] in the rarefied gas regime for the heat-losses by conduction. This theory considers the probability that a heated soot particle collides with an object present in a volume or with an air molecule. Michelsen [6], Snclling [16] and Bladh [19] use the cxpressions Eq. (3.4- 3.5), proposed by Melton, for the conductive cooling. Schittkowski et al. [17] calculate the heat-transfer coefficient, using the Sutherland approximation [20]

$$
h=\frac{1}{1+G \cdot K n} k_{0}\left(\frac{T_{p}}{T_{k 0}}\right)^{3 / 2} \frac{T_{k 0}+S_{k}}{T_{p}+S_{k}} .
$$

in which $S_{k}$ is the Sutherland constant for thermal conductivity, $k_{0}$ is a reference value for thermal conductivity and $T_{k 0}$ the corresponding temperature. The heat transfer coefficient is taken to be a power law of the temperature in the Sutherland 


\begin{tabular}{|l|l|}
\hline Paper & Value $\alpha_{T}$ \\
\hline Melton [1] & 0.9 \\
Kock in free-molccular regime [4] & 0.3 \\
Michelsen [6] & 0.3 \\
Roth [12] & 1 \\
Will [13] & Not given \\
Filippov [14] and Kock [5] in transition regime & $f\left(K n_{c}\right)$ \\
Schraml [15] & Not given \\
Snclling [16] & 0.9 \\
Schittkowski [17] & Not given \\
Lehre [18] & Not given \\
Bladh [19] & Not given \\
\hline
\end{tabular}

Table 3.1: Comparison of several values for the thermal accommodation coefficient in the different models.

approximation [20]. Lehre et al. [18] calculated the heat-transfer cocfficient, based on the Fuchs approach [21]

$$
h=\alpha_{T} \frac{p_{a}}{2} \sqrt{\frac{8 k_{B}}{\pi M_{a} T_{a}}} \frac{\gamma+1}{\gamma-1} .
$$

in which $p_{a}$ and $T_{a}$ are the ambient pressure and temperature resp., $M_{a}$ is the molar weight of the ambient gas and $k_{B}$ is the Boltzmann constant. Will [13] and Schraml [15] do not specify how $h$ is defined.

The value of the accommodation coefficient $\alpha_{T}$ varies quite tremendously between scveral models (see Table 3.1).

\subsubsection{Vaporative/sublimative cooling}

There is discussion about the phase change of the solid soot particles that may take place at elevated temperatures [2]. Michelsen [6] considers both melting and sublimation in her model. The major change in the radius of the particles is caused by sublimation of the particles. The mass change in her model can be described with

$$
\frac{d m_{p}}{d t}=-4 \pi r_{p}^{2} \sum_{\jmath=1}^{5} \frac{W_{\jmath} U_{\jmath} \alpha_{\jmath} B_{\jmath}}{R_{m} / p_{0} T_{p}}
$$

in which $U_{J}$ is the average escape velocity of the sublimated carbon species $\mathrm{C}_{\mathrm{J}}$ with $W_{3}$ the corresponding molar mass and $p_{0}$ is the standard atmospheric pressure. She considers $\mathrm{C}_{1}$ to $\mathrm{C}_{5}$ as relevant species. $B$, is a factor which considers the convective contributions to the heat and mass transfer from the particle to the environment. The energy loss can simply be calculated with

$$
\dot{q}_{s u b}=\frac{d m_{p}}{d t} \cdot \Delta H_{s}
$$


in which $\Delta H_{s}$ is the specific sublimation heat of solid carbon

Many authors, however assume that the phase change which takes place is due to vaporisation [4 12-19] All models determinc the mass loss rate on the basis of Eq (3 8) However several other expressions for the mass flux are present in LII models [30] Snclling et al [16] and Bladh and Bengtson [19] define the mass flux by

$$
q_{v a p}=\frac{\Delta H_{\imath}}{4} \pi r_{p}^{2} \beta p_{v}\left(T_{p}\right) \sqrt{\frac{M_{\imath}}{2 \pi R_{m} T_{p}}},
$$

in which $\Delta H_{v}$ is the specific vaporisation heat of soot, $M_{v}$ is the molar mass of soot vapor, $p_{v}$ is the vapor pressure of the soot and $\beta$ is a mass accommodation coefficient which corrects for the efficiency with which soot evaporates from the heated soot particle, which function is comparable to the accommodation cocfficient in the conduction term

Melton [1] defines the heat loss by vaporisation with

$$
q_{v a p}=\frac{\Delta H_{v}}{4} \pi r_{p}^{2} p_{v}\left(T_{p}\right) \sqrt{\frac{M_{\imath}}{2 R_{m} T_{p}}}
$$

Roth and Filippov [12] Will et al [13] and Schraml et al [15] do not specify how they calculate the mass flow rate Kock et al [4] and Filıppov et al [14] use a Knudsen number dependent function for the mass flow rate The expression is similar to their expression for conduction

$$
q_{v a p t r}=f\left(K n_{v}\right) \quad q_{\imath a p c}
$$

in which $f\left(K n_{v}\right)$ is a Knudsen-number-dependent interpolation function, in which $K n_{v}$ is the Knudsen number based on the properties of the soot vapor $K n_{\imath}$ is defined as

$$
K n_{v}=\frac{\lambda_{m \int p 1}}{r}
$$

in which $\lambda_{m f p} v$ is the mean frec path of the vapor, which is calculated by [10]

$$
\lambda_{m f p v}=2 \mathbb{D} \sqrt{\frac{\frac{M_{d}}{N_{A}}}{2 k_{B} T_{v}}}
$$

in which $\mathbb{D}$ is the diffusion coefficient of the vapor into the ambient gas, defined as $[22]$

$$
\mathbb{D}=\frac{1}{3} \lambda_{m f p a}{ }^{\prime \prime a}
$$

The vapor temperature $T_{v}$ is assumed to be equal to the particle tomperature Detalls on the interpolation function are given in $\$ 331$ 


\subsubsection{Radiation}

Most models also include radiation as a cooling process $[14,16]$. LII takcs place at high temperatures and the radiation is determined by Planck's radiation law [7]

$$
\dot{q}_{r a d}=4 \pi r_{p}^{2} \varepsilon \sigma_{S B}\left(T_{p}^{4}-T_{a}^{4}\right) .
$$

in which $\varepsilon$ is the emissivity of soot. The cooling contribution by radiation is often negligible for small soot particles. As a consequence. some models neglect the heatlosses by radiation [14, 16].

\subsection{Cooling model applied in this study}

This paragraph gives more details about the model which has been used to analyze the in-cylinder measurement results. In the cylinder of a modern Diesel engine the pressure varies by about two orders of magnitude during a combustion cycle. Under the conditions prevalent in such an enginc. the cooling rate of laser-heated soot particles is dominated by heat conduction. This cooling rate is therefore strongly dependent on the in-cylinder temperature and pressurc [1,28]. The physical model that is used for comparison to the experimental data will have to be able to cope with the pressure variation in the engine. At low prcssures the cooling is in the freemolecular regime, whereas at high pressures the cooling of the particles proceeds in the continuum regime.

Williams and Loyalka [10] introduced empirical interpolation functions for heat transfer models for pressures between those of the free-molccular and the continuum regime for conduction and vaporisation (Eq. 3.18 and Eq. 3.28). The interpolation functions which they introduced use the Knudsen number as interpolating variable. Kock et al. $[4,5]$ introduced the interpolation functions for modeling of the TR-LII transicnts at elevated pressures. We have adopted their model to estimate soot particle sizes from the measured TR-LII decay curves.

The heat capacity is defined as [10]

$$
C_{p}=a_{\jmath, p}+b_{\jmath, p} T_{p}+\frac{c_{\jmath, p}}{T_{p}^{2}}
$$

in which $a_{\jmath}, b_{\jmath, p}$, and $c_{\jmath, p}$ are matcrial constants of graphitic carbon. A similar expression is used for the heat capacity of the ambient gas

$$
C_{a}=a_{\jmath, a}+b_{\jmath, a} T_{a}+\frac{c_{j, a}}{T_{a}^{2}}
$$

of which the successive values of the constants can be found again in the appendix. The model assumes that heating tracc and the cooling trace can be strictly separated. The heat-up temperature is measured with two-color pyrometry and consequently the absorption term does not need to be modeled. The radiation term is taken according to the model of Melton. Further assumptions of the model are 
that the particles are sphcrical and that agglomeration has no effect on the cooling behavior. The temperature of the particles is assumed to be uniform, which is allowed because the thermal conductivity of carbon is estimated to be some orders of magnitude larger than the thermal conductivity of the surrounding gas under typical engine conditions (sec calculation in Appendix B). In the following paragraphs some details about the different cooling terms are given.

\subsubsection{Interpolation functions}

For both the conductive and the vaporisation cooling terms empirical interpolation functions have been used, which have been taken from aerosol theory. The interpolation functions are applicable for an interpolation between the continuum and free-molecular regimes, at pressures which are typically present in the engine environment. In the transition regime the cooling rate can be written as [10]

$$
\dot{q}_{\imath, t r}=f_{\imath}\left(K n_{\imath}\right) \cdot \dot{q}_{\imath, c},
$$

in which

$$
f_{\imath}\left(K n_{\imath}\right)=\left[1+K n_{\imath} \frac{\frac{q_{r}}{q_{f m}} \xi_{\imath}+\zeta_{\imath}}{K n_{\imath} \xi_{\imath}+1}\right]^{-1},
$$

and $\xi_{2}$ and $\zeta_{2}$ are empirically determined interpolation constants (see Appendix). In this equation the subscript $\imath$ stands for vaporisation or conduction, and the subscripts $c$ and $f m$ stand for the continuum and free-molecular regime respectively. The functions for the heat losses in the continuum regime have been given in the previous paragraph.

In Fig. 3.2 and Fig. 3.3, respectively, the simulated heat loss rates by conduction and vaporisation as a function of the pressure are plotted. The corresponding Knudsen numbers have been plotted in the graphs as well. The particle radius is $25 \mathrm{~nm}$, the ambient temperature is $1000 \mathrm{~K}$ and the temperature of the heatcd soot particle is $3500 \mathrm{~K}$. It can be seen that, under the conditions prevalent in the engine, the heat loss rate by conduction is much more efficient than the heat loss rate by vaporisation. In addition, it can be seen that with increasing pressure the heat loss rate by conduction is increasing and the heat loss rate by vaporisation is decreasing. 


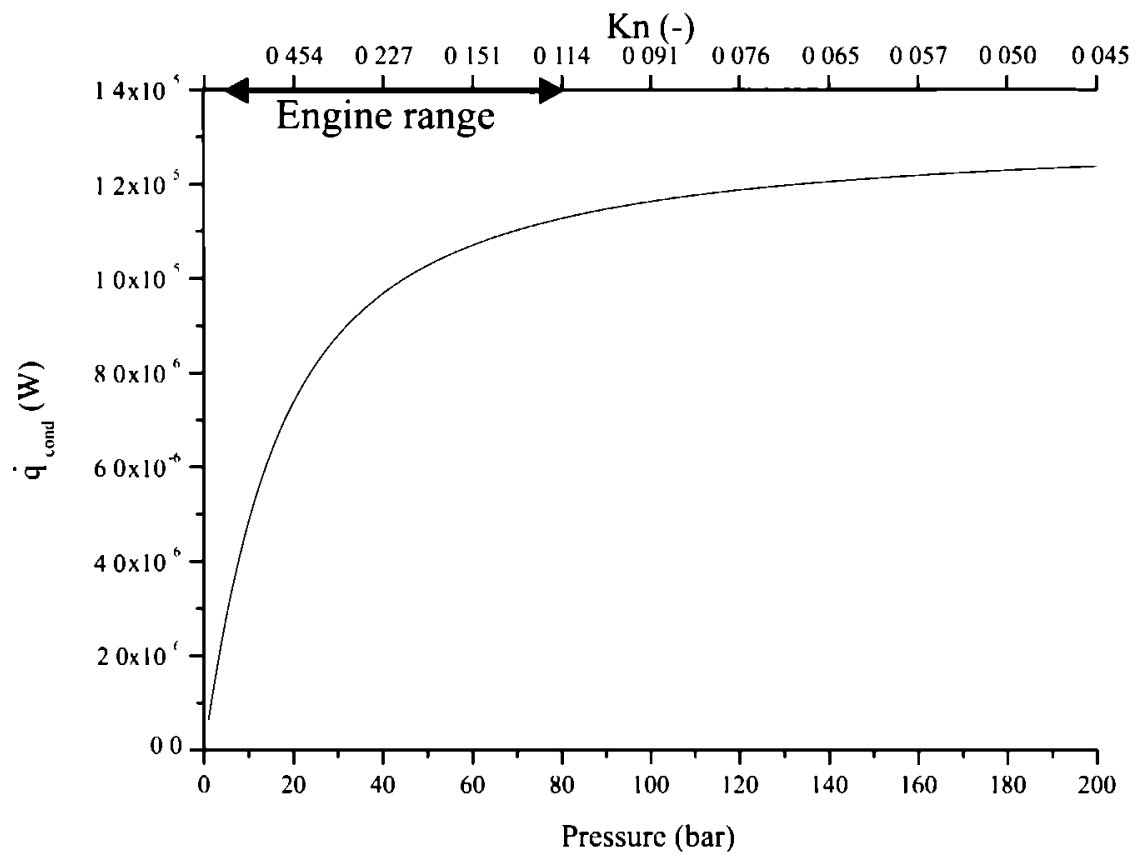

Figure 3.2: Calculated heat loss rate by conduction as a function of the pressure for a particle with a radius of $25 \mathrm{~nm}$ at a tempcrature of $3500 \mathrm{~K}$ in an environment with an ambient temperature of $1000 \mathrm{~K}$. At the upper horizontal axis. the corresponding Knudsen numbers have been plotted. The pressure regime for the engine environment is indicated. 


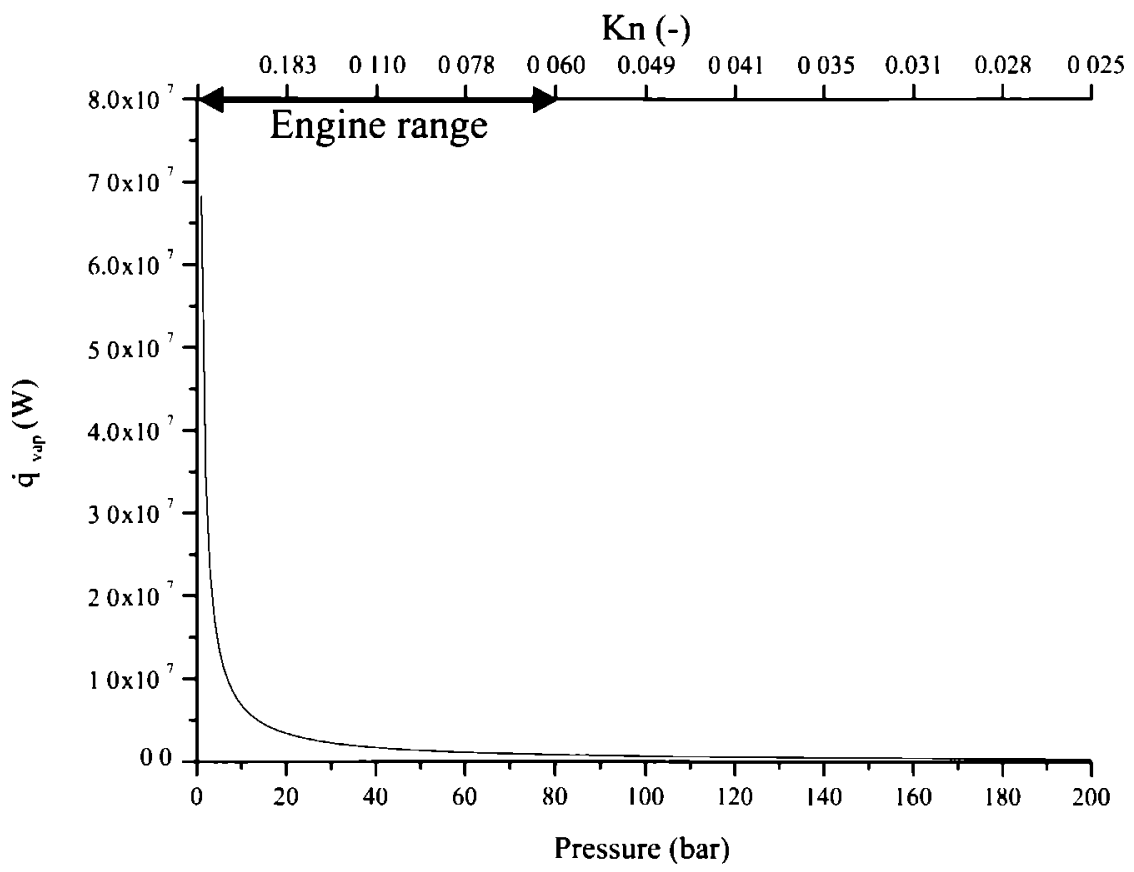

Figure 3.3: Calculated heat loss rate by vaporisation as a function of the pressure for a particle with a radius of $25 \mathrm{~nm}$ at a temperature of $3500 \mathrm{~K}$ in an environment with an ambient temperature of $1000 \mathrm{~K}$. At the upper horizontal axis. the corresponding Knudsen numbers have been plotted. The pressure regime for the engine environment is indicated. 


\section{Bibliography}

[1] L.A. Melton (1984): Soot diagnostics based on laser heating. Appl. Opt. 23 (13), 2201-2208.

[2] C. Schulz, B.F. Kock, M. Hofmann, H. Michelsen, S. Will, B. Bougie, R. Suntz and G. Smallwood (2006): Laser-induced incandescence: recent trends and current questions. Appl. Phys. B 83 (3), 333-354.

[3] T. Dreier, B. Bougic, N. Dam and T. Gerber (2006): Modeling of time-resolved laser-induced incandescence transients for particle sizing in high-pressure spray combustion environments: a comparative study. Appl. Phys. B 83 (3), 403-411.

[4] B.F. Kock, Th. Eckhardt and P. Roth (2002): In-cylinder sizing of Diesel particles by time-resolved laser-induced incandescence (TR-LII). In: Proc. Combust. Inst. 29, 2775-2781.

[5] B.F. Kock and P. Roth (2003): Two-color TR-LII applicd to in-cylinder Diesel particle sizing. In: Proc. Europcan Combustion Meeting 2003, paper 093.

[6] H. Michelsen (2003): Understanding and predicting the temporal response of laser-induced incandescence from carbonaceous particles. JCP 118 (15), 70127045 .

[7] D.R. Lide (2001): CRC Handbook of Chemistry and Physics. CRC Press. Florida.

[8] J.O. Hirschfelder. C.F. Curties and R.B. Bird (1954): Molecular thcory of gases and liquids. J. Wiley \& Sons.

[9] J.R. Burke and D.J. Hollenbach (1983): The gas-grain interaction in the interstcllar medium: thermal accommodation and trapping. APJ 265. 223-234.

[10] M.M.R. Williams and S.K. Loyalka (1991): Aerosol Science Theory and Practice, With Special Applications to the Nuclear Industry. Pergamon Press.

[11] P.W. Atkins (1998): Physical Chemistry $6^{\text {th }}$ ed.. Oxford University Press. U.K. 
[12] P. Roth and A.V. Filippov (1996): In situ ultrafine particle sizing by a combination of pulsed laser heatup and particle thermal emission. J. Aerosol Sci. 27 (1), 99-104.

[13] S. Will. S. Schraml. K. Bader and A. Leipertz (1998): Performance characteristics of soot primary particle size measurements by time-resolved laser-induced incandescence. Appl. Opt. 37 (24), 5647-5658.

[14] A.V. Filippov. M.W. Markus and P. Roth (1999): In-situ characterization of ultrafine particles by laser-induced incandescence: Sizing and structure determination. J. Acrosol Sci. 30 (1), 71-87.

[15] S. Schraml, S. Dankers, K. Bader, S. Will and A. Leipertz (2000): Soot tempcrature mcasurements and implications for time-resolved laser-induced incandescence (Tire-LII). Combust. Flame 120 (4). 439-450.

[16] D.R. Snelling, F. Liu, G.J. Smallwood and Ö.L. Gülder (2000): Evaluation of the nanoscale heat and mass transfer model of LII. In: Proc. NHTC 200012132.

[17] T. Schittkowski. B. Mewes and D. Brüggemann (2002): Laser-induced incandescence and Raman measurements in sooting methane and ethylene flames. PCCP 4 (11). 2063-2071.

[18] T. Lehre. B. Jungfleish. R. Suntz and H. Bockhorn (2003): Size distributions of nanoscaled particles and gas temperatures from time-resolved laser-induced incandcscence measurements. Appl. Opt. 42 (12): 2021-2030.

[19] H. Bladh and P.-E. Bengtson (2004): Characteristics of laser-induced incandescence from soot in studies of a time-dependent heat- and mass-transfer model. Appl. Phys. B 78 (2). 241-248.

[20] F.M. White (1991): Viscous Fluid Flow. McGraw Hill.

[21] N.A. Fuchs (1964): The Mechanics of Aerosols, Pergamon Press, Oxford.

[22] E.H. Kennard (1938): Kinetic Theory of Gases. McGraw Hill, New York.

[23] B.J. McCoy and C.Y. Cha (1974): Transport phenomena in the rarefied gas rcgimc. Chem. Eng. Sc. 29 (2). 381-388.

[24] M. Charwath. R. Suntz and H. Bockhorn (2006): Influcnec of the temporal response of the detection system on time-resolved laser-induced incandescence signal evolutions. Appl. Phys. B 83 (3), 435-442.

[25] B.F. Kock. B. Tribalet. C. Schulz and P. Roth (2006): Two-color time-resolved LII applied to soot particle sizing in the cylinder of a Diesel engine. Combust. Flame 147 (1-2), 79-92. 
[26] H.R. Leider, O.H. Krikorian and D.A. Young (1973): Thermodynamic properties of carbon up to the critical point. Carbon 11 (5). 555-563.

[27] W.C. Hinds (1982): Acrosol Technology: properties, behavior and mcasurcment of airborne particles. Wiley. New York.

[28] M. Hofmann, W.G. Bessler. C. Schulz and H. Jander (2003): Lascr-induced incandescence (LII) for soot diagnostics at high pressures. Appl. Opt. 42 (12). 2052-2062.

[29] J. Steinbeck, G. Dresselhaus and M.S. Dresselhaus (1990): The properties of liquid carbon. Int. J. Thermophysics 11 (4), 789-796.

[30] G.J. Smallwood, D.R. Snelling, F. Liu and Ö.L. Gülder (2001): Clouds over soot evaporation: Errors in modeling laser-induced incandescence of soot. J. Heat Trans. 123 (4), 814-818. 


\section{Chapter 4}

\section{Optical diagnostics of diesel spray injections and combustion in a}

\section{high-pressure}

high-temperature cell*

We report on spatially and temporally resolved optical diagnostic measurements of propagation and combustion of Dicsel sprays introduced through a single-hole fuel injector into a constant volume, high-tempcrature. high-pressure cell. From shadowgraphy images in non-reacting environments of pure nitrogen. penctration lengths and dispersion angles were determined for non-vaporizing and vaporizing conditions, and found to be in reasonable agreement with standard modcls for liquid jet propagation and breakup.

Quasi-simultaneous two-dimensional images were obtained of laser elastic light scattering. shadowgraphs and spectrally integrated flame emission in a rcacting cnvironment (cell temperature $850 \mathrm{~K}$ ). In addition laser-induced incandescence was employed for the identification of soot-loaded regions. The simultancously recorded spray images exhibit remarkable structural similarity and provide complementary information about the spray propagation and combustion process. The measurements also reveal the fucl vapor cloud extending well beyond the liquid core and close to the nozzle tip. Ignition takes place close to the tip of the spray within the mixing layer of fucl vapor and surrounding air. Soot is formed in the vapor core region at the tip of the liquid fucl jet. Our results support recently developed a

- Adapted from B Bougic, M Tulej. T Dreier. N J Dam. J J. ter Meulen and T Gerber. Appl Phys B $80(8), 10391045$ (2005) 
phenomenological model on Diesel spray combustion.

\subsection{Introduction}

Because of their high thermal efficiency Diesel engines offer great advantages in comparison with other internal combustion concepts for purposes of transportation. However, due to increasingly stringent exhaust emission legislation, aimed at reducing environmental and health concerns (notably involving soot and $\mathrm{NO}_{\mathrm{x}}$ ), a deeper understanding of the physico-chemical mechanisms of Diesel combustion processes is mandatory. Essential features of the combustion process of a Diesel fuel spray. such as vaporization. ignition and soot formation. have therefore to be identified for wide ranges of operating conditions.

In Diesel engines spray evolution is strongly influenced by fucl injector design and characteristics (nozzle geometry, injection pressure, etc.) and ambient conditions in the combustion chamber (temperature. pressure. composition, turbulence intensity, etc.). This concerns the propagation and dispersion of a high-speed liquid fuel jet into a mostly turbulent high density gaseous environment, its breakup into droplets, vaporization and ignition. On their turn these processes affect the subsequent combustion, soot formation and exhaust gas emission. Since in practice these phenomena are highly unstcady, the unravcling of corrclations between different scalars necessitates simultaneous observation of as many parameters as possible during one single spray injection event. Optical techniques constitute a useful tool for in situ diagnostics of these processes with high temporal and spatial resolution. Combustion strategies for the reduction of soot and toxic emissions in Diesel cngincs might also benefit from such in situ observation of mutual dependencies between reactive and non-reactive scalars. Besides gaining a deeper understanding of, e.g., soot/flame interactions during the combustion process, multi-scalar imaging will help in the validation of existing spray propagation models [1. 2]. and assist in the interpretation of the outcomes of Diesel cngine combustion modeling [3]. In the present work a combination of several optical imaging techniques - flashlight shadowgraphy (SG), laser elastic scattering (LES) and chemiluminescence imaging - were applicd quasi-simultancously. i.e.. within a temporal window that is short relative to the characteristic time scales of spray evolution. Experiments werc performed in an optically accossible, constant volume high-temperature. high-pressure cell. In addition, laser induced incandescence (LII) was applied to visualize soot in the spray combustion process. Together with its valve-operated inlet and outlet ports this test facility provides measurement conditions that approach a realistic Diesel combustion cycle near top dead center (8 MPa. $520-850 \mathrm{~K}$ before combustion) with the benefit of reduced complications concerning optical access to the combustion chamber. as compared to real production engines [4-6]. 


\subsection{Measurement techniques}

Various optical and laser spectroscopic tools were applied to gather a multitude of complementary information related to the spray propagation and combustion processes. The techniques used in the present study are described brictly below. Shadowgraphy (SG) experiments [7] image the spray against a uniformly lit background. These images depict regions of a spray that exhibit lower transmittance to a background light source-due to scattering, absorption and deflection of light. Altcrnatively, in laser elastic scattering (LES) [8] two-dimensional imaging from a region within a thin light shect is possible in a direction perpendicular to the sheet. In the gas phase, LES provides a two-dimensional image related to the density of the scattering medium. For gas mixtures of which the individual species concentrations and respective scattering cross sections are known. temperatures can be evaluated from LES signal intensities. if the latter are calibrated in known environments. After careful calibration, Espey et al. obtained quantitative twodimensional fuel vapor phase distributions during spray propagation in an optically accessible Diesel engine cylinder [9]. With a similar tcchnique Andersson ct al. performed quantitative imaging of fuel equivalence ratios in DME sprays introduced into hot atmospheres of a combustion vessel [10]. In laser-induced incandescence (LII) particles (typically in the size range of $1-100 \mathrm{~nm}$ ) are heated close to thcir vaporization temperature by absorption of radiation from a strong laser pulse and their thermal radiation intensity is recorded in a narrow spectral range during or shortly after the exciting laser pulse. LII is commonly applied for the determination of the local particle volume fraction, such as soot in flames [11-13] and exhaust streams [14]. This information can be inferred from an analysis of the energy and mass balance in the particle ensemble, accounting for absorption of radiation. and cooling by evaporation or sublimation, radiation and heat conduction [15. 16]. Size distribution measurements are also possible via the temporally resolved LII signal intensity [16-18] (sec also Ch. 2). Finally, imaging the spectrally integrated chemiluminescence (CL) intensity (spatially or tcmporally resolved) from electronically excited species and/or thermal soot radiation provides a global impression of spray ignition. combustion and soot production [19].

\subsubsection{Experimental Setup}

The high-pressurc high-temperature cell is described in detail in chapter 2 . Here we present only the optical arrangements for the experiments discussed below. LES and LII experiments were performed with a frequency-doubled Nd:YAG laser $(532 \mathrm{~mm}$. 10 ns pulse-width). whereas for shadowgraphy a Xenon flash-lamp ( $1 \mu$ s pulse duration) was used (sce Fig. 4.1). The laser beam was expanded using one cylindrical lens ( $\mathrm{f}=-30 \mathrm{~mm}$ ), and subsequently loosely focused by a spherical lens ( $\mathrm{f}=500 \mathrm{~mm}$ ) into a thin light sheet $(0.8 \mathrm{~mm}$ thick) across the full width of the top entrance window of the ccll in a plane containing the main spray propagation axis. A $50 \%$ beam splitter allows simultaneous imaging with two intensified CCD- 


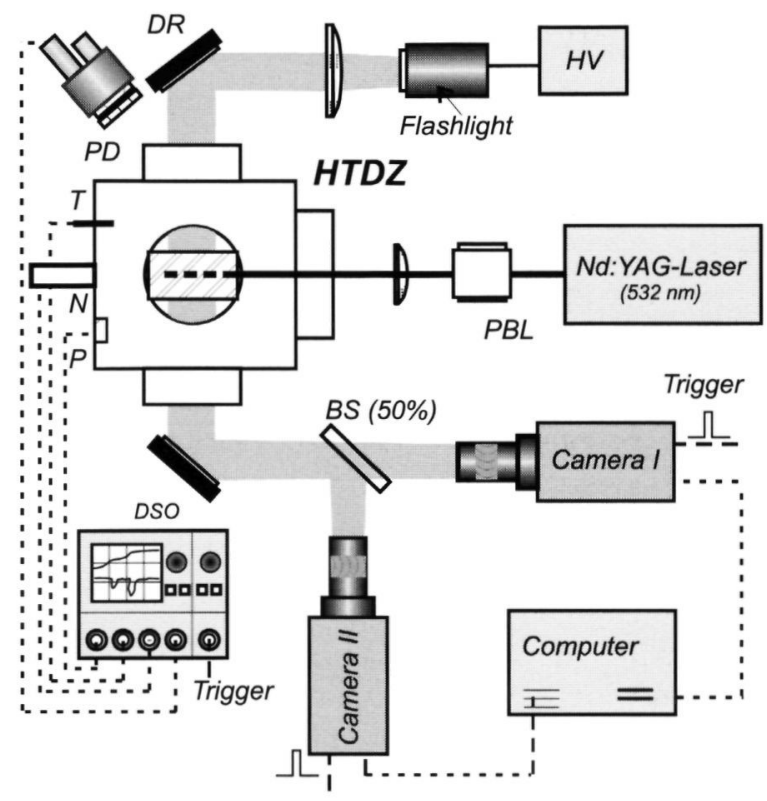

Figure 4.1: Top view of experimental arrangement for multi-scalar imaging in the spray combustion cell. Time resolved recording of cell pressure, temperature, needle lift and nozzle fuel pressure are recorded during a single spray injection/combustion event with the resp. sensors in the experimental setup. The chemiluminescence is recorded with a photodiode $(\mathrm{PD})$. The laser beam is directed via a prism beam lift (PBL) through the top cell window, and traverses the cell perpendicular to the plane of the figure. BS: beam splitter, DR: diffuse reflector, DSO: digital storage oscilloscope, T, P: temperature, pressure sensor, N: fuel nozzle

cameras (Dicam-PRO, PCO) through one of the side windows perpendicular to the laser entrance window. Both cameras were equipped with a double-framing option to capture two images within an adjustable delay larger than a minimum of $500 \mathrm{~ns}$ necessary for data storage. This allowed the recording of up to four images within less than $1.5 \mu \mathrm{s}$. Compared with the relevant time scales of spray propagation of several $100 \mu \mathrm{s}$, these observations can be considered as instantaneous. A digital delay generator and coincidence trigger unit synchronized the external devices with valve and nozzle injection timing. The prompt LII-signal was detected behind a narrow-band interference filter (bandpass $650 \pm 40 \mathrm{~nm}$ ). Spray penetration was evaluated from a series of consecutive images of sequential injections taken with one camera at increasing time delays (in steps of 10 to several $100 \mu \mathrm{s}$ ) after start of injection (SOI). A photodiode coupled to a digital storage oscilloscope recorded spectrally and spatially integrated time-resolved chemiluminescence. Simultane- 
ously, pressurc and temperature of the gas as well as the ncedle lift signal during fuel injection were captured for each injection cvent

\subsection{Results and discussion}

\subsubsection{Non-reacting spray injection}

Spray propagation in high-density gascous cnvironments without combustion was studied for non-vaporizing and vaporiung conditions by fuel injection into pure n1trogen at temperatures of 520 and $850 \mathrm{~K}$, respectively SG and LES images for these conditions a gas pressure of $4 \mathrm{MPa}$ and fuel injection pressurc of $100 \mathrm{MPa}$ are shown in Fig 42 SG and LES images wcre taken simultaneously with one camera in double framing mode, each with a 100 ns gate opening time and firing the Nd YAG-laser $1 \mu$ s after the Xe flashlight With a spatial resolution of approxımately $015 \mathrm{~mm} /$ pıxel, and a fluid injection speed of approximatcly $200 \mathrm{~m} / \mathrm{s}$ this timing sequence ensured the recording of temporally frozen events For the higher gas temperature (right column in Fig 42) the image quality is degraded by refractive index variations due to hot air convection in the optical path betwcen cell window and camerd objective From a scrics of similar iecordings at constant environmental conditions but varying delay between SOI and firing of the background flash light penetration and dispersion of the individual spray liquid cores were evaluated For the lower temperature case of $520 \mathrm{~K}$ it takes several milliseconds for a droplet to vaporize [20] In this case the contour lines in the quasi-simultaneous images of spray shadow and ldser scattering (left column in Fig 42 ) exhibit striking simnlarities The outer spray boundary is corrugated due to the presence of turbulent mixing caused by alr entrainment and mixing with large scale structures from the liquid core For vaporisming conditions ( $850 \mathrm{~K}$ right column in Fig 42 ) the SG image shows a relatively short and narrow liquid core region In the LES image this same spatial area exhibits a high scattcring intensity surrounded by areas of lower scattering intensity attributed mostly to vaporized fuel droplets A clear distinction between fuel vapor and small droplets however is not possible with the employed techniques Since Diesel fuel vapor exhibits a much larger Rayleigh scattering cross section $\sigma_{\mathrm{R}}$ than molecular nitrogen from the bulk gas $\left(\sigma_{\mathrm{R}}(\right.$ Diesel $\left.) \approx 100 \sigma_{R}\left(N_{2}\right)\right)[21]$ the recorded scattering intensity also contains contributions from the vapor phase

Following the andysis by Naber ct al [20], the liquid core region was cvaluated by transforming the SG image into a binary image The penetration length was then defined as the distance between nozzle tip and the downstream tip of the spray cloud projected on the spray propagation axis A measure of spray dispersion was defined as the cone angle formed between the two lines connecting the spray boundary at half the penetration depth with the cone origin at the nozzle exit Examples of penetration length $S(t)$ (squares) and dispersion curves $\theta(t)$ (triangles) for vaporızing (open symbols) and non-vaporizing (solıd symbols) conditions are 


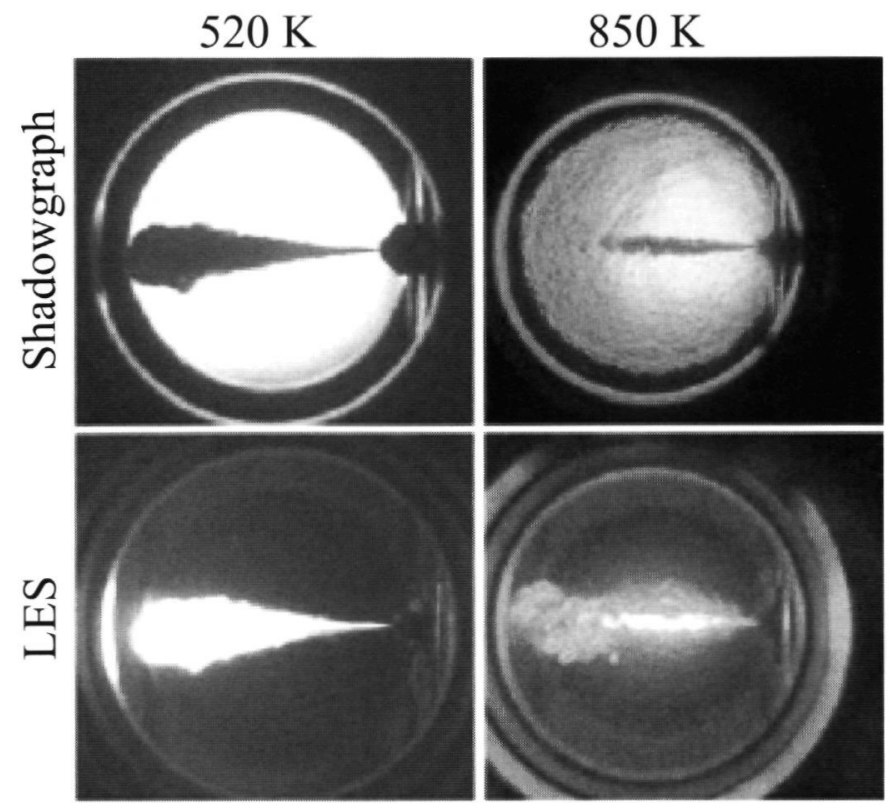

Figure 4.2: Shadowgraph (upper row) and laser scattering images (bottom row) of Diesel fuel spray $0.4 \mathrm{~ms}$ after SOI for vaporizing (right column) and non-vaporizing (left column) conditions. At each temperature images in each column were recorded during the same injection event using one camera in double shutter mode, with a gate duration of $100 \mathrm{~ns}$ and a time separation of $1.0 \mu$ s between both exposures. Conditions: $P_{a}=4 \mathrm{MPa}$, fuel injection pressure $P_{f}=100 \mathrm{MPa}$

presented in Fig. 4.3. In the dispersion curve the spray angle first increases to a maximum, which is located slightly before the spray breakup time (see Eqs. 4.2, 4.6 below). For the lower temperature investigated, the curve slowly declines again and remains fairly constant throughout the investigated propagation duration, as is also shown by the data taken at higher temperature. For a nozzle diameter similar to ours $(0.198 \mathrm{~mm}$ instead of $0.150 \mathrm{~mm})$ and a fuel pressure of $110 \mathrm{MPa}$ Naber et al. [20] give a correlation between dispersion angle and the ratio of ambient to fuel densities of $\tan (\theta / 2)=0.31\left(\rho_{a} / \rho_{f}\right)^{0.19}$, from which a steady-state angle of $\theta=21^{\circ}$ can be calculated for a gas temperature of $500 \mathrm{~K}$. The apparent discrepancy to our experiment (approx. $14^{\circ}$ opening angle, see Fig. 4.3) is not surprising owing to the different nozzle hole diameter (33\% larger than ours) and fuel type employed in their experiments. It is also known that the geometric shape of nozzles has a pronounced effect on spray characteristics [22].

The experimental data were correlated with semi-empirical spray penetration models $[1,20]$ developed for scaling the propagation characteristics for a number of 


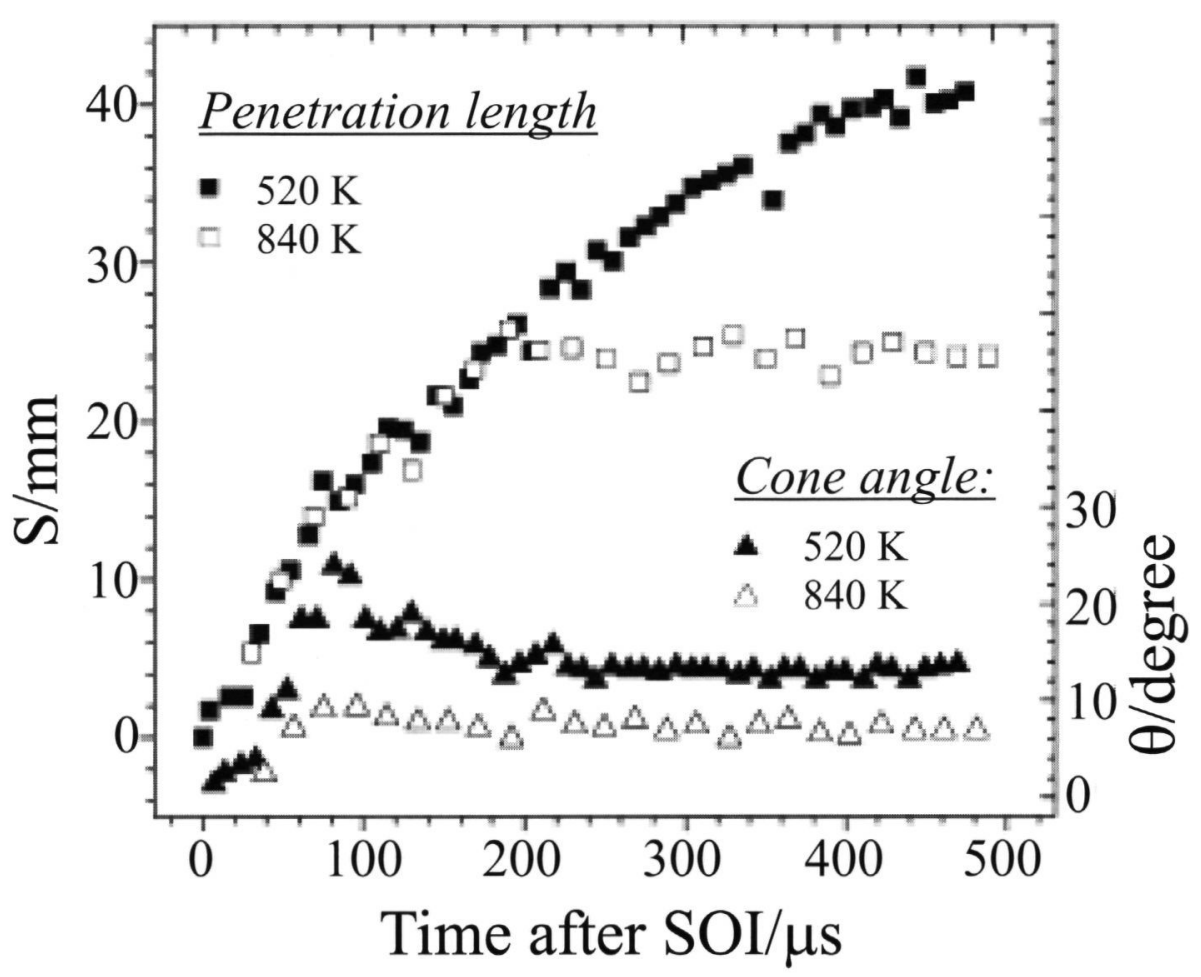

Figure 4.3: Spray penetration length $S(t)$ (squares) and dispersion angle $\theta(t)$ (triangles) as a function of time after Start of Injection, obtained for a chamber pressure of $6 \mathrm{MPa}$ and temperatures of $520 \mathrm{~K}$ and $840 \mathrm{~K}$, respectively. $P_{f}=100 \mathrm{MPa}$

different fuel types and a variety of environmental conditions and nozzle shapes. In general, propagation of a non-vaporizing fuel spray in a dense gaseous environment can be subdivided into four regimes [22]: (a) the 'opening transient', which is governed by the needle tip movement with a corresponding time-dependent effective orifice opening area; (b) the propagation of the liquid core into the surrounding atmosphere; (c) the droplet breakup stage, and (d) propagation of the droplet clouds. Hiroyasu et al. [1] developed a model based on the jet disintegration theory of Levich [23] which proves that experimental data points for penetration length in double logarithmic plots should fall approximately on straight lines in the range of propagation phases (b) and (d). Beyond the transient opening phase this model predicts an initial linear increase with time of the spray penetration length $S_{H}(t \rightarrow 0):$ 


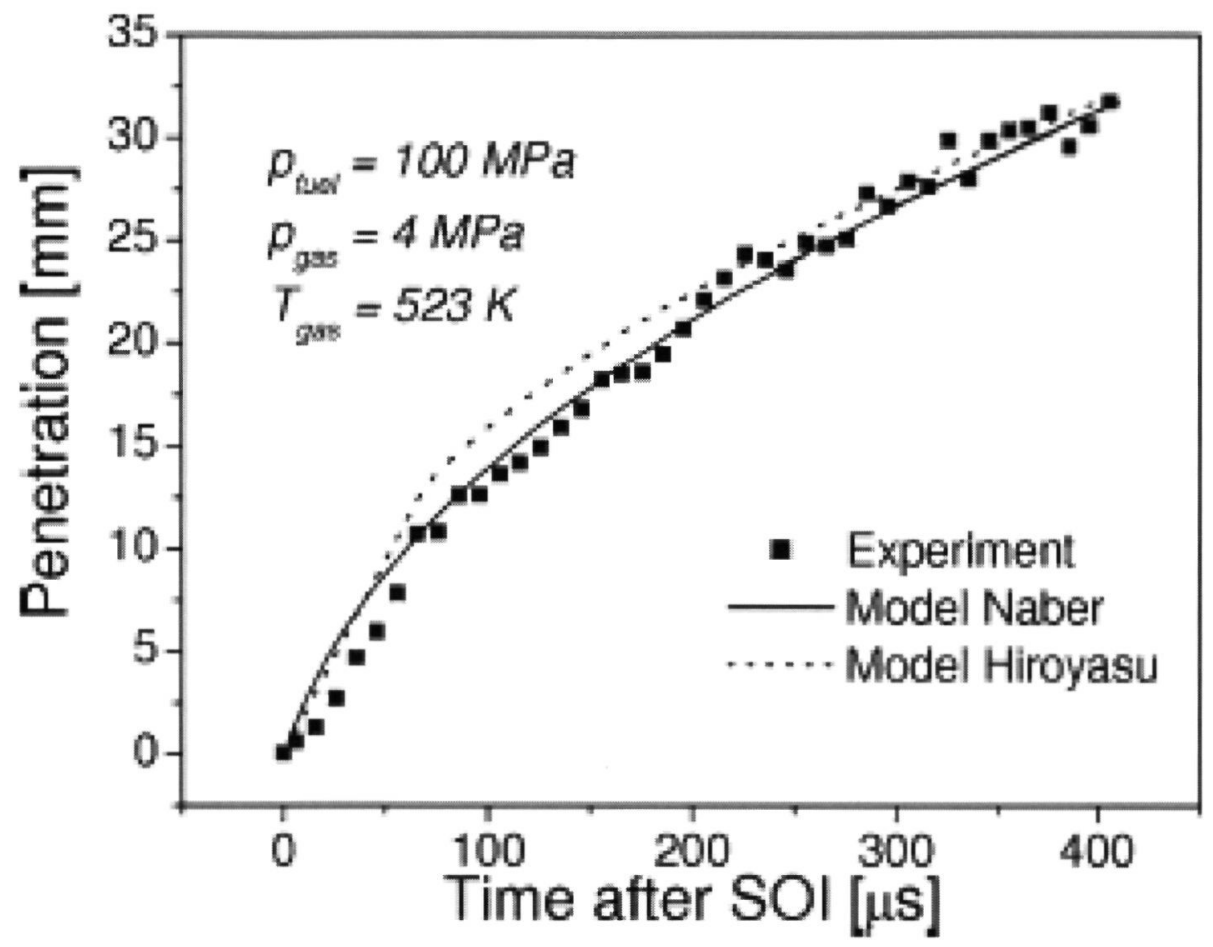

Figure 4.4: Experimental (squares) penetration curve together with model predictions from Hiroyasu [1] (dashed line) and Naber et al. [20] (solid line). $P_{\text {fuel }}=100 \mathrm{MPa}, P_{\text {gas }}=4 \mathrm{MPa}, T_{\text {gas }}=520 \mathrm{~K}$

$$
S_{H}(t \rightarrow 0)=0.39 \sqrt{\frac{P_{f}-P_{a}}{\rho_{f}}} t .
$$

After a 'breakup time' of

$$
t_{b, H}=28.7 \frac{d_{0} \sqrt{\tilde{\rho}}}{\sqrt{\left(P_{f}-P_{a}\right) / \rho_{f}}}
$$

for long times after SOI a square-root time dependence according to

$$
S_{H}(t \rightarrow \infty)=2.95 \sqrt{\sqrt{\frac{P_{f}-P_{a}}{\rho_{a}}} d_{0} t}
$$


is postulated. Here, $d_{0}$ denotes the gcometric nozzle hole diameter, and $\tilde{\rho}=\rho_{f} / \rho_{a}$ is the dimensionless density ratio of fuel and ambient air with pressures $P_{f}$ and $P_{a}$. respectively.

Alternatively, the model of Naber et al. [20] can be applied to a large varicty of fuel types and environmental parameters. In dimensionless form the time $\tilde{t}$ to reach a penetration depth $\tilde{S}$ is given by

$$
\tilde{t}=\frac{\tilde{S}}{2}+\frac{\tilde{S}}{4} \sqrt{1+16 \tilde{S}^{2}}+\frac{1}{16} \ln \left(4 \tilde{S}+\sqrt{1+16 \tilde{S}^{2}}\right)
$$

where $d_{f}=\sqrt{C_{a}} d_{0}$ is the diameter of the liquid fuel jet at the nozzle cxit, and the exit velocity can be calculated with

$$
U_{f}=C_{v} \sqrt{2 \frac{P_{f}-P_{a}}{\rho_{f}}} .
$$

Furthermore, $C_{a}$ is the area contraction coefficient, and $C_{v}$ a vclocity coefficient through which a discharge coefficient $C_{d}=C_{a} C_{v}$ is detined. This considers the fluid flow restriction through the valve orifice opening area during retraction of the needle from its scat. Length and time in Eq. 4.4 are scaled into dimensionless form using $d_{f}, \tilde{\rho}, \theta$ and $U_{f}$ (for a full derivation sec [20]). Naber et al. define their 'breakup time' $t_{b, N}$ as the 'transition time' where $\tilde{t}=1$, which leads to:

$$
t_{b, N}=\frac{\sqrt{C_{a} / 2}}{C_{v} a \tan \theta} \frac{d_{0} \sqrt{\tilde{\rho}}}{\sqrt{\left(P_{f}-P_{a}\right) / \rho_{f}}} .
$$

In Fig. 4.4 the measured $S(t)$ data (symbols) for a particular experiment in the nonvaporizing case $\left(T_{a}=520 \mathrm{~K}, P_{f}=100 \mathrm{MPa}, P_{a}=4 \mathrm{MPa}\right)$ are plotted together with results from both models above. For our conditions an appararent discharge coefficient of 0.4 and a breakup time of $20 \mu$ s wcre derived from the Naber model, whereas the Hiroyasu model predicts a $t_{b . H}$ of $66 \mu \mathrm{s}$, which corresponds to a breakup length of roughly $12 \mathrm{~mm}$. As is outlined in [20] Eqs. 4.2 and 4.6 reveal that the Hiroyasu brcakup times are a factor of 3.7 larger than those calculated in the Naber model. Our data more closely follow the Naber model, although it overestimates penetration lengths at short injection times, probably due to the rather slow opening times realized in our nozzle. Also the opening transient of our nozzle obviously does not allow a clear distinction of the initial spray penetration behavior described above.

Similar to findings in $[1,20]$, for vaporizing conditions at higher gas temperatures $\left(T_{a}>750 \mathrm{~K}\right.$, i.e., above the boiling point of the fucl) we observe the liquid core penetration to cease and dispersion to decrease. i.e.. the spray liquid length stays constant with time and exhibits a smaller cone angle (see Fig. 4.3). In addition. the LES images indicate a vapor cloud around and far beyond the liquid jet (sec Fig. 4.2). 


\subsubsection{Reacting sprays}

Spray penetration, fuel/air mixing and auto ignition.

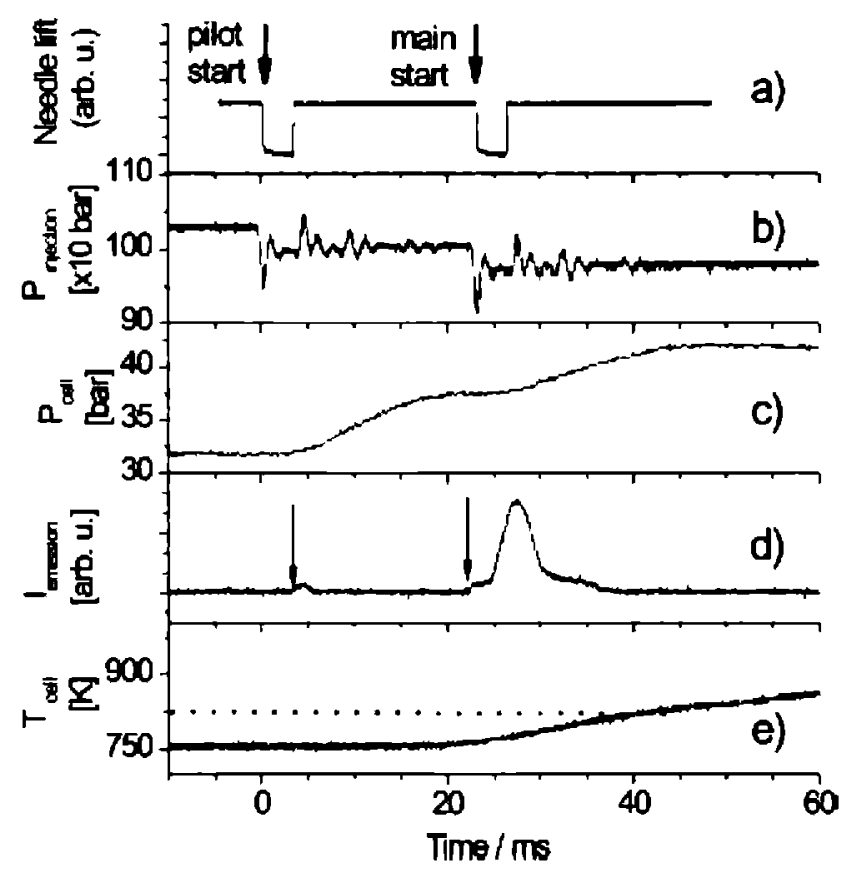

Figure 4.5: Sinnultaneous recording of the needlc lift signal, rail pressure. gas pressure. chemiluminescence and gas temperature (panels a-e, respectively) in the combustion vessel during a single spray injection/combustion cycle. The arrows in panel d mark the start of ignition after pilot and main injection. which approximately takes place at a gas tempcrature of $770 \mathrm{~K}$ (horizontal dotted line in panel e). Injection duration: $3.5 \mathrm{~ms}$ (pilot), $4 \mathrm{~ms}$ (main). $P_{a}=3.2 \mathrm{MPa} . P_{f}=100 \mathrm{MPa}$

Combustion was initiated in the cell through self-ignition of the injected fuel spray in air loads of given temperature and pressure. The end boiling point of the fucl is located at $360^{\circ}$ at atmospheric conditions. Pancls $\mathrm{c}$ and $\mathrm{e}$ in Fig. 4.5 display the respective temporal history of pressure and temperature for an experiment performed during combustion of a pilot and main Diescl injection with initial air pressure and temperature of $3.2 \mathrm{MPa}$ and $850 \mathrm{~K}$. respectively. and an injection pressure of $100 \mathrm{MPa}$. Nozzle opening durations for pilot (3.5 ms) and main (4 ms) injection cvent can approximately be deduced from the simultaneously recorded signals of the needle lift sensor or the pressure sensor in the fuel line (traces a and $b$ in Fig. 4.5. respectively). The thermocouple bead is located $20 \mathrm{~mm}$ next to the nozzle 
tip and protrudes $15 \mathrm{~mm}$ into the gas. Therefore, its reading is not representative for the temperature near the core of the spray, but rather an indication of a global gas temperature before injections and after combustion gases have mixed with the residual gas in the chamber. Trace $d$ shows the chemiluminescence intensity recorded with the photodiode. The arrows above the chemiluminescence trace mark the first detectable emission signals after injections following the respective pressure drop in the fuel line. The auto-ignition delay times for pilot and main injections of $(3.15 \pm 0.10) \mathrm{ms}$ and $(0.36 \pm 0.06) \mathrm{ms}$, respectively, were derived from the time delays between pressure or needle lift indicators and the first appearance of chemiluminescence emission. Placing a UV-transmitting filter in front of the detector qualitatively revealed radiation emitted during the pilot injection phase to be almost entirely due to flame emission. The rather long auto-ignition delay for the pilot injection is due to the low initial gas temperature. The CL trace, although changing in shape and intensity from one cycle to the other, qualitatively exhibits the displayed temporal characteristic of a two-stage intensity during the main injection event. Although no spectral filtering of the detected radiation was performed we attribute the initial small rise of the emission intensity to first flame emission, i.e., radical species; the large peak later in the light emission profile during main injection indicates thermal soot radiation (see below).

Shadow

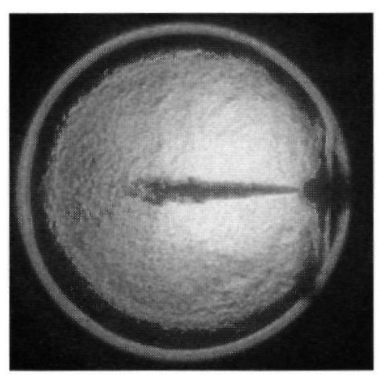

A

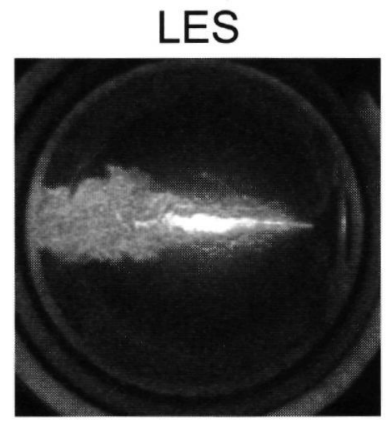

B
Chemiluminescence

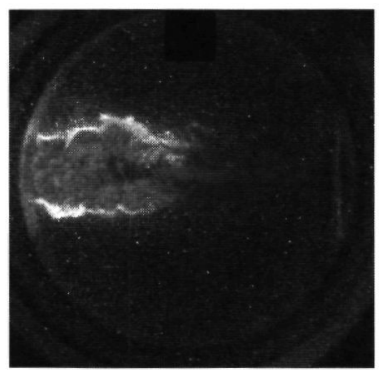

C

Figure 4.6: Shadowgraphy, laser elastic scattering (LES) and chemiluminescence images (from A to $\mathrm{C}$ ) recorded quasi-simultaneously with two cameras. Camera 1 was triggered at the time of the Xe-flashlight peak, and captured the shadowgraph image A during the first gate opening time, while the chemiluminescence signal C was registered during a second exposure $1 \mu$ s after this event. Recording of the LES image B was accomplished with camera 2 triggered at the time of the Nd:YAG laser firing. Reacting spray conditions $0.5 \mathrm{~ms}$ after start of main injection event. Initial conditions: $T_{a}=770 \mathrm{~K}, P_{a}=4 \mathrm{MPa}, P_{f}=103 \mathrm{MPa}$, pilot injection duration: $3 \mathrm{~ms}$, main injection duration: $2 \mathrm{~ms}, 20 \mathrm{~ms}$ after pilot injection 
needle-lift signal, are shown in Fig 46 In these experiments fuel was injected into $4 \mathrm{MPa}$ of dir at $780 \mathrm{~K}$, ddditionally heated to approximately $850 \mathrm{~K}$ by the pilot combustion event Progress of the main fuel injection was systematically studied by applying shadowgraphy The set of SG, LES and CL images depicted in Fig 46 was recorded quasi-simultancously with two cameras Within the first gate opening time camera 1 captured the SG image during the peak of the Xe-fldshlight, while the CL image was recorded $1 \mu$ s later during the second gate openıng ("framing option") Camera 2 was triggered in between these two events to record the $532 \mathrm{~nm}$ filtered LES image induced by the firıng Nd YAG laser Durmng this stage of combustion there was no evidence of soot formation, $1 \mathrm{e}$, the emission features manly originate from radical chemistry [19] A series of similar images taken at different delay times from SOI indicatcd that the full liquid jet length of $\sim 24 \mathrm{~mm}$ was rapidly bult up during the first $\sim 02 \mathrm{~ms}$ and remained fairly constant for the rest of the injection duration (cf Fig 43) At $850 \mathrm{~K}$ the temperature is high enough for a significant fraction of the fuel to have vaporized at the time the image (panel B) was taken, and the LES may be dommated by a vapor cloud at the tip region and surrounding the liquid core upstream, even close to the nozzle exit Combustionrelated CL emission occurs over the downstream portion of the vapor cloud, mainly from within the mixing layer between fuel vapor and surrounding alr Inspection of the LES and the CL images in Fig 46 (pancls B C respectively) suggests that ignition takes place along the rim of the vapor cloud establishing a diffusion or partially premixed flame This carly relatively weak radiation can be ascribed to exothermic chemical reactions [24] (note the images were taken before the onset of soot radiation displayed in Fig 45 , trace d, as the large CL peak after main fuel injection) Although caution is appropriate in interpreting expcrimental results, spectrally selected chemiluminescence emissions from intcrmediate species give some indication for the spatial location of intial heat release due to combustion $[25,26]$ After the start of intense soot incandescence the order of magnitude larger radiation intensity will hamper this interpretation

\section{Premixed combustion and soot formation regions}

Following the conceptual model of Dec for spray combustion in a DI Diesel engine [2] the initial soot formation region is situated nedr the tip of the fuel-rich premixed reaction zone of the vaporized liquid spray corc In our experiments such a zone is identıfied approximatcly around $07 \mathrm{~ms}$ after SOI, when SG, LES and CL images indicate changes in the spray combustion event the shadowgraphs reveal the appearance of opaque regions withm the luminous combustion zone Simultaneously spatial regions exhibiting strong light scattering and thermal soot radiation in the respective LES and CL images provide evidence of soot formation Soot particle concentration and size continuc to increase with combustion progress and are accumulating in the leading portion of the jet boundaries $[2,27]$ This combustion stage is accompanied by a sharp increase of the CL signal intensity iecorded by the photodiode (trace d in Fig 4 5) 
Images recorded still later in the combustion cycle ( $1 \mathrm{~ms}$ after SOI) are shown in Fig 47 Shadow and chemlummescence images (panels A, B in Fig 4 7, respectively) were rccorded with camera 1 (with gate opcning times separatcd by $1 \mu \mathrm{s}$ ) while the LES image (C) was captured with camerd 2 through the $532 \mathrm{~nm}$ interference filter The LII minge (D) was recorded from a separate injection event at the same delay after SOI Because the LII mage required filter exchange in front of the camera lens, in the current setup a quasi-simultaneous recording with the other images was not possible The shadowgraph image indicates a dense, ndarrow liquid spray core and a spatially more spread-out cloud downstream where soot is formed This is also evident from the chemilummescence mage, which essentially is dommated by thermal soot radiation The LES image $(C)$ agdin shows a close correspondence with the SG image in the soot-loaded as well as the liquid core region of the spray Finally, the LII-Image (D) also demonstrates the existence of an extensive soot formation region downstream of the spray tip (We attribute the visible faint "pencil-like" structurc extending from the noz 2 le tip to (laser-induced) soot radiation scattered off fuel droplets in the spray) It is important to note that the SGand CL-images represent line-of-sight views from within the focused object space determined by the aperture and transfer function of the camerd objectıve, whereds images $\mathrm{C}$ and D are two-dimensional cross sections of the spray/soot cloud spatially integrated only over the laser shcet thickness (approx $08 \mathrm{~mm}$ ) Nevertheless, all three images taken simultaneously exhibit quite similar spatial features, and they clearly identify soot formation regions in the combusting vapor cloud downstream of the dense spray region

\subsection{Conclusions and outlook}

A constant volume combustion bomb was constructed, that is suitable for detalled optical diagnostics of Diesel fuel spray injection, propagation and ignition in highdensity gaseous environments $\left(T<850 \mathrm{~K}, P_{a}<8 \mathrm{MPa}\right)$ Inert gds or aur is introduced into the cell through a cam-shaft actuated inlet valve prior to Diesel fucl injection Pre-combustion of a plloted fuel injection allowed a short-term temperature increase of the pressurized and preheated gas load prior to the mam injection event As a novelty, quasi-simultaneous imaging of spray propagation and combustion was performed using two ICCD-cameras with double framing options Two-dımensional flash-light shadowgraphy, laser elastıc scatterming and chemilumınescence were applied to investigate various phases of fuel propagation and combustion after start of injection In addition soot formation was investigated with laser-induced incandescence

From the results presented in this paper the following conclusions can be drawn

- The combination of shadowgraphy and laser eldstic scattering shows that before spray breakup the shape of the dense liquid phase region of the spray is similar in the non-reacting as woll as the reacting environment 

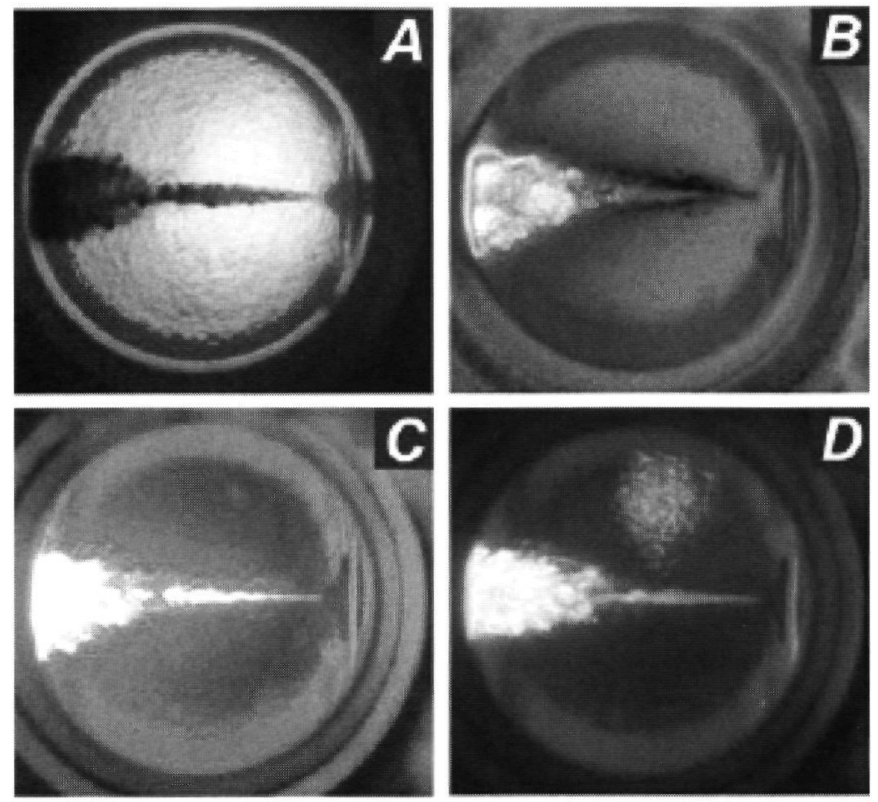

Figure 4.7: Shadowgraph A, chemiluminescence B, laser elastic scattering C, and LII D images obtained at $1 \mathrm{~ms}$ after SOI. Same conditions as in Fig. 4.6. Images A and $\mathrm{B}$ were recorded with camera 1 (with intensifier gates separated by $1 \mu \mathrm{s}$ ), while image $\mathrm{C}$ was taken with camera 2 through a $532 \mathrm{~nm}$ interference filter. Image D was captured with camera 2 (equipped with the $650 \mathrm{~nm}$ interference filter) on a separate injection event at otherwise identical conditions

- At $4 \mathrm{MPa}$ and temperatures below $550 \mathrm{~K}$ the combination of shadowgraphy and laser elastic scattering indicate that liquid fuel droplets still exist up to a penetration length of at least $40 \mathrm{~mm}$ (length/diameter ratio $=67$, limited by the field of view). Penetration lengths and angle dispersion match with scaling predictions from the literature.

- In the combusting spray the combination of laser elastic scattering, shadowgraphy, chemiluminescence emission and LII indicate initial soot formation near the tip of the spray cloud.

In conclusion, our spray combustion cell allows the study of multiphase flows and combustion of sprays within parameter ranges relevant in Diesel engines. 


\section{Acknowledgments}

The financial support of the Swiss Federal Office of Encrgy and the Technology Foundation STW in the Netherlands, as well as the technical expertise of P. Obrecht (ETH Zentrum. Zürich) during installation and initial opcration of the test cell facility are gratefully acknowledged. 


\section{Bibliography}

[1] H. Hiroyasu and M. Arai (1990): Structures of fuel sprays in Diesel cngines. SAE Tech. Pap. Series 900475.

[2] J.E. Dec (1997): A Conceptual Model of DI Diesel Combustion Based on Laser-Sheet Imaging. SAE Tech. Pap. Series 970873.

[3] P.F. Flynn, R.P. Durrett. G.L. Hunter, A.O. zur Loye, O.C. Akinyemi, J.E. Dec and C.K. Westbrook (1999): Diesel Combustion: An integrated vicw combining laser diagnostics, chemical kinetics, and empirical validation. SAE Tech. Pap. Series 1999-01-0509.

[4] J.E. Dec and E.B. Coy (1996): OH radical imaging in a DI dicsel cngine and the structure of the carly diffusion flame. SAE Tech. Pap. Series 960831.

[5] F. Hildenbrand and C. Schulz (2001): Mcasurements and simulation of incylinder UV-absorption in spark ignition and Diesel engines. Appl. Phys. B $73(2), 165-172$.

[6] H. Kubach, J. Gindele and U. Spicher (2001): Investigation of mixture formation and combustion in gasoline direct injection engines. SAE Tech. Pap. Series 2001-01-3647.

[7] G.S. Settles (1964): Schlicren and Shadowgraph Techniques. Springer.

[8] A.C. Eckbreth (1996): Laser Diagnostics for Combustion, Temperature and Species. Taylor \& Francis Inc., London.

[9] C. Espey, J.E. Dcc. T.A. Litzinger and D.A. Santavicca (1997): Planar laser Rayleigh scattering for quantitative vapor-fucl imaging in a Diesel jet. Combust. Flame 109 (1-2), 65-86.

[10] Ö. Andersson, R. Collin, M. Aldén and R. Egnell (2000): Quantitative imaging of equivalence ratios in DME sprays using a chemically preheated Combustion Vessel. SAE Tcch. Pap. Series 2000-01-2785. 
[11] H. Zhao and N. Ladommatos (1998): Optical diagnostics for soot and temperature measurement in Dicscl engines. Prog. in En. Combust. Sci. 24 (3), 221-255.

[12] P.O. Witze, S. Hochgreb, D. Kayes, H.A. Michclsen and C.R. Shaddix (2001): Time-resolved laser-induced incandescence and laser elastic-scattering measurements in a propane diffusion flame. Appl. Opt. 40 (15), 2443-2452.

[13] K. Kohse-Höinghaus and J. Jeffreys (eds.) (2002): Applied Combustion Diagnostics, Taylor \& Francis Inc., Cambridge, United Kingdom.

[14] D.R. Snclling, G.J. Smallwood, R.A. Sawchuk, W.S. Neill, D. Gareau, D. Clavel. W.L. Chippior. F. Liu. Ö.L. Gülder and W.D. Bachalo (1999): Particulate matter measurements in a diesel engine exhaust by laser-induced incandescence and the standard gravimetric procedure. SAE Tech. Pap. Serics 1999-01-3653.

[15] L.A. Melton (1984): Soot diagnostics based on laser heating. Appl. Opt. 23 (13), 2201-2208.

[16] B.F. Kock and P. Roth (2003): Two-color TR-LII applied to in-cylinder Diesel particle sizing. In: Proc. Europcan Combustion Meeting 2003, paper 093.

[17] P. Roth and A.V. Filippov (1996): In situ ultrafine particle sizing by a combination of pulsed laser heatup and particle thermal emission. J. Aerosol Sci. 27 (1), 99-104.

[18] T. Lehre, B. Jungflcisch, R. Suntz H. Bockhorn (2003): Sizc distributions of nanoscaled particles and gas temperatures from time-resolved laser-induced incandescence measurements. Appl. Opt. 42 (12), 2021-2030.

[19] A.G. Gaydon and H.G. Wolfhard (1979): Flames, Chapman \& Hall. London.

[20] J.D. Naber and D.L. Sicbers (1996): Effects of gas density and vaporization on penetration and dispersion of Diescl sprays. SAE Tech. Pap. Series 960034.

[21] A.I. Vogel (1946): Physical properties and chemical constitution of aliphatic hydrocarbons. J. Chem. Soc. Feb. 133-139.

[22] A.H. Lcfcbvre (1989): Atomization and Sprays. Hemisphere Publishing Comp. New York.

[23] V.G. Levich (1962): Physicochcmical Hydrodynamics, Prentice Hall Inc.

[24] Y. Ohta and M. Furutani (1991): Identification of cool and bluc flames in compression ignition. Archivum Combustionis 11 (1-2). 43-52. 
[25] H.N. Najm. P.H. Paul. C.J. Mueller and P.S. Wyckhoff (1996): On the adequacy of ccrtain experimental obscrvables as measurements of flame burning rate. Combust. Flame 113 (3). 312-332.

[26] Y. Hardalupas and M. Orain (2004): Local measurements of the timcdependent heat release rate and equivalence ratio using chemiluminescent emission from a flame. Combust. and Flame 139 (3), 188-207.

[27] C. Crua. D.A. Kennaird M.R. Heikal (2003): Lascr-induced incandescence study of diescl soot formation in a rapid compression machine at clcvated pressures. Combust Flame 135 (4). 475-488. 


\section{Chapter 5}

\section{Laser-induced incandescence particle size measurements in a heavy-duty Diesel engine*}

\section{$5.1 \quad$ Introduction}

Laser-induced incandescence (LII) is a relatively new experimental method for studying the soot formation process in flames [1 11$]$. LII is based on the quasiinstantaneous heating of soot particles. by means of a high-cnergy pulsed laser bcam. to alnost their vaporization temperature. resulting in a strong but transient increase in their incandescence After the laser pulse the particles cool down. at a rate which is dependent on their surface-to-volume ratio. The decay rate of the laser-induced incandescence intensity thus contains information on the particle sizc distribution within the irradiated volume. In this commumcation we report on the characterization of soot by tme-resolved LII (TR-LII) measurements in a heavyduty Diesel engine, with peak pressures up to $6 \mathrm{MPa}$. paying particulas attention to the correction required for the finite time resolution of the hardware. and to the role of the initial particle temperature.

\subsection{Measurement and data analysis}

Experiments wore performed in an optically accossible cylinder of a heavy-duty sixcylinder diesel enginc (DAF 95XF) running on commercial low-sulfur diescl fuel at about $25 \%$ load (boost pressure 0.4 bar. inlet ais temperature $313 \mathrm{~K} .62 \mathrm{mg}$

* Adapted from B l3ougie L C Ganippa. A P van Vliet, W L Meerts $N$ J Dam and J J ter Meulen. Combust Flame 145 (3) $6.35 \quad 6.37$ (2006) 
injected fuel). Incandescence was induced by $9 \mathrm{~mJ}\left(\mathrm{ca} .0 .05 \mathrm{~J} / \mathrm{cm}^{2}\right)$ of the fundamental wavelength of a pulsed Nd:YAG laser (10 ns pulse width) and detected through a Schott BG 1 filter by a fast photomultiplicr tube (PMT EMI 9814B). rcsulting in an effective transmission band of $375 \pm 100 \mathrm{~nm}$. The PMT was connected to a digital oscilloscope (LeCroy $9361 ; 2.5 \mathrm{Gs} / \mathrm{s}$. analog bandwidth $300 \mathrm{MHz}$ ). The combination of laser and detection system shows a half-width of ca. $16 \mathrm{~ns}$. To check the absence of interference with Swan-band emission the prompt signal was simultaneously recorded on an ICCD camera connected to a spectrograph. In order to increase the signal strength, only rudimentary spatial filtering was applied. resulting in a cylindrical probe volume of about $10 \mathrm{~mm}$ height and $5 \mathrm{~mm}$ diameter, located in the upper part of the combustion chamber, between two fucl sprays. A more detailed description of the sctup is given in [12].

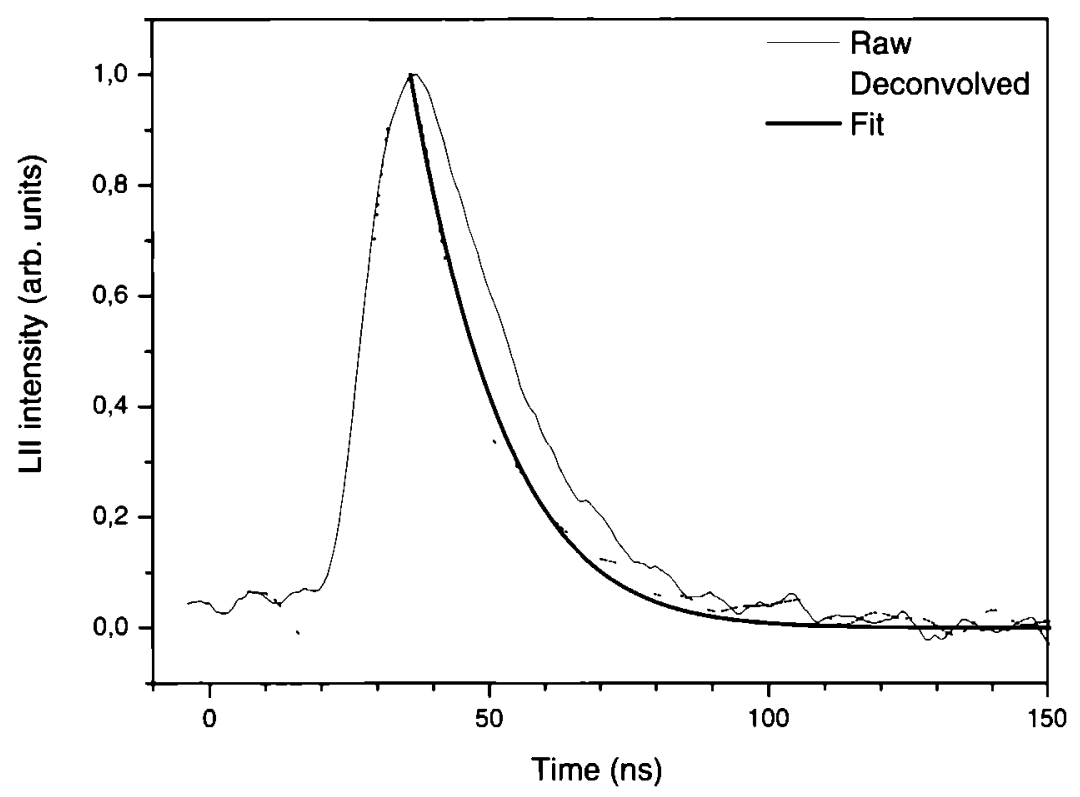

Figure 5.1: Example of a measured LII curve with the corresponding deconvolved LII curve. The curve was measured at $18^{\circ}$ aTDC. A fit to the deconvolved LII trace is included

The model of Kock et al. [7. 9] was used to analyze the measured LII traces. For the time being. we interpret the LII data in terms of primary particle size. assuming a mono-disperse size distribution. For an individual soot particle. the energy balance 
can be described by

$$
\frac{d}{d t}\left(m_{p} C_{p} T_{p}\right)=\dot{Q}_{a b s}-\dot{Q}_{c o n}-\dot{Q}_{s u b}-\dot{Q}_{r a d} .
$$

The term at the left-hand side describes the change in internal encrgy of the particle (mass $m_{p}$. specific heat $C_{p}$ ) at a temperature $T_{p}$. The terms on the right-hand side are the rate at which laser energy is absorbed by the particle and the rates of heat loss by conduction, sublimation, and radiation, respectively. Details on the individual terms can be found in [7,9]. The model does not include all conceivable contributions to the encrgy balance [10]. but is able to provide acceptable fits to the recorded LII traces. In the Raylcigh limit the soot particles are all heated to the same initial tempcrature by the laser pulse, irrespective of their sizc [3]. The measured timc-dependent incandescence intensity is proportional to $\dot{Q}_{\text {rad }}$. An important feature of the model concerns the use of a Knudsen-number bascd interpolation function (see [13]) for the heat loss rates. This makes it possible to take crank-angle dependent combustion chamber conditions into account, which vary between the frec molecular regime and the continuum regime during a stroke.

\subsection{Results and discussion}

Fig. 5.1 shows a typical LII trace, recorded at $18^{\circ}$ aTDC. The characteristic decay time is about 30 ns. which is of the same order of magnitude as the response time of the detection system (16 ns). Therefore, before the time dependence is analyzed. the traces are deconvolved with the detector response time (measured by recording scattered light from frequency-doubled Nd:YAG laser pulses). For deconvolution a Wicner filter was used, with the regularization parameter chosen to conserve the noise power present before arrival of the laser pulse [14]. This choice avoids artificially increasing the decay time of the deconvolved traces. The deconvolved LII trace is included in Fig. 5.1.

We least-squares-fitted the deconvolved LII traces to the model predictions for a monodisperse size distribution. using the particle tempcrature immediately after the laser pulse and the particle size as the only free parameters. The ambient temperature was derived from the measured pressure curve in combination with the adiabatic gas law (it is not a critical parameter. as we will show below). The fit results showed evidence of many local minima. Therefore. we calculated the full $\chi^{2}=(\text { modeled trace }- \text { measured trace })^{2}$ error landscape for cach curve. An cxample is shown in Fig. 5.2. for a measurement at $18^{\circ}$ aTDC. It shows that the fit is very insensitive to the initial particle temperature. but that the particle size can be determined within reasonable uncertainty margins. For the illustrated case a particle radius of about $28 \mathrm{~nm}$ was obtained. The uncertainty in this value is estimated as about $\pm 30 \%$. detcrmined mainly by the uncertainties in soot properties [15] and the restriction to a monodisperse size distribution.

Figure 5.3 shows the particle size as a function of the crank angle. During the complete combustion cycle the primary particle radius is found to vary only slightly, 


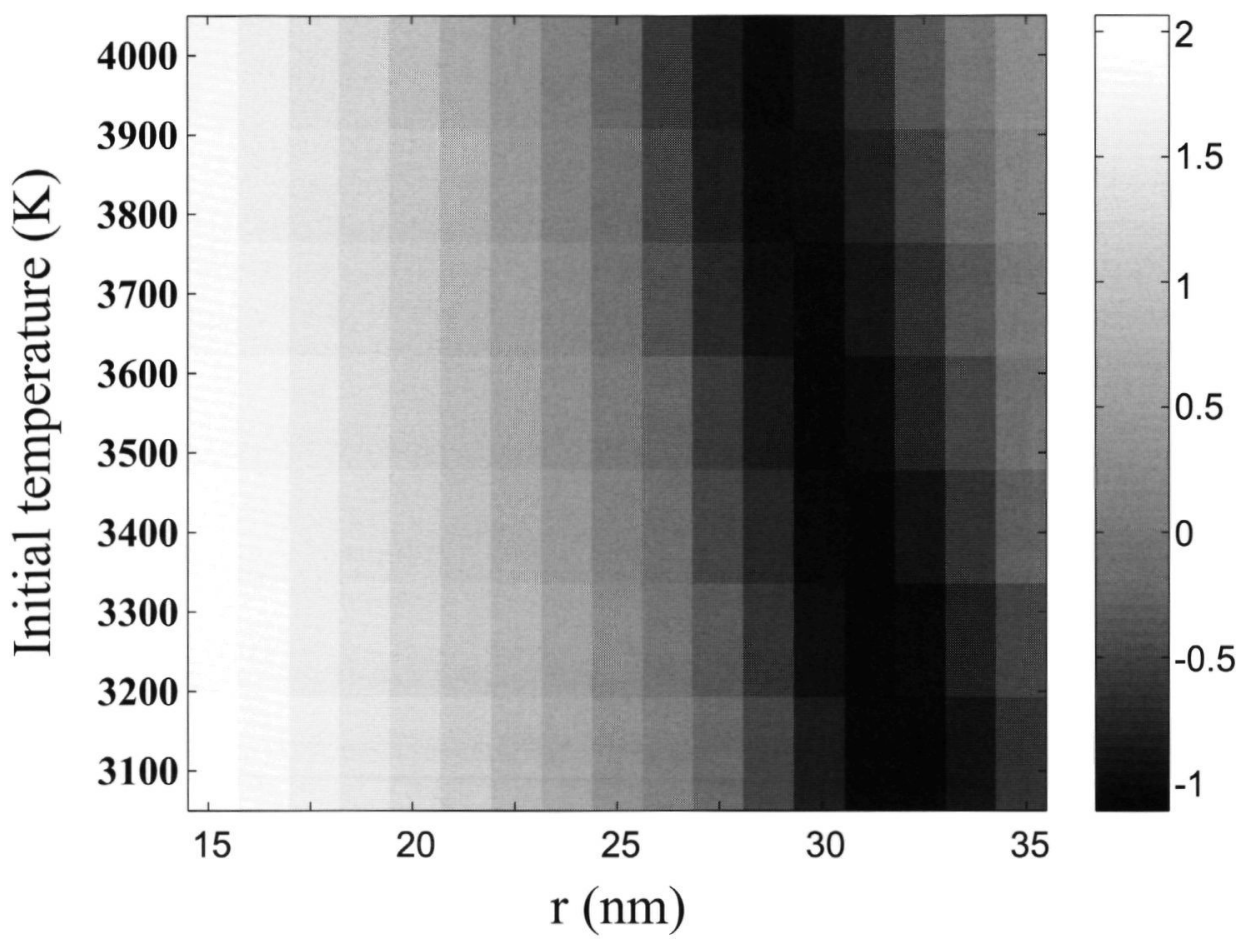

Figure 5.2: Chi-squared landscape. The gray scale gives $\log \chi^{2}$ as a function of the two fit parameters (radius and initial temperature) for a LII trace measured at $18^{\circ}$ aTDC, under the assumption of a monodisperse size distribution.

between 15 and $25 \mathrm{~nm}$, as indicated by the trend line in the figure. The relatively small variation of primary particle size is surprising, but possibly related to the fact that the LII intensity is dominated by the contribution of larger particles. Similar particle sizes are reported in the literature $[7,16]$. The influence of the deconvolution process on the retrieved particle size is clearly visible. At $18^{\circ}$ aTDC a datapoint is included for an assumed bath temperature of $1500 \mathrm{~K}$; it does not deviate significantly from the data point corresponding to the average gas temperature (1037 K). Future work is directed to the simultaneous detection of LII signal by two PMTs through different filters, in order to simultaneously estimate the instantaneous temperature by two-color pyrometry, to the inclusion of a finite size distribution in the fit procedure, and to a systematic study of the in-cylinder primary particle size as a function of engine operating conditions.

The main conclusions of this brief communication are (i) that the finite time res- 


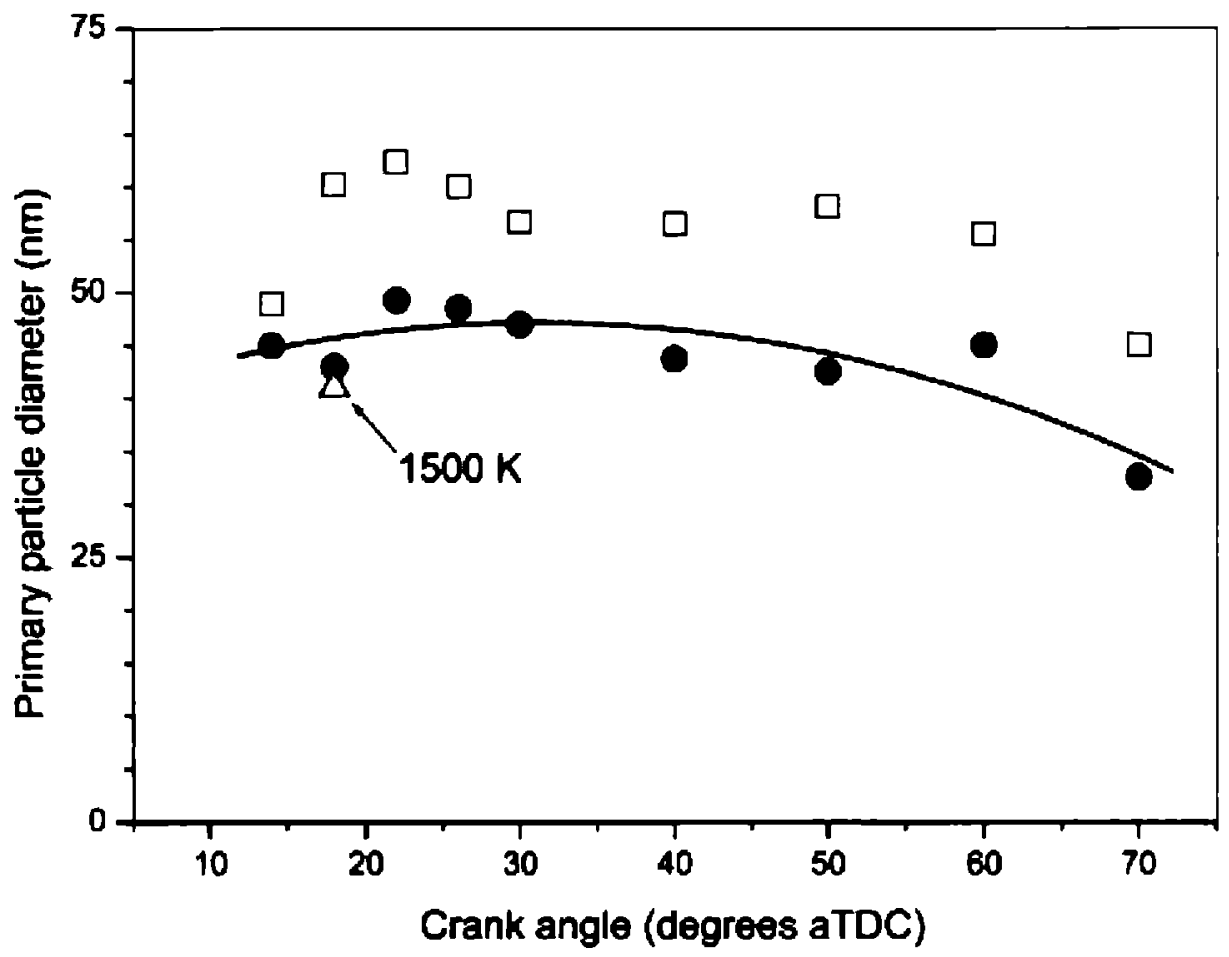

Figure 5.3: Particle size as a function of crank angle, detcrmined from the raw measurements $(\square)$ and from the deconvolved LII traces $(\bullet)$. A trend line for particle size as a function of crank angle is included. Uncertainties estimated as $\pm 30 \%$. For the $18^{\circ}$ aTDC measurement, the influence of the ambient temperature is illustrated by an additional datapoint $(\triangle)$ for $1500 \mathrm{~K}$ assumed bath temperature (average gas temperature is $1037 \mathrm{~K}$ ).

olution of the hardware (laser + detection) should be taken into account in the interpretation of in-cylinder LII data, (ii) that data fitting is prone to end up in local minima. and (iii) that ambient and initial particle temperature are relatively uncritical parametcrs.

\section{Acknowledgments}

This work has been made possible by financial support from the Technology Foundation of the Netherlands. We gratefully acknowledge P. Roth and B. Kock from the University of Duisburg for their support in the LII modeling. 


\section{Bibliography}

[1] L.A. Melton (1984): Soot diagnostics based on laser heating. Appl. Opt. 23 (13). 2201-2208.

[2] S. Will. S. Schraml and A. Leipertz (1995): Two-dimensional soot-particle sizing by time-resolved lascr-induced incandescencc. Opt. Lett. 20 (22). 23422344.

[3] P. Roth and A.V. Filippov (1996): In situ ultrafine particle sizing by a combination of pulsed laser heatup and particle thermal cmission. J. Acrosol Sci. 27 (1), 99-104.

[4] H. Geitlinger, T. Streibel, R. Suntz and H. Bockhorn (1998): Two-dimensional imaging of soot volume fractions. particle number densitics and particle radii in laminar and turbulent diffusion flames. In: Proc. Combust. Inst. 27. 1613-1621.

[5] D.R. Snelling, G.J. Smallwood. R.A. Sawchuk. W.S. Neill. D. Gareau. W.L. Chippior. F. Liu, Ö.L. Gülder and W.D. Bachalo (1999): Particulate matter measurcments in a Diesel cngine exhaust by laser-induced incandescence and the standard gravimetric procedure. SAE Tech. Pap. Scries 1999-01-3653.

[6] S. Schraml.S. Will and A. Lcipcrtz (1999): Simultaneous measurement of soot mass concentration and primary particle size in the exhaust of a DI Diesel engine by time-resolved lascr-induced incandescence (TIRE-LII). SAE Tech. Pap. Series 1999-01-0146.

[7] B.F. Kock. Th. Eckhardt and P. Roth (2002): In-cylinder sizing of Diescl particles by timc-rcsolved laser-induced incandescence (TR-LII). In: Proc. Combust. Inst. 29, 2775-2781.

[8] M. Hofmann, W.G. Bessler, C. Schulz and H. Jander (2003): Laser-induced incandescence (LII) for soot diagnostics at high pressures. Appl. Opt. 42 (12). 2052-2062.

[9] B.F. Kock and P. Roth (2003): Two-color TR-LII applied to in-cylinder Diescl particle sizing. In: Proc. European Combustion Meeting 2003. paper 093. 
[10] H.A. Michelsen (2003): Understanding and predicting the temporal response of laser-induced incandescence from carbonaceous particles. J. Chem. Phys. 118 (15), 7012-7045.

[11] H.A. Michelsen. P.O. Witze, D. Kayes and S. Hochgreb (2003): Time-resolved laser-induced incandescence of soot: the influence of cxperimental factors and microphysical experiments. Appl. Opt. 42 (27), 5577-5590.

[12] B. Bougie, L.C. Ganippa, A.P. van Vliet, N. Darn. W.L. Meerts, and J.J. ter Mculen (2005): Soot characterization with laser-induced incandescence in a heavy-duty Diesel enginc. In: Proc. Europcan Combustion Meeting, pap. 166.

[13] M.M.R. Williams and S.K. Loyalka (1991): Aerosol Science Theory and Practice, With Special Applications to the Nuclcar Industry, Pergamon Press.

[14] M. Kunt (1986): Digital Signal Processing. Norwood, MA: Artech House, Lausanne. Switzerland.

[15] G.J. Smallwood. D.R. Snelling. F. Liu and Ö.L. Gülder (2001): Clouds over soot evaporation: Errors in modeling laser-induced incandescence of soot. J. Heat Transf. 123 (4), 814-818.

[16] K. Park, D.B. Kittelson and M.C. McMurray (2004): Structural properties of Diesel exhaust particles measured by transmission electron microscopy (TEM): Rclationships to particle mass and mobility. Aer. Sci. and Techn. $38(9), 881$ 889. 


\section{Chapter 6}

\section{On particulate}

\section{characterization in a}

\section{heavy-duty Diesel engine by time-resolved laser-induced incandescence*}

Tinne-resolved laser-induccd incandescence (TR-LII) measurements have been performod inside the combustion chamber of a heavy-duty diesel engine rumning at low load and regular dicscl fuel. The traces werc interpreted in terms of a primary particle size distribution using an existing model for the time dependence of the incandescence intensity. A comparison is made between two different assimed particle size distributions: a mono-disperse and a log-normal distribution. The initial temperature of the particles (immediatcly after the laser pulse) is estimated with two-color pyrometry. We conclude that the initial temperature of the particles is not very critical for the outcome of the fitting procedure for the radius. Even under the high-pressure conditions in the engine. the time dependence of the LII intensity contains sufficient structure to allow retrieval of details of the particle size distribution.

* Adapted from: B. Bougie, L.C. Ganippa, N.J. Dam and J.J. ter Meulen. Appl. I'lyys. B 83 (3), $477-485(2006)$. 


\subsection{Introduction}

Exhaust gases emitted from internal combustion engines cause problems for the human health and contribute to the global warming effect. For Dicsel engines it concerns NO and particulates. like soot. The particulate formation processes are not completely understood. although much effort has been devoted to study the particulate formation and the chemical reaction mechanisms which contribute to the formation of soot (e.g. [1.2]).

It is generally agreed that in Diesel engines soot formation occurs on the fucl-rich side of the reaction zone. where the oxygen concentration is low and the temperature is sufficiently high to initiate soot nucleation rcactions [3, 4]. The soot is formed as primary particles, which form aggregates later on. Optical diagnostics offers great potential to get information. on the time-dependent soot characteristics. Several possible measurement techniques that can be used to mcasure the particulate matter emission from a Diesel engine have been reviewed by Witze [5] and Zhao and Ladommatos [6]. Micro-orifice uniform deposit impactors (MOUDI) and scanning mobility particle sizers (SMPS) have proved to be uscful techniques for nano-particle sizing. The drawback of these techniques is that they only can be applied cx-situ. A technique which can be used for in-situ particle-sizing is laser-induced incandescence (LII).

Theorctically and experimentally the LII method was first demonstrated by Melton [7]. Since then. LII is being used as a powerful tool for obtaining the soot volume fraction in atmospheric pressure flames [8-10]. The basic principle of LII is to heat soot using a high-cnergy laser pulse to almost its evaporation temperature. The heatcd soot particles emit radiation according to Plancks radiation law. In the Rayleigh limit. the intensity of the emitted radiation is almost proportional to the soot volume fraction [7].

The first application of LII to measure the in-cylinder soot volume fraction in an optically accessible heavy duty Diesel engine was performed by Dec and coworkers [11 13]. In the process of understanding the soot formation and combustion processes in Diesel engines Raylcigh scattering measurements wore performed as well to investigate the soot evolution and its distribution in Diesel sprays [11. 14-16]. It was reported that the soot emission decreases with an incrcase in the injection pressure due to a higher air entrainment ratc. Since scattering in the Rayleigh limit is proportional to the $6^{\text {th }}$ power of the particle diameter and LII to the $3^{\text {rd }}$ power of the particle diameter. combined Rayleigh scattering and LII was investigated [17.18] to study the soot concentration. volume equivalent diameter of soot aggregates and number density. It was reported by Kosaka [17] that as the soot particles grow. their number density decreases. The potential of measuring soot aggregate sizes using combined Rayleigh and LII was also investigated in laminar and turbulent flames [19. 20].

More recently it has been identified that particles of different size exhibit different cooling behavior. Particles with a bigger surface-to-volume ratio cool faster. Timeresolved laser-induced incandescence (TR-LII) was used to measure primary soot 
particle sizes in atmospheric flames by Will [21] and Roth [22] and later on by several others [23-25]. Application of TR-LII to measure the soot particle sizes in the exhaust of Diesel engines has also been investigated by various groups [26. 27]. TRLII is generally taken to measure the primary particle size. although recently some discussion about the influence of the aggregate shape on TR-LII was initiated [28]. The complexity of measuring TR-LII in a Diesel engine is partly caused by the large cooling rate under high pressure conditions [29]. The higher the pressure the shorter the decay-time of the LII intensity. In the present paper we describe TRLII measurements in a heavy-duty Diesel engine. The model described by Kock and Roth et al. $[30,31]$ was used in this work to derive the particle size from the mcasured signal.

Special attention is paid to the way of analysis of the data. At the high pressures in the engine the response time of the systcm turned out to be important in the analysis. A comparison has been made between two particle size distributions (PSD): a log-normal distribution [32] and a mono-disperse PSD. The latter one has also been used to get insight in the significance of the initial temperature in retrieving the radius of the particles.

\subsection{Theory}

The TR-LII technique is bascd on the principle of energy and mass transfer between the laser-heated soot particles and the surrounding environment. as described in [7]. The size of the particles is derived from the temporal behavior of the LII signal. The basic idca bchind the evaluation of the LII signal is the same as discussed by [7. 2125$]$.

The model we use is the one proposed by Kock et al. [30. 31]. because to our knowledge it is the only model taking into account the influcnce of the high ambient pressure in both the heat transfer by conduction and the mass transfer by sublimation. The model is based on the energy balance

$$
\frac{d\left(m_{p} c_{p} T_{p}\right)}{d t}=\dot{q}_{a b s}-\dot{q}_{c o n d}-\dot{q}_{s u b l}-\dot{q}_{7 a d}
$$

in which the term at the left hand side is the change in enthalpy of the particles. where $m_{p}$ is the mass of the particle. and $c_{p}$ the specific heat of soot. which is a function of the particle temperature $T_{p}$. In principle. all quantities depend on time. The terms on the right hand side are the laser energy absorbed by the particles and the heat losses by conduction. sublimation and radiation, successively. Equation 6.1 does not include energy changes by oxidation. melting or annealing of the particles and non-thermal photodesorption of carbon clusters from the particle surface as proposed by Michelsen [33].

The soot particles which are hit by the laser beam absorb encrgy of the laser. causing an increase of their temperature up to a maximum value which is called the "initial temperature". For particles which are in the Rayleigh limit $\left(r_{p} / \lambda_{e x}<<1\right.$. 
in which $r_{p}$ is the particle radius and $\lambda_{e x}$ is the excitation wavelength) the initial temperature of the particles is independent of the particle size [22], but it does, of course, depend on the laser intensity.

The cooling rate of the particles, after the laser pulse, is dependent on the surfaceto-volume ratio of the particles (size) and is determined by the various cooling processes, mentioned before. The heat flux due to conduction $\left(\dot{q}_{c o n d}\right)$ dominates the cooling behavior in a high-pressure environment [31,34]. The heat flux due to radiation $\left(\dot{\mathrm{q}}_{\mathrm{rad}}\right)$ is negligible in comparison to the other modes of energy transfer [21]. The measured emission spectrum of the heated particles is a measure of their temperature, according to Planck's radiation law,

$$
P_{\text {rad }}\left(\lambda_{d e t}\right)=\lambda_{\text {det }}^{-5}\left(\exp \left\{\frac{h c}{\lambda_{d e t} k_{B} T_{p}}\right\}-1\right)^{-1} \varepsilon\left(\lambda_{d e t}\right) .
$$

in which $\lambda_{d e t}$ is the detection wavelength. $c$ the speed of light. $k_{B}$ Boltzmann's constant and $h$ Plancks constant. The emissivity coefficient $\varepsilon\left(\lambda_{\text {det }}\right)$ accounts for gray-body effects. In our implementation of this model. it is assumed that the surrounding environment is at the global gas temperature, which is obtained from thermodynamic cvaluation of the cylinder pressure.

The heat flux due to sublimation is dependent on the mass flux. It can be described by $[35]$

$$
\frac{d r_{p}}{d t}=\frac{1}{4 \pi r_{p}^{2}} \frac{\dot{q}_{s u b}}{\Delta h_{v a p}} .
$$

in which $\Delta h_{v a p}$ is the specific vaporisation heat for carbon. Solving Eq. 6.1 and Eq. 6.3 simultaneously as an initial value problem the soot particle temperature and size as a function of time arc acquired during the decay of the LII signal. With increasing pressure the mean free path $\lambda_{\text {mip }}$ decreases. and consequently the interaction between the particle and the surrounding gas is enhanced. The Knudsen number is defined by the ratio between the the mean free path and the particle size

$$
K n=\frac{\lambda_{m f p}}{r_{p}} .
$$

This number identifics the cooling regime. A Knudsen number bigger than 10 characterizes the free molecular regime and a Knudsen number smaller than 0.1 characterizes the continuum regime. At typical engine conditions the Knudsen number varies between 1 and 20 .

In this work the mean free path for conductive cooling is calculated based on the gas phase, by using the ideal gas law. For spherical like molecules in a gas, the mean frec path is given by [36]

$$
\lambda_{m f p}=\frac{1}{\sqrt{2} n \sigma_{\mathrm{coll}}},
$$

in which $n$ is the number of air molecules per unit volume and $\sigma_{\text {coll }}$ is the effective collision cross section of the air molecules. for which the properties of nitrogen 
have been assumed. In typical engine environments the cylinder pressure is in the order of scveral tens of bars, with an increasing pressure tendency in more modern engines. The vapor pressure for the sublimated soot was calculated from the Clausius-Clapeyron equation [37], in combination with the ideal gas law. The calculation of the Knudsen number for sublimation was based on the mean free path for the vapor pressure. More details on the model can be found in the original papers $[30,31]$.

\subsection{Experimental setup}

Experiments arc performed on one cylinder of a six-cylinder. heavy-duty Diesel engine (see Chapter 7 for an extensive description). The first cylinder has been modified for optical access to perform in-situ measurements, as described below. The engine is fitted with an in-line fuel pump and an eight-hole nozzle with a hole diameter of $224 \mu \mathrm{m}$. LII measurements discussed in this paper are performed at the extension of one of the sprays. In order to avoid overheating of the non-lubricated measurement cylinder, the engine is operated in a skip-fire mode of one in thirty-five cycles. For all measurements described in this paper the engine is run on regular diesel fucl, with a boost pressure of 1.4 bar abs.. and an inlet air temperature of $313 \mathrm{~K}$. Start of fuel injection is at $5^{\circ} \mathrm{bTDC}$ and the cnd of injection is at $5^{\circ}$ aTDC. The quantity of injected fuel during this period is $62 \mathrm{mg} /$ cyclc. These settings correspond to an engine load of about $25 \%$. The pressure curve for this load is given in Fig. 6.1. From the first derivative of the graph in Fig. 6.1, it follows that the combustion starts at $1^{\circ}$ aTDC. The maximum heat release is at $5^{\circ}$ aTDC.

The configuration of the measurement cylinder and the optical arrangement used for the TR-LII measurements are shown in Fig. 6.2. Optical access to the combustion chamber of the measurement cylinder is provided by a large window in the piston bowl, a smaller window replacing one of the outlet valves. and a window in the side of the cylinder wall. A slot was cut in the rim of the piston bowl, between valve window and side window, in order to have optical access to the combustion chamber for a larger part of the engine cycle.

The fundamental wavelength of a pulsed Nd:YAG laser $\left(0.25 \mathrm{~J} / \mathrm{cm}^{2}\right)$ was fired top-down through the engine. Radiation from the laser-heated soot particles was observed through the side window, simultaneously by two photomultiplier tubes (PMT; Thorn EMI, < 2 ns risc time) and a spectrograph (Acton 300I imaging monochromator with a Princeton Instruments ICCD512T intensified CCD camera on its exit port). In order to suppress the background flame luminosity, the LII was filtered with a Schott BG18 filter (centre wavelength $500 \mathrm{~nm}$. FWHM $200 \mathrm{~nm}$ ). The light detected by PMT1 (type 9814QB) was filtered with a Schott BG1 filter (centre wavelength $420 \mathrm{~nm}$, FWHM $200 \mathrm{~nm}$ ). In combination with the sensitivity of the PMT itself this resulted in an effective detection wavelength of $370 \mathrm{~nm}$ (FWHM $40 \mathrm{~nm}$ ). The second PMT (type 9863QA) was provided with a Schott OG 450 filter (450 nm long-pass filter). The filter combination together with the sensitivity of 


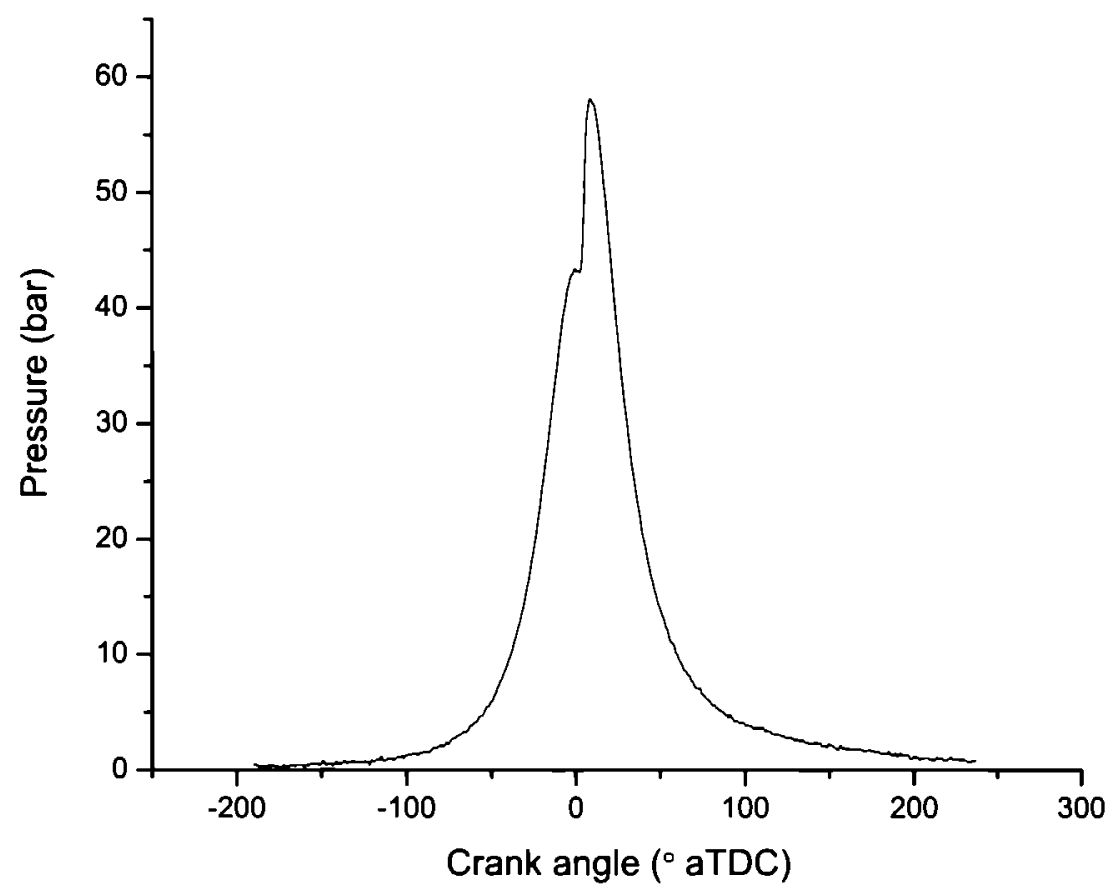

Figure 6.1: Pressure curve for the selected engine load. The boost pressure is 1.4 bar and the inlet temperature is $313 \mathrm{~K}$. The amount of injected fucl is $62 \mathrm{mg} / \mathrm{cycle}$ and the start of injoction is $5^{\circ}$ bTDC.

the PMT resulted in an effective detection wavelength of $560 \mathrm{~nm}$ (FWHM $50 \mathrm{~nm}$ ). The spectrograph was used for two purposes. In separatc experiments we checked that the emitted light did not contain obvious molecular emission lines (notably from the Swan bands of $\mathrm{C}_{2}$ ). Initially. we attempted to use the spectrograph for temperature measurements by recording a large wavelength range. but it turned out that the LII signal was not sufficiently intense. This is why we took recourse to two-color pyrometry. During LII data collection. the spectrograph was used in $0^{\text {th }}$ order to record spatially resolved (but spectrally integrated) LII images (gate width $20 \mathrm{~ns}$ ).

In order to increase the signal strength and to define a spccific probe volume in the engine. LII radiation was imaged onto the PMTs by two spherical lenses. We estimate the probe volume to be roughly cylindrical along the lascr beam direction. with a height of about $10 \mathrm{~mm}$ and a diameter of about $3 \mathrm{~mm}$ (determined by the 


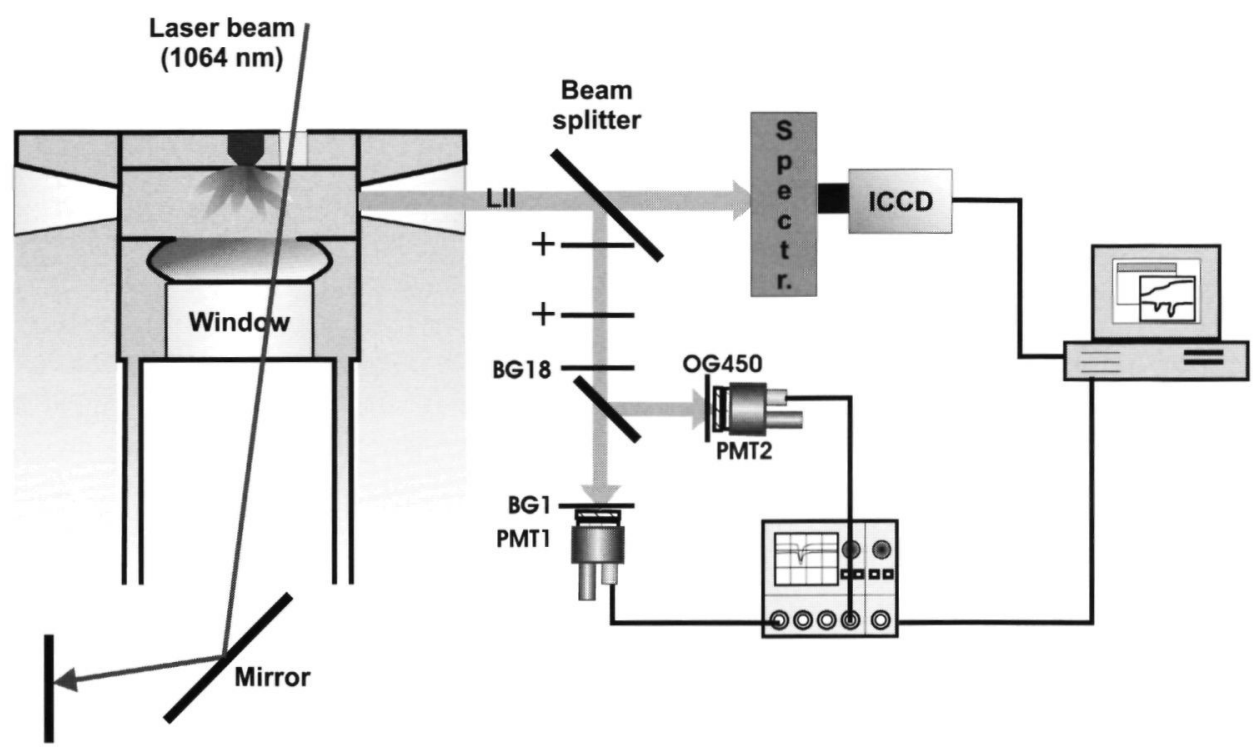

Figure 6.2: Schematic picture of the experimental setup.

laser beam). The PMT outputs were displayed on a dual channel digital oscilloscope (Lecroy $9630 ; 350 \mathrm{MHz}$ analog bandwidth, $2.5 \mathrm{Gs} / \mathrm{s}$ ). The data was read out to a PC using a GPIB interface. The time response of the whole detection chain was determined separately (see below). The data fitting procedure was done with a least-square fitting routine in Matlab. All measurements were performed on the basis of single laser shots, without averaging.

\subsection{Results and discussion}

TR-LII measurements were performed in the engine on two PMTs simultaneously, covering different spectral ranges. For each laser shot the observed signal was only interpreted as LII if it was present on both PMT channels and if on the spectrograph glowing soot (that is, localized emission spots in the path of the laser beam) was visible simultaneously. This strategy resulted in positively identified LII signals for about $0-20 \%$ of the laser shots (depending on crank angle). For about $20 \%$ of the laser shots, signal was present on only one of the PMT channels, or not accompanied by evidence on the spectrograph. These shots were discarded. For the remaining laser shots, no LII signal was detected on the PMTs at all. The spectrograph images also showed that the soot is not at all distributed uniformly. During the whole stroke expansion, soot emission spots were always highly localized. 


\subsubsection{Detection system time response}

The response time of the detcction system is governed by the PMTs, the oscilloscope. and the finite duration of the lascr pulse. Ideally. this time response would have been measured with a short ( $\mathrm{ps}$ or fs) light pulse, but that was not available. We have estimated it by measuring the clastically scattercd light of the frequencydoubled Nd:YAG-laser $(\lambda=532 \mathrm{~nm})$. This curve is plotted in Fig. 6.3 (solid line; only for PMT1). A typical TR-LII curve (excited with $1064 \mathrm{~nm}$ ) has been plotted in Fig. 6.3 as well (dots: same PMT). The curves have not been measured simultaneously, and have been superposed in Fig. 6.3 in order to emphasize their similarity. It can be seen that the time response of the detection system is of the same order of magnitude as the typical duration of a TR-LII signal.

Interestingly. the rising edge of the TR-LII curve is slightly stceper than the rising edge of what we call the response curve. At first sight this might seem surprising, but it is essentially due to the $\mathrm{T}^{4}$-dependence of the radiative power in combination with the finite heating ratc of soot particles. Figure 6.4 gives the result of a simulation of the heating process of soot particles with a radius of $15 \mathrm{~nm}$. During the heating process by a Gaussian-shaped laser pulse as a function of time (FWHM $10 \mathrm{~ns}$, laser energy $0.25 \mathrm{~J} / \mathrm{cm}^{2}$ ) the cooling by conduction has been calculated as well. For the conductive cooling a typical engine condition has been taken $\left(p_{a}=36.8 \mathrm{bar}\right.$, $T_{a}=1017 \mathrm{~K}$, corresponding to engine conditions at $25^{\circ}$ aTDC). Figure 6.4 gives the normalized profiles for the laser intensity, the soot particle temperature and the radiative power (which is the property which is measured with LII). The figure shows that the normalized radiative power increases faster than the normalized intensity of the laser. Figure 6.4 shows that the LII intensity comes up slightly faster than the time response curve for the TR-LII detection system inclusive the laser pulse. In fact, it is the time-response function of the detcction system in combination with the finite duration of the laser pulse that is measured in an clastic scattering experiment.

On the cooling side of the TR-LII curve the influence of the finite duration of the laser pulse is less severe, because the cooling process, being governed by conduction and other cooling mechanisms, takes longer than the heating process. Thercfore, and since the information of interest is extracted from only the decaying tail of the LII profiles, we will interpret the clastic scattering data as the time response function of our detection system.

\subsubsection{Deconvolution}

From Fig. 6.3 it is clear that under the conditions prevalent in the engine, the time response of the LII detection system cannot be neglected relative to the duration of the LII transient itsclf. Thereforc. all measured LII time profiles have been deconvolved with the expcrimentally determined time response function. In order to avoid excessive noisc blow-up. a Wiener deconvolution procedure was applied. 


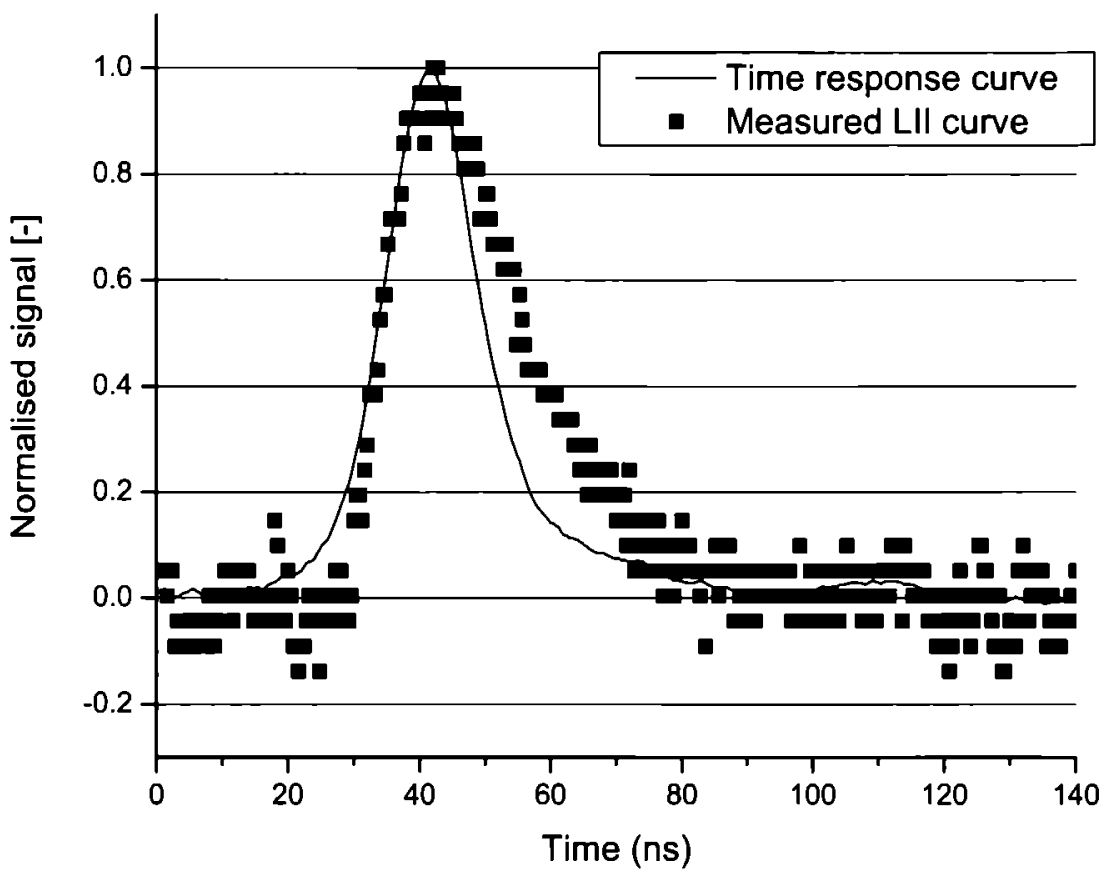

Figure 6.3: The response of the PMT on the Rayleigh scattered laser light (solid line, $532 \mathrm{~nm}$ ) plotted as a function of the time in comparison with a typical TR-LII curve (dots: measured at $25^{\circ}$ aTDC. when $p \approx 37$ bar). The curves are shifted in time relative to each other. in order to cmphasize their similarity. The decay times are of a similar order of magnitude.

Mathomatically this is described (in Fouricr space) by

$$
\hat{F}(\Omega)=\left[\frac{1}{H(\Omega)} \frac{|H(\Omega)|^{2}}{|H(\Omega)|^{2}+S_{n}(\Omega) / S_{f}(\Omega)}\right] G(\Omega) .
$$

in which $\hat{F}(\Omega)$ is the Fouricr-transform (FT) of the deconvolved 'real' signal. $H(\Omega)$ is the FT of the response function of the detection system. $S_{n}(\Omega)$ is the power spectrum of the noise. $S_{f}(\Omega)$ is the power spectrum of the original signal and $G(\Omega)$ is the FT of the measured signal [38]. all as a function of the angular frequency $\Omega$. The ratio $S_{n}(\Omega) / S_{f}(\Omega) \stackrel{\text { def }}{=} \eta(\Omega)$ functions as a regularization parameter for this inverse problem. Its choice requires some care. because it also affects the range 


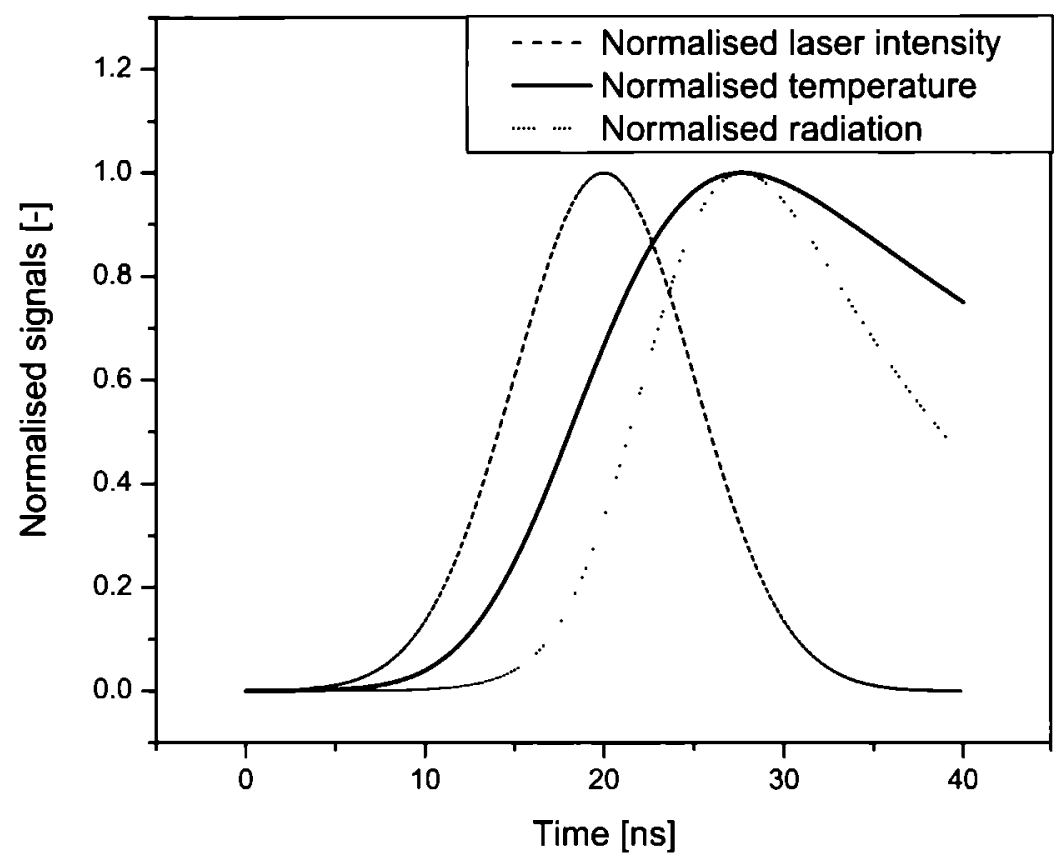

Figure 6.4: The modeled heating process for particles with a radius of $15 \mathrm{~nm}$. The dash-dotted line indicates the normalised Gaussian time-dependent laser profile $($ FWHM $=10 \mathrm{~ms})$. The solid line is the normalised temperature of the heatedparticles. The dashed line is the normalised LII signal.

of frequencies that contributes to the deconvolved signal. Although rigorous, but mathematically involved. methods for its detcrmination exist. we have opted for a physical approach. similar to the one used by Tolboom et al. [39]. Thus. we chose $\eta(\Omega)$ to be constant, with a value such that the noisc power in that part of the LII trace before arrival of the laser pulse was the same before and after cleconvolution. In this way. no noise was added by the deconvolution process. nor is excessive smoothing introduced by regularization.

An example of a deconvolved curve is shown in Fig. 6.5. The increase in signal is faster for the deconvolved curve in comparison with the raw measurement. For the extraction of decay times the rising slope is irrclevant. The influence of the deconvolution on the fitted particle size is a Ieduction of about $10 \%$ (Chapter 5 ). 


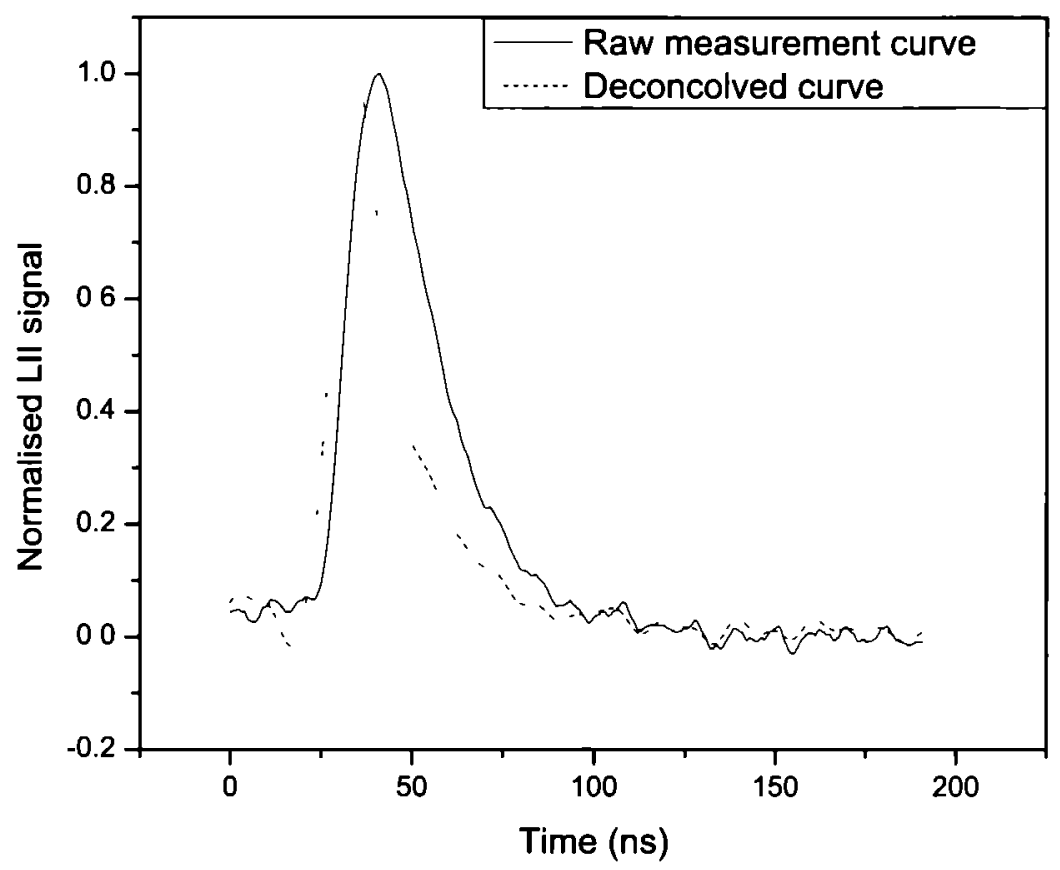

Figure 6.5: Example of a typical deconvolved LII transient at $30^{\circ}$ aTDC.

\subsubsection{Initial Temperature}

In Fig. 6.6 the measured maximum tempcrature of the soot particles as a function of the CA is plotted for several injections. This "initial temperature" was derived by application of two-color pyrometry [40]. The signals of both PMTs were integrated over $1 \mathrm{~ns}$ around the maximum. Their ratio is a measure for the emitter's temperature. Signals wcre cvaluated at the central wavelength of cach PMT/filter combination, and the setup was calibrated off line by means of a NIST calibrated $20 \mathrm{~W}$ band lamp (type Mikropack DH-2000) positioned where the laser beam would pass through the engine. This procedurc results in kind of an effective initial temperature over that part of the probe volume that contributes to the LII signal. Wo estimate the uncertainty in these temperatures to be $\pm 300 \mathrm{~K}$.

It can be seen from Fig. 6.6 that the initial temperature varies quite a lot from injection to injection. Several factors are likcly to contribute to this fluctuation. 


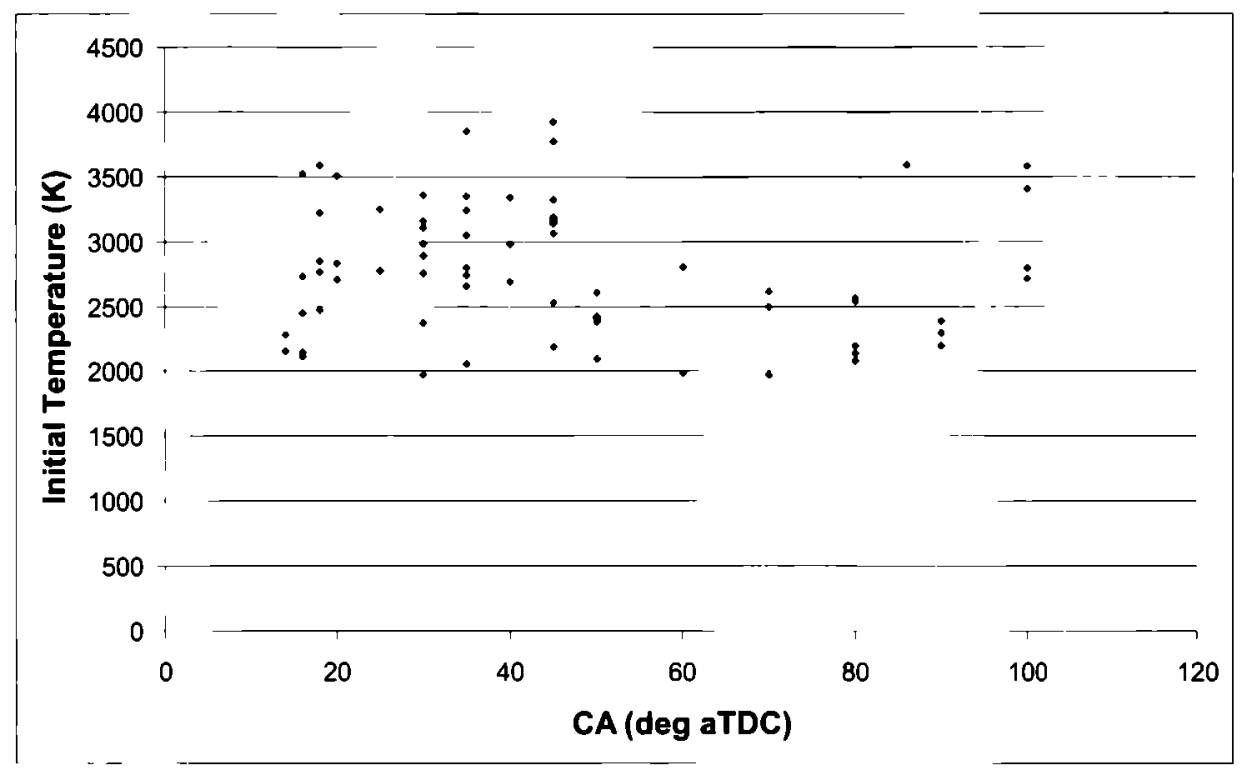

Figure 6.6: The measured initial temperature as a function of the crank angle. Each dot corresponds to a single shot measurement.

In the first place there is the pulse-to-pulse fluctuation in laser energy. Sccondly, there is an unpredictable amount of attenuation between the location where the laser beam cnters the cylinder and the probe location [41]. And finally. as discussed above. the soot is irregularly distributed, so that it is sometimes partially hit by the laser beam and sometimes more 'head-on', which will also result in a variation in initial temperature.

\subsection{4 $\quad \chi^{2}$-error landscape}

After deconvolution, the temporal decay of the LII intensity was least-squares fitted to the model expression described above. Since we do not consider the initial particle temperature derived from two-color pyrometry to be more than indicative, we have tried to estimate the effect of initial temperature uncertainty on the fitted particle size. Figure 6.7 shows the influence of the initial temperature on the fitted particle radius. For different initial temperature (vertical axis) and different particle radii (horizontal axis) the $\chi^{2}$-crror has becn calculated, defined as

$$
\chi^{2}=\sum_{\imath}(\text { calculated intensity }- \text { measured intensity })_{\imath}^{2} .
$$


in which the summation runs over all data points (0.4 ns time steps) of a single measured decay curve. In this calculation it has been assumed that the PSD is mono-disperse. Figure 6.7 a shows the $\chi^{2}$-error landscape for the hypothetical situation that no sublimation of the heated soot is present, and Fig. 6.7b shows the $\chi^{2}$-error landscape for the situation when both sublimation and conduction are involved in the cooling process. (Radiative energy loss is negligible in both cases.) Both pictures are more or less similar. Only at high temperatures the influence of sublimation of the soot is visible; the additional heat loss pathway is compensated for by a slightly larger retrieved particle radius.

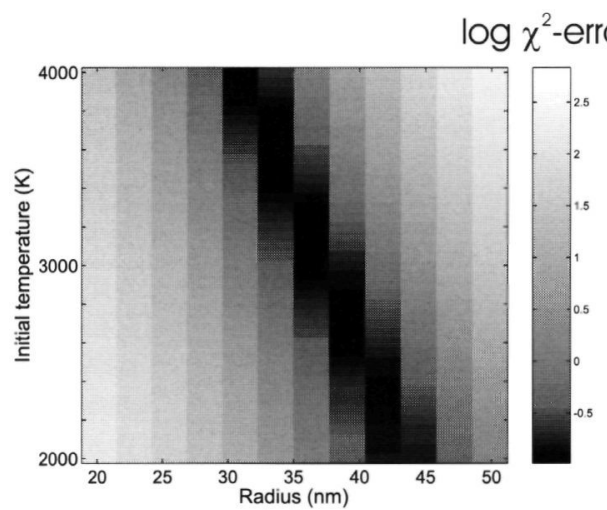

(a)

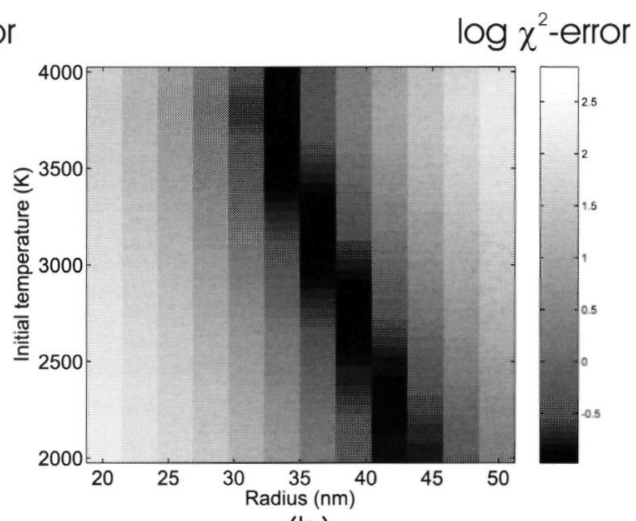

(b)

Figure 6.7: Example of a $\chi^{2}$ error calculation (a) without sublimation and (b) with sublimation. For the experimental data a deconvolved LII trace recorded at $30^{\circ}$ aTDC was used.

In both cases the map shows a narrow, well-defined 'gorge' in which $\chi^{2}$ finds a minimum (note the logarithmic gray scale). As a result, for any given initial temperature the particle radius retrieved from the fit is well-defined. The bottom of the 'gorge', however, is virtually flat, so that the absolute minimum in $\chi^{2}$ is ill-defined. Apparently, many sets of parameters (initial temperature; particle radius) fit the experimental data about equally well. In other words, the high-pressure LII data do not possess sufficient structure to discriminate between multiple parameter sets, at least in the presence of the amount of noise in the single-shot experimental data. Fortunately, the dependence of the retrieved particle size on the initial temperature is not very strong. This can be explained from the fact that the dominant heat loss rate under the circumstances of our experiments, by conduction, is linearly proportional to both the the difference of the particle temperature $T_{p}$ and the ambient temperature $T_{a}$ and on $r_{p}$, that is (see Appendix C),

$$
\lim _{P_{a} \rightarrow \infty} \dot{q}_{\mathrm{cond}} \propto \sqrt{P_{a}}\left(T_{p}-T_{a}\right) r_{p},
$$


in which $P_{a}$ is the ambient pressurc.

Because the LII intensity scales with $T_{p}^{4}$. all the LII signal is emitted under conditions in which $\Delta T$ is largc. Variations in $T_{p}$ are then relativcly small, so that the concomitant variations in $r$. required to end up with the same conduction heat loss rate (that fits the experimental LII intensity decay rate) are also small. Therefore. even if we take the scatter in the initial temperature data points from Fig. 6.6 as an uncertainty in an individual temperature (say $T_{p}(\mathrm{t}=0)=3000 \pm 500 \mathrm{~K}$ ). this will translate into an uncertainty of roughly $10 \%$ in the retrieved particle radius ( $36 \pm$ $3 \mathrm{~nm}$ for the example of Fig. 6.7).

The calculation leading to Fig. 6.7 assumes a mono-disperse PSD. Since this is hardly to be expected in practice, it is of interest to try whether parametcrs of a finite-width PSD can be retrieved from the LII traces recorded in the engine. To this end, we have calculated $\chi^{2}$-maps for sclected experimental traccs, assuming a well-known initial temperature and a log-normal PSD [32].

$$
P\left(r_{p}\right)=\frac{1}{\sqrt{2 \pi} \sigma_{m} r_{p}} \exp \left\{-\frac{\left(\ln r_{p}-\ln r_{m}\right)^{2}}{2 \sigma_{m}^{2}}\right\} .
$$

Here, $r_{m}$ is the mean particle radius and $\sigma_{m}$ is the width of the distribution; both arc treated as free parametcrs in the $\chi^{2}$-maps. For the initial temperature a representative value of $3100 \mathrm{~K}$ was taken: its value docs not significantly affect the topology of the maps. An example plot is shown in Fig. 6.8 (experimental data recorded at $30^{\circ}$ aTDC). The map again shows a quite well-defined valley of minimal $\chi^{2}$. An increase in $\sigma_{m}$ implies a greater proportion of relatively large particles in the distribution, and this is compensated for by a smaller mean radius in order to arrive at a fit of similar quality. This explains the general trend of the figure (the NW-SE orientation of the vallcy). Interestingly, the absolute minimum in Fig. 6.8 is fairly well defined (here located at $\left(r_{m}=22.5 \mathrm{~nm}, \sigma_{m}=0.35\right)$ ) and clearly away from the mono-disperse limit $\left(\sigma_{m}=0\right)$. Although the map is, of coursc, sensitive to noise, it means that it is possible to fit details of the PSD on the basis of the used model, a well-known initial tempcrature and assuming a log-normal PSD. That is, even though the TR-LII signal shows little structure, it should still be possible to extract relatively detailed information on the PSD from it. Figure 6.9 shows the complete measured deconvolved LII curve (inclusive the heating part). Two different fitted decay curves are shown. one for a virtually mono-disperse distribution. with $r_{m}=38 \mathrm{~nm}$ and $\sigma_{m}=0.01$. and one for a log-normal PSD with $r_{m}=24 \mathrm{~nm}$ and $\sigma_{m}=0.35$. The latter one is the minimum value in the $\chi^{2}$-plot. The PSD with the small width fits significantly worse than the broader PSD. especially in the tail of the LII-dccay curve. in which only the bigger particles are still cooling down. In the approach of an (almost) mono-disperse size distribution. this tail cannot be fitted well. because of the absence of bigger particles. This tail is much better represented by a log-normal distribution. Of course. a broader distribution would also imply a larger proportion of small sizes in the distribution. These will contribute predominantly to the early part of the LII traces. that is most severcly affected by the finite time resolution of the hardware. 


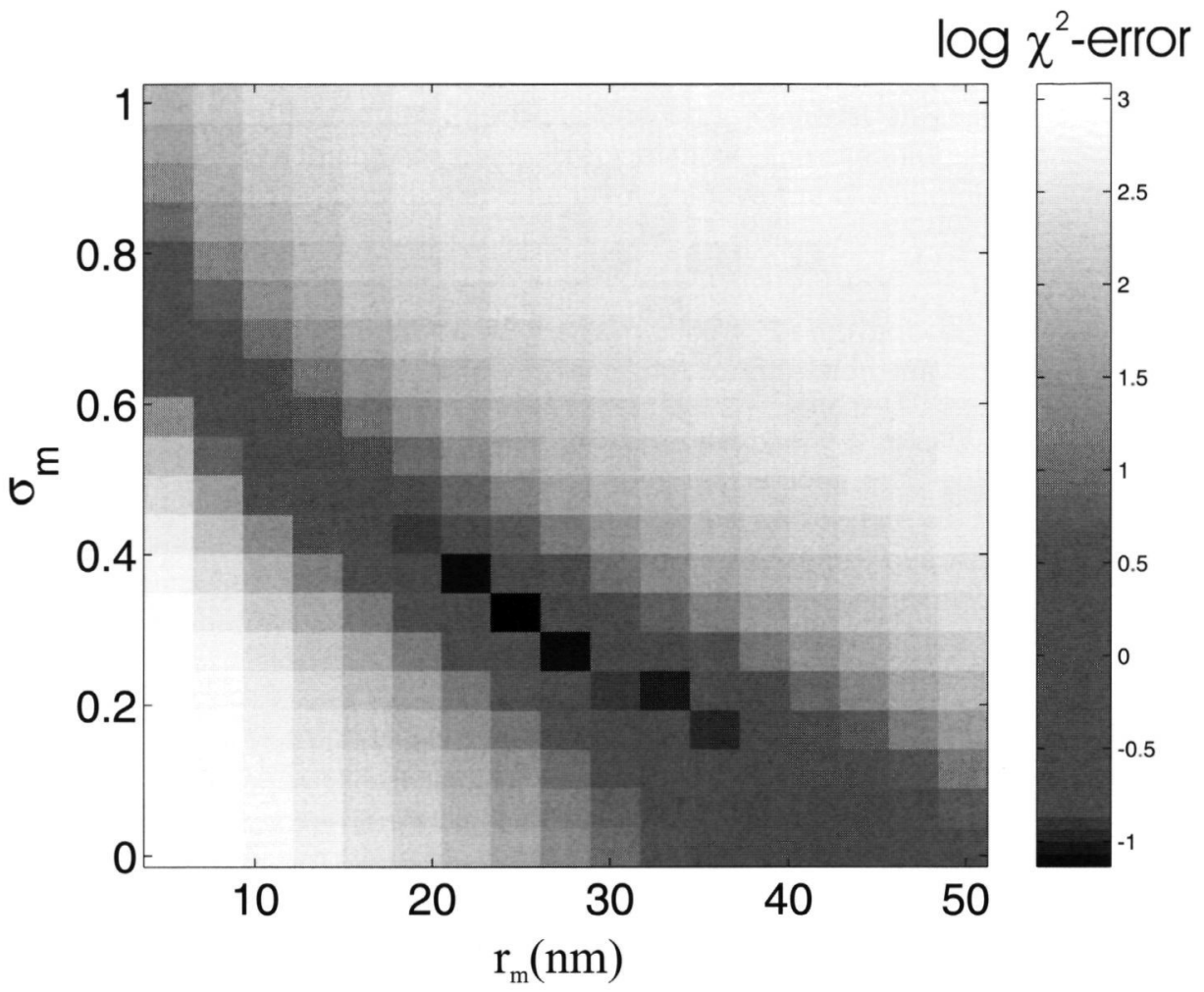

Figure 6.8: Chi-square plot for different $r_{m}$ and $\sigma_{m}$ for a measured LII curve at $30^{\circ}$ aTDC. Note the presence of a global minimum at $\left(r_{m}=22.5 \mathrm{~nm}, \sigma_{m}=0.35\right)$ as well as several local minima (not always well reproduced in this grey scale)

In conclusion, the high-pressure LII data, even though relatively structureless, do seem to contain sufficient structure to discriminate between individual PSDs. The example curve in Fig. 6.9 is fitted significantly better by a log-normal distribution than by a mono-disperse distribution, and judging from the fits a bimodal distribution might possibly do an even better job.

\subsubsection{Crank angle dependent measurements}

TR-LII curves have been measured during the power stroke of the combustion cycle. All curves were deconvolved with the system time response function and fitted to the model expression as described above. It was assumed that the size distribution was mono-disperse. Data-evaluation using a more realistic log-normal distribution is in progress. This is a complicated and numerically intensive procedure, because 


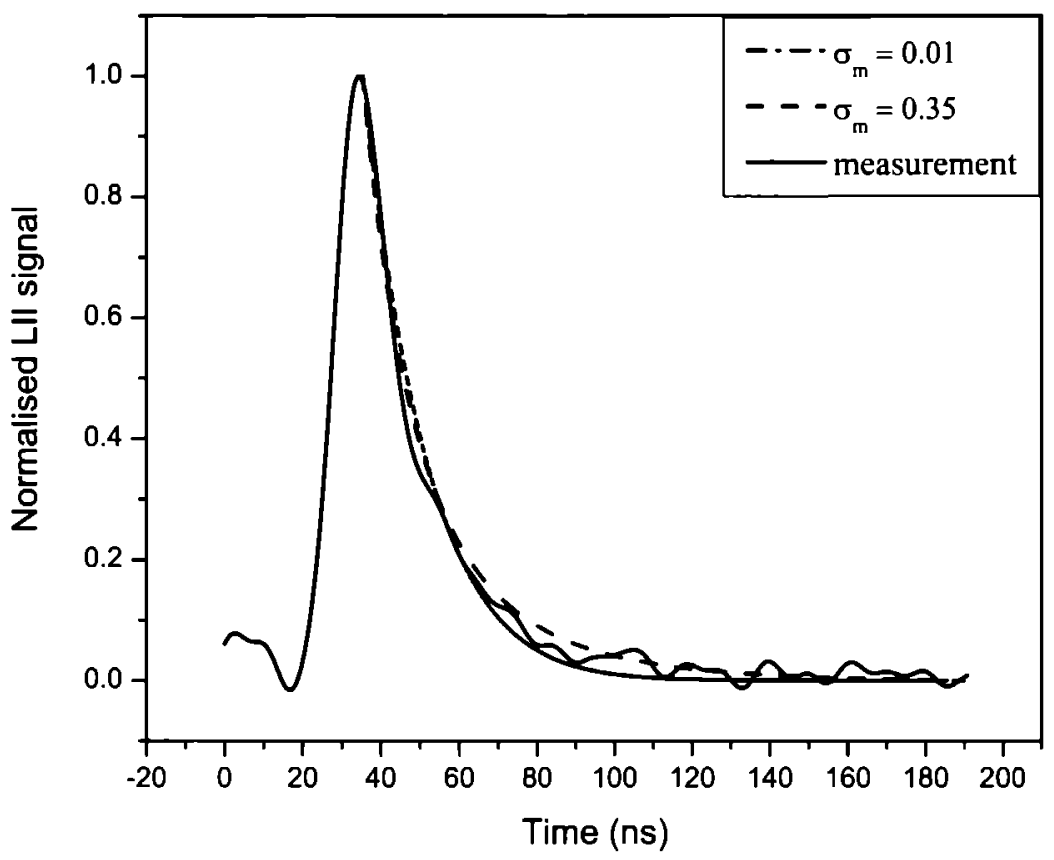

Figure 6.9: Example of a deconvolved measured curve (straight line), together with a fitted curve assuming a narrow log-normal size distribution $\left(\sigma_{m}=0.01\right)$ and a fitted assuming a log-normal PSD with $\left(\sigma_{m}=0.30\right)$. The measurement was done at $30^{\circ}$ aTDC.

of the regular presence of many local minima in the $\chi^{2}$-map. especially if the initial temperature is also treated as a frec parameter. First results indicate that the mono-disperse distribution overestimates the particle size systematically by about a factor of two. but that the trend (radius as a function of crank angle) is the same. The results for the crank angle dependent mono-disperse particle size are shown in Fig. 6.10. The solid line is a parabolic trend line which has been fitted through the data. The first LII signal is visible at $14^{\circ}$ aTDC. Afterwards an increase in soot particle radius is seen until about $55^{\circ}$ aTDC. Then there is a decrease in particle size again until at least $100^{\circ}$ aTDC. The smallest particle radius which has been measured is $24 \mathrm{~nm}$. the biggest particle radius found is about twice as large. Before $14^{\circ}$ aTDC no LII signal could be found. given our criteria for accepting 


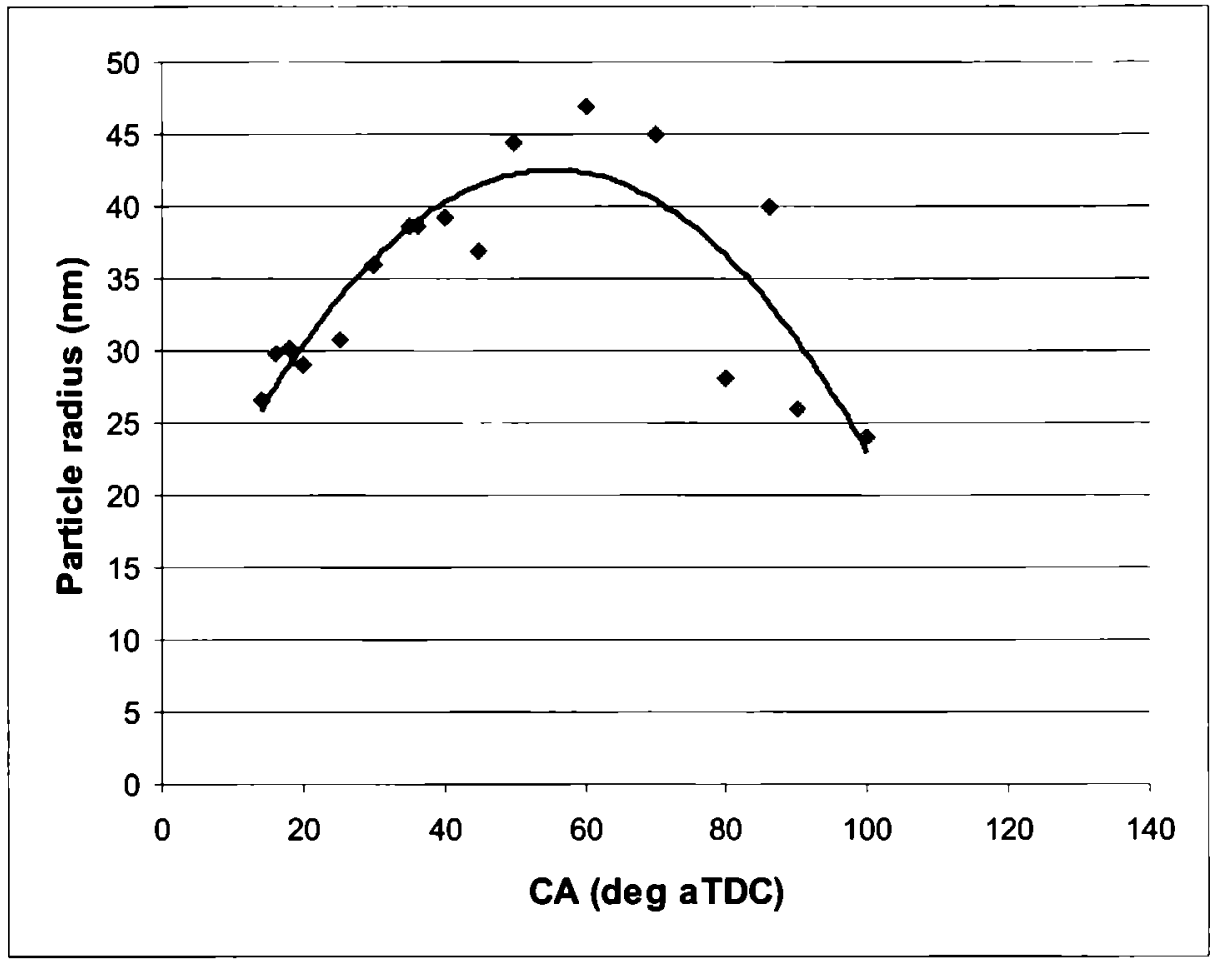

Figure 6.10: Trend of the experimental soot particle radius as a function of the crank angle, based on the cvaluation of TR-LII measurements assuming a mono-disperse PSD. The solid line is a $2^{\text {nd }}$ order polynomial trend line fitted to the averages.

PMT signals. Whether this is due to insufficient soot or too small soot particles, or too much in-cylinder attenuation of laser intensity or LII intensity cannot be decided. Later in the stroke than $100^{\circ}$ aTDC LII signal occurred crratically and with insufficient $\mathrm{S} / \mathrm{N}$ for evaluation.

It is generally belicved that soot needs a nucleation period. during which the soot particle develops [42]. Then the particles start to grow, partially due to surface growth and partially due to coagulation. Still later the particle size is cxpected to decrease due to oxidation. This is at least qualitatively in agreement with the trend in Fig. 6.10. Transmission electron microscope (TEM) measurements have shown different structures of soot particle aggregates present in Diesel engines. such as ball-like [30] or chain-like [43]. The structure of the soot aggregates influences the cooling process of the laser-heated soot particles [28.33], although there is still debate about its extent. In the model the influence of the aggregatc structure has 
not been taken into account. This gives an extra uncertainty in the interpretation of the results.

\subsection{Summary and Conclusions}

Time-resolved lascr-induced incandescence (LII) measurements have been demonstrated on a single-shot basis inside the combustion chamber of a heavy-duty diesel engine operated on regular diesel fuel. Unambiguous LII signal could be observed from $14^{\circ}$ onwards. In all cases, the temporal behavior of the LII intensity was relatively structurcless on a time scale comparable to the response time of the detection system and the pulse duration of the excitation lascr. We have interpreted the time-dependent LII intensity by fits to the model expression developed by Kock et al. [30. 31] for transition regime conditions, in terms of an assumed primary PSD. The experimental traces are found to be well-fitted by this model. assuming a lognormal size distribution and a well-defined initial temperature. A mono-disperse PSD provides significantly worse fits. Neglect of a correction for the finitc response time of the detection system (incl. laser pulse width) results in a systcmatic shift of about $10 \%$ to larger values of the primary particle sizc.

A main conclusion of our paper is that the high-pressure LII transients in many cases do appear to contain sufficient structure to allow at lcast first and second moments of a PSD to be extracted. but care should be taken of local minima in the $\chi^{2}$-maps. Information on the contribution of relativcly small particle sizes is contained in the early part of the LII transient. the resolution of which requires not only a faster detection system than the one available for this study. but also a shorter-pulse excitation laser (preferentially ; $1 \mathrm{~ns}$ ). The large-particle tail of the size distribution. on the other hand. dominates the long-time tail of the LII transient (and often also the absolute intensity). Its evaluation poses great demands on the $\mathrm{S} / \mathrm{N}$ ratio of the LII signals, which are difficult to meet experimentally under the conditions of a realistic diesel engine. Thus, under the present circumstances. we have interpreted our experimental LII transients in terms of an effective primary particle size of a mono-disperse size distribution. Earliest detectable soot (at $14^{\circ}$ aTDC) is found with a particle radius of about $26 \mathrm{~nm}$, which increases to about twice this size around $60^{\circ}$ aTDC. after which it gradually declines again. This trend is at least qualitatively consistent with current idcas about soot evolution during diesel combustion.

\section{Acknowledgements}

P. Roth and B. Kock from the University of Duisburg are gratefully acknowledged for the input in the modeling. This work is financially supported by the Technology Foundation STW. applied science division of NWO and the technology progi am of the Dutch Ministry of Economic Affairs. 


\section{Bibliography}

[1] B.S. Haynes and H.Gg. Wagner (1981): Soot formation. Prog. Energy Combust. Sci. 7 (4). 229-273.

[2] H. Richter and J.B. Howard (2000): Formation of polycyclic aromatic hydrocarbons and their growth to soot - a review of chemical reaction pathways. Prog. Energy Combust. Sci. 26 (4-6). 565-608.

[3] G. Bruneaux (2001): A study of soot cloud structurc in high pressurc single hole common rail Diesel injection using multi-layered laser-induced incandescence. In: COMODIA. 622-630.

[4] D. Sicbers and D. Higgins (2001): Flame lift-off on direct-injection Diesel sprays under quiescent conditions. SAE Tech. Pap. Series 2001-01-0530.

[5] P.O. Witze (2001): Diagnostics for the measurement of particulate matter emissions from reciprocating engines. In: COMODIA, 7-12.

[6] H. Zhao and N. Ladommatos (1998): Optical diagnostics for soot and temperature measurement in Dicscl engines. Prog. Encrgy Combust. Sci. 24 (3). 221-255.

[7] L.A. Melton (1984): Soot diagnostics based on laser heating. Appl. Opt. 23 (13), 2201-2208.

[8] B. Quay, T.-W. Lee. T. Ni and J.R. Santoro (1994): Spatially resolved measurements of soot volume fraction using laser-induced incandescence. Combust. Flame 97 (3-4). 384-392.

[9] T. Ni. J.A. Pinson. S. Gupta and J.R. Santoro (1995): Two-dimensional imaging of soot volume fraction by the use of laser-induced incandescence. Appl. Opt. 34 (30). 7083-7091.

[10] C.R. Shaddix and K.C. Smyth (1996): Laser-induced incandescence monsurements of soot production in steady and flickering mothane. propane. and ethylene diffusion flames. Combust. Flame 107 (4). 418-452. 
[11] J.E. Dec. A.O. zur Loye and D.L. Siebers (1991): Soot distribution in a D.I. Diesel engine using 2-D lascr-induced incandescence imaging. SAE Tech. Pap. Series 910224 .

[12] J.E. Dec (1992): Soot distribution in a D.I. Diescl engine using 2-D imaging of laser-induced incandescence, elastic scattering. and flame luminosity. SAE Tech. Pap. Series 920115.

[13] J.E. Dcc and C. Espey (1995): Ingition and early soot formation in a D.I. Diesel engine using multiple 2-D imaging diagnostics. SAE Tech. Pap. Series 950456 .

[14] J.E. Dec and C. Espey (1992): Soot and fuel distributions in a D.I. Diesel engine via 2-D imaging. SAE Tech. Pap. Series 922307.

[15] S.S. Mcrola. B.M. Vaglieco. S. Cosales. F.E. Corcione and G. Formisano (2001): Determination of Size of Fucl Droplets and Soot Particles in a Diesel Engine by Broadband Extinction and Scattering Spectroscopy. Part. Part. Syst. Charact. 18 (5-6), 235-242.

[16] S.S. Merola and B.M. Vaglicco (2004): Analysis on Common Rail diesel engine combustion process by optical diagnostics. In International Conference on Automotive Tcchnology "Future Automotive Technologies on Powertrain and Vehicle“. Pap. 4.

[17] H. Kosaka, Y.H. Won and T. Kamimoto (1992): A study of the structure of Diescl sprays using 2-D imaging techniques. SAE Tech. Pap. Series 920107.

[18] J.A. Pinson. D.L. Mitchell. R.J. Santoro and T.A. Litzinger (1993): Quantitative, planar soot measurements in a D.I. Diesel engine using laser-induced incandescence and light scattering. SAE Tech. Pap. Scrics 932650.

[19] K. Inagaki, S. Takasu and K. Nakakita (1999): In-cylinder quantitative soot concentration measurement by laser-induced incandescence. SAE Tech. Pap. Series 1999-01-0508.

[20] D.J. Bryce. N. Ladommatos and H. Zhao (2000): Quantitative investigation of soot distribution by laser-induced incandescence. Appl. Opt. 39 (27), 50125022 .

[21] S. Will. S. Schraml and A. Leipertz (1995): Two-dimensional soot-particle sizing by time-resolved laser-induced incandescence. Opt. Lett. 20 (22). 23422344 .

[22] P. Roth and A.V. Filippov (1996): In situ ultrafine particle sizing by a combination of pulsed laser heatup and particle thermal emission. J. Aerosol Sci. 27 (1). 99-104. 
[23] H. Geitlinger, T. Streibel, R. Suntz and H. Bockhorn (1998): Two-dimensional imaging of soot volume fractions, particle number densities and particle radii in laminar and turbulent diffusion flames. In: Proc. Combust. Inst. 27. 1613-1621.

[24] S. Schraml. S. Will and A. Leipertz (1999): Simultaneous measurement of soot mass concentration and primary particle size in the exhaust of a DI Dicscl engine by time-resolved laser-induced incandescence (Tire-Lii). SAE Tech. Pap. Series 1999-01-0146.

[25] D.R. Snelling, G.J. Smallwood, R.A. Sawchuk. W.S. Neill, D. Garcau, W.L. Chippior, F. Liu, Ö.L. Gülder and W.D. Bachalo (1999): particulate matter measurements in a Diescl engine exhaust by laser-induced incandescencc and the standard gravimetric procedure. SAE Tech. Pap. Series 1999-01-3653.

[26] S. Schraml, S. Dankers, K. Bader, S. Will and A. Leipertz (2000): Soot temperature measurements and implications for timc-resolved laser-induced incandescence (TIRE-LII). Combust. Flame, 120 (4), 439-450.

[27] G.J. Smallwood, D. Clavel, D. Gareau, R.A. Sawchuk, D.R. Snclling, P.O. Witzc, B. Axelsson, W.D. Bachalo and Ö.L. Gülder (2002): Concurrent quantitative laser-induced incandescence and SMPS measurements of EGR effects on particulate emissions form a TDI Diesel engine. SAE Tech. Pap. Serics 2002-01-2715.

[28] L. Liu, G.J. Smallwood and D.R. Snclling (2005): Effects of primary particle diametcr and aggregate size on the temperature of soot particles heated by pulsed lasers. J. Quantum Spectrosc. Radiat. Transf. 93 (1-3), 301-312.

[29] M. Hofmann. W.G. Bessler. C. Schulz and H. Jander (2003): Laser-induced incandescence (LII) for soot diagnostics at high pressurcs. Appl. Opt. 42 (12). 2052-2062.

[30] B.F. Kock. Th. Eckhardt and P. Roth (2002): In-cylinder sizing of Diesel particles by time-resolved laser-induced incandescence (TR-LII). In: Proc. Combust. Inst. 29, 2775-2781.

[31] B.F. Kock and P. Roth (2003): Two-color TR-LII applied to in-cylinder Diesel particle sizing. In: Proc. European Combustion Meeting 2003. papcr 093.

[32] H. Bockhorn. H. Geitlinger, B. Jungfleisch. Th. Lehre, A. Schön. Th. Streibel and R. Suntz (2002): Progress in characterization of soot formation by optical techniques. PCCP 4 (15), 3780-3793.

[33] H. Michelsen (2003): Understanding and predicting the temporal response of laser-induced incandescence from carbonaceous particles. JCP 118 (15). 70127045 . 
[34] B. Bougic, L.C. Ganippa, A.P. van Vliet, N.J. Dam. W.L. Mcerts and J.J. ter Meulen (2005): Soot charactcrization with laser-induced incandescence in a heavy-duty Diesel engine. In: Proc. Europcan Combustion Mceting, paper 166 .

[35] M.M.R. Williams and S.K. Loyalka (1991): Acrosol Science Theory and Practice. With Special Applications to the Nuclear Industry $1^{\text {st }}$ ed. Pergamon Press.

[36] E.H. Kennard (1938): Kinetic Theory of Gases. McGraw-Hill Book Company.

[37] P.W. Atkins (1998): Physical Chemistry $6^{\text {th }}$ ed. Oxford University Press.

[38] M. Kunt (1986): Digital Signal Processing. Artech Housc.

[39] R. Tolboom. N. Dam, H. ter Meulen. J. Mooij and H. Maassen (2004): Quantitative imaging through a spectrograph. 1. Principles and theory. Appl. Opt. 43 (30). 5669-5681.

[40] S. de Iuliis. M. Barbini. S. Benecchi. F. Cignoli and G. Zizak (1998): Determination of the soot volume fraction in an ethylene diffusion flame by multiwavelength analysis of soot radiation. Combust. Flame. 115 (1-2), 253-261.

[41] K. Verbiezen, R.J.H. Klein-Douwel. A.P. van Vlict, A.J. Donkerbroek. W.L. Meerts. N.J. Dam and J.J. ter Mculen (2006): Attemuation corrections for in-cylinder NO LIF moasurements in a heavy-duty Dicsel engine. Appl. Phys. B. 83 (1). 155-166.

[42] J.B. Heywood (1988): Internal Combustion Engine Fundamentals. McGraw Hill.

[43] R.L. Vanderwal. T.M. Ticich and A.B. Stephens (1999): Can soot primary particle size be determined using laser-induced incandescence? Combust. Flane, 116 (1-2). 291-296. 


\section{Chapter 7}

\section{Soot particulate size}

characterization in a

\section{heavy-duty Diesel engine for different engine loads by} laser-induced incandescence*

\subsection{Introduction}

Soot is a generally undesired byproduct of combustion. Due mainly to its negative impact on people"s health it recently reccived increased political interest. which has resulted in legislation specifically ained at reducing the fine-dust component in air. In the Netherlands. for instance. this has recently led to cancellation or postponing of construction works. because the cap for fine dust could not be met.

Automotive Dicsel engines are a main source of fine particulates. Although much effort has already been devoted to unraveling the soot formation processes in combustion [1-3]. Diesel engines provide a still badly understood environment.

Most studies on the effect of engine operating conditions on soot characteristics have focused on the exhaust gas (sce c.g. Mathis et al. [4] for a recent example). Recently. Kock et al. [5] published a paper on particle size measurements with single-color time-resolved laser-induced incandescence (Tire-LII) within a light-duty. 2-stroke Diesel engine. They found good agrement between the particulate size distributions in exhaust gas obtained by Tire-LII and independently by a DMPS

* Adapted from: B. Bougie. L.C. Ganippa. A.P. van Vliet. W.L. Meerts. N.J. Dam and J.J. ter Meulen. Proc. Combust. Inst. 31 (1). $685-691$ (2007). 
system (Differential Mobility Particlc Sizer), lending credit to both the experimental method and their data evaluation model. During combustion, the particle size distribution was found to vary only little in the $22-90^{\circ}$ crank angle range.

Time-resolved laser-induced incandescence was used to estimate primary particle size distributions inside the combustion chamber of a heavy-duty Diesel engine as a function of the crank angle, for two different engine loads at two different probe locations. Assuming a log-normal particle size distribution, an increase of the mean primary particle size is observed during the first stages of the combustion cycle. followed by a decrease later on during the combustion process.

\subsection{Time-Resolved Laser-Induced Incandescence}

The basic idca behind Laser-Induced Incandescence (LII) is to quickly heat particulates by irradiation with a ns laser pulse. and to record the resulting transient radiation increase. In Time-Resolved LII (TR-LII), the glowing soot is monitored by a fast detector (PMT + sampling oscilloscope, in general). The temporal behavior of the incandescence intensity is then to be interpreted, using a model description of the energy balance. Basically, smaller particles cool faster than larger ones, so that the decay 'constant' contains information on the particle size distribution.

Several models for the interpretation of TR-LII data have been published. including various contributions to the particle energy loss besides radiation [5-10]. In fact, radiative energy loss is usually negligible in terms of energy, but of course it does provide the data for the measurcments. The most sophisticated model to date is that of Michelson [9]. In our experiments. we deliberately keep the excitation laser intensity at a low level, in order to reduce the importance of several cooling mechanisms that operate at high particle temperatures or high incident light intensities. The model we use for data interpretation is that of Roth and coworkers [5. 10]. because that is, to our best knowledge, the only model that takes into account the pressure dependence in both conductive and evaporative cooling by introduction of the Knudsen number. It will be described only briefly here. The energy balance cquation for a single soot particle is written as [10]

$$
\frac{d\left(m_{p} C_{p} T_{p}\right)}{d t}=\dot{q}_{a b s}-\dot{q}_{c o n d}-\dot{q}_{v a p}-\dot{q}_{r a d}
$$

The left hand side describes the time rate of change of the energy of a soot particle with mass $m_{p}$ and specific heat $C_{p}$ at an instantaneous temperaturc $T_{p}$. All thesc parameters may in principle depend on time. The terms on the right hand side of Eq. (7.1) describe various energy gain and loss mechanisms. $\dot{q}_{a b s}$ models the absorbed laser pulse energy, $\dot{q}_{\text {cond }}$ the heat loss by thermal conduction. $\dot{q}_{\text {vap }}$ the heat loss due to vaporisation, and $\dot{q}_{\text {rad }}$ the radiative heat loss. Hcat transfer terms for oxidation. melting. annealing and non-thermal photodissociation like proposed by Michelson [9] are not present in the model. 
Under the conditions prevalent in the Diesel engme the heat loss is dommated by the conduction term [11] The conduction term is more important under highpressure conditions because it is inverse proportional to the Knudsen number [12] which is small in typical engine environments The vaporisation term however is less important under high-pressure conditions, because it is proportional to the Knudsen number [12] For the particle heat loss the radiation term is negligible as well, but of course the instantaneous temperature is decisive for the radiative power, which is the quantity that is detected experimentally During the combustion stroke pressure and temperature within the combustion chamber vary to such an extent that the conduction heat loss term must be modeled in various flow regimes This is incorporated in the model by including a Knudsen-number dependent interpolation function in the conduction heat loss term This interpolation function piovides a smooth transition between the heat loss terms in the continuum regime and the free molecular regime [10 12] The temperature of the ambient gas in which the laserheated particles cool down is assumed to be equal to the mean gas tempcrature as evaluated from the ideal gas law and the time-dependent prossure in the combustion chamber (see experimental setup) The wavelength-dependent radiatıve power emitted by a particle at temperature $T_{p}$ follows from Planck $s$ law as

$$
P_{\text {rad }}(\lambda)=\lambda^{-5}\left(\exp \left\{\frac{h c}{\lambda k T_{p}}\right\}-1\right)^{-1} \varepsilon_{\lambda}(\lambda)
$$

in which the absorption cocficient $\varepsilon_{\lambda}$ accounts for gray-body effects In our experments, the LII signal is detected through narrow-band colored glass filters and we cvaluate $\mathrm{Eq}(72)$ at a single wavelength in the center of each filtcr s transmission curve An important aspect in the data intcrprctation is that under the high pressure and temperature conditions within the engine, the decay time of the incandescence intensity is so short (cd $20 \mathrm{~ns}$ ) that the finite response time of the detection system $(\sim 10 \mathrm{n} s)$ and the finite duration of the excitation laser pulse ( $~$ 8 ns) can no longer be neglected Essentially the detected LII power is a convolution of three time-dependent terms, viz the laser pulse intensity the LII power as if it were excited by an infinitely short laser pulse, and the detection system time response We extract clean temporal LII decay curves from the raw clata by deconvolution with a system response function (see experımental section)

\subsection{Experimental setup}

Experiments were performed on a six-cylinder heavy-duty Diesel engine with a compression ratio of 15 One of the cylinders was modified to provide optical access for $\imath$-situ measurements The configuration of the medsurement cylinder and the optical arrangement used for the TR-LII medsurements ase shown in Fig 71 Optical access was obtained by replacing the ouginal piston and cylinder by a liner arrangement including an extended piston with a quart $\angle$ bottom This piston window provides a wide ficld of view from below into the combustion chamber 


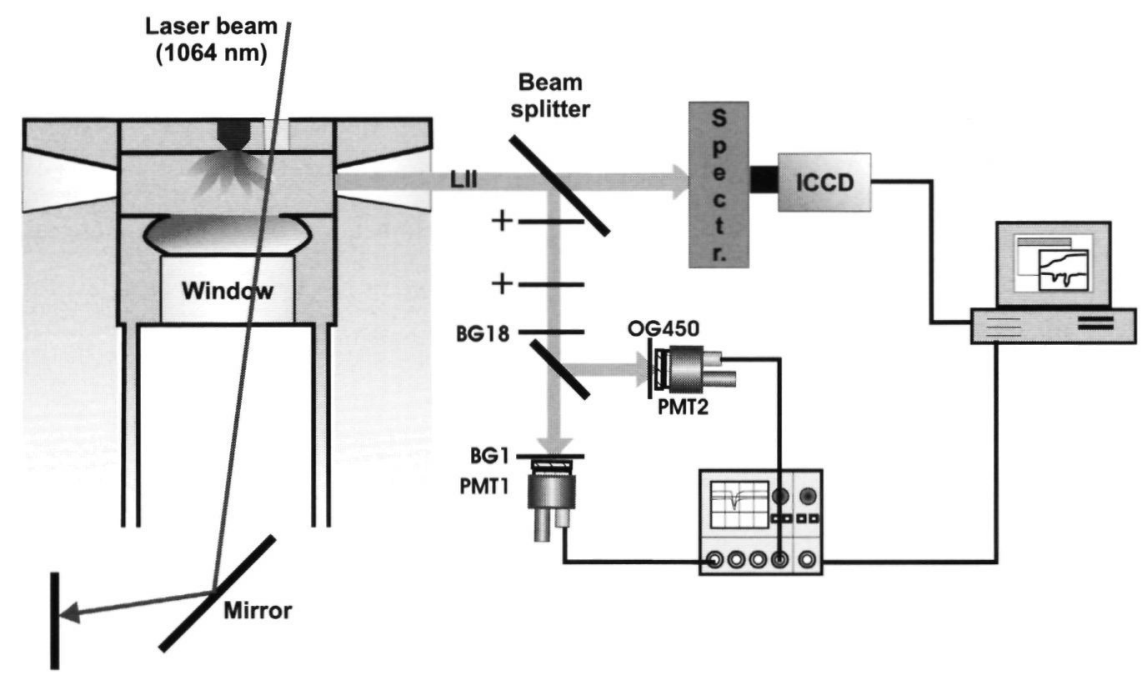

Figure 7.1: Schematic picture of the experimental setup.

Besides this, two quartz windows in the top of the cylinder wall provide a side view of the combustion chamber. One of the exhaust valves has been replaced by a quartz window to enable laser beams to pass top-down through the engine. The piston crown was provided with a slot to enhance optical access through the side window in the early phase of the combustion cycle. To reduce fouling of the quartz windows by soot, no lubricants were used to operate the engine. The engine is equipped with an in-line pump (start-of-injection at $5^{\circ} \mathrm{bTDC}$ ), and runs on commercial, low-sulphur Diesel fuel. Soot measurements were performed at two positions: between two sprays and through a spray (closed circle and open circle resp. indicated in Fig. 7.2).

The fundamental wavelength of a pulsed Nd:YAG laser $(\lambda=1064 \mathrm{~nm})$ was used to heat the soot inside the combustion chamber through the valve window. A laser fluence of $0.25 \mathrm{~J} / \mathrm{cm}^{2}$ (at the entrance window) was chosen to minimize fluctuations of the LII signal. Incandescence of the laser-heated soot particles was observed through one of the side windows both by an imaging grating spectrograph and by two band-pass-filtered photomultiplier tubes (PMTs). The entrance slit of the spectrograph was kept fully open to increase signal strength. An intensified CCD camera mounted on the exit port was used to read out the spectra of the LII signal. In separate experiments, the prompt LII signal was recorded over the wavelength range from $310 \mathrm{~nm}$ to $610 \mathrm{~nm}$ for successive injections. During each individual injection the spectrograph covered a range of $30 \mathrm{~nm}$. In this way it was revealed that there was no interference from any other species (precursors of soot, or Swan band emission of $\mathrm{C}_{2}$ ) for the chosen excitation wavelength. 

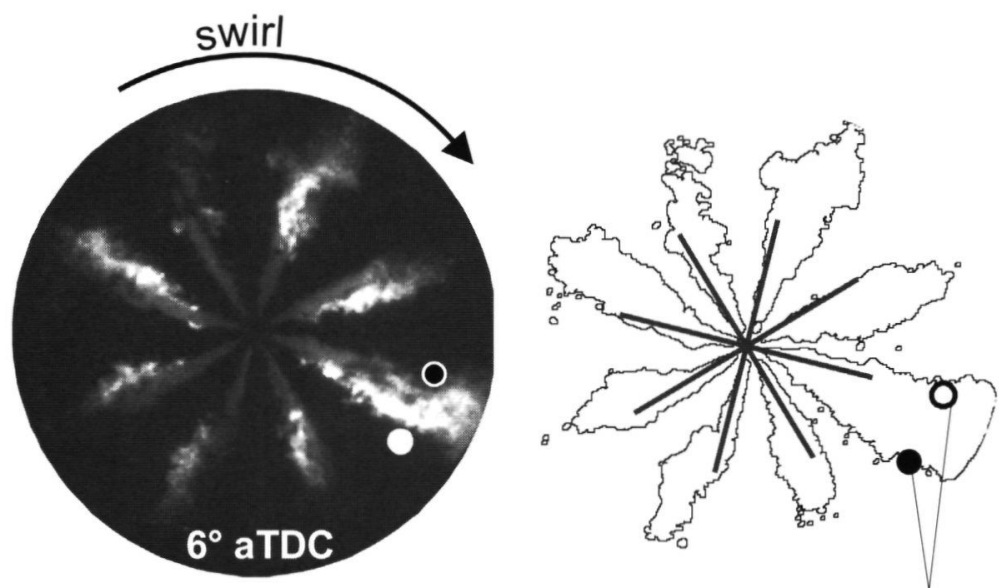

\section{probe locations}

Figure 7.2: Natural luminosity image recorded through the piston window, with indication of the two probe locations in the engine. At the right a contour plot in which the spray axes are indicated.

The TR-LII radiation was filtered by a Schott BG-18 filter, and imaged onto the PMTs by two spherical lenses. By using a beamsplitter the LII was split into two different beams and detected by two PMTs (Thorn EMI). The light registered by the PMT of type $9814 \mathrm{QB}$ was additionally filtered by a Schott BG1-filter before detection, and the light detected by the PMT of type 9863QA was filtered by a Schott OG450 filter. This resulted in two central detection wavelengths of $370 \mathrm{~nm}$ $(\mathrm{FWHM} 40 \mathrm{~nm})$ and $562 \mathrm{~nm}(\mathrm{FWHM} 50 \mathrm{~nm}$ ) respectively, taking into account the spectral sensitivity of the PMTs. The detected Tire-LII signal from the PMTs was displayed on a $300 \mathrm{MHz}(2.5 \mathrm{Gs} / \mathrm{s}$ ) digital oscilloscope (Lecroy 9630), digitized, and stored and analyzed on a PC.

Tire-LII measurements were performed for two engine loads; the corresponding cylinder pressures are shown in Fig. 7.3. The low engine load, from now on called $25 \%$ load, consisted of a boost pressure of 1.4 bar, inlet air temperature of $313 \mathrm{~K}$, and $62 \mathrm{mg}$ fuel injected per cycle. The higher engine load, from now on called $50 \%$ load, consisted of a boost pressure of 1.7 bar, inlet air temperature of $313 \mathrm{~K}$, and $96 \mathrm{mg}$ fuel per injection. In both cases, the engine ran at $1430 \mathrm{rpm}$, and the measurement cylinder was skip-fired (1:35, or about once per $3 \mathrm{~s})$. 


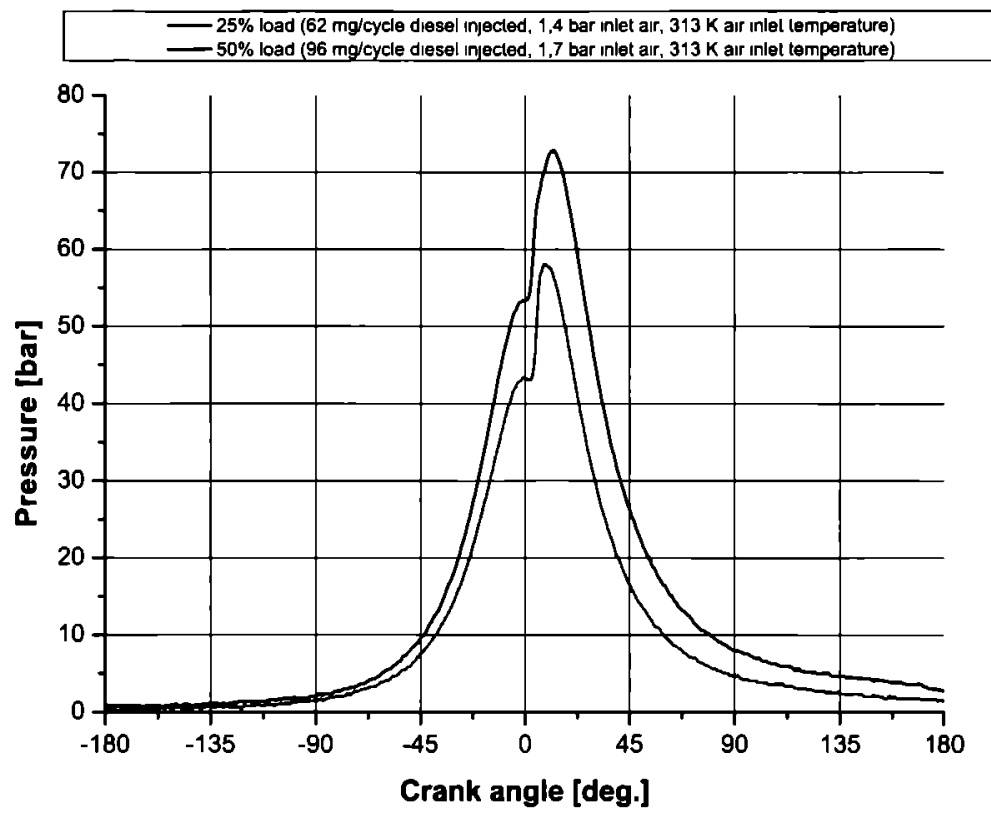

Figure 7.3: Pressure curves for the selected engine loads.

\subsection{Results and discussion}

The TR-LII light was simultaneously measured by two different PMTs. covering disjunct wavelength ranges. In the Rayleigh limit the tempcrature immediately after the laser pulse is independent of the particle size [13], but it does, of course, depend on the local laser power. It was calculated from the ratio of the pcak intensities (2-color pyrometry) to provide an initial tempcrature for the fit of the measured TR-LII curves [14]. The initial tcmpcrature varied between $2200 \mathrm{~K}$ and $3800 \mathrm{~K}$. probably as a result of variations in available laser intensity in the probe volume. due to beam profile and in-cylinder attenuation. However, the initial temperature has been shown not to be very critical for the calculation of the particle sizes from the TR-LII curves (Chapter 5). at least under the conditions that exist within the Diesel engine.

Under the conditions prevalent in the engine. the LII intensity decay was found to be so fast that the response time of the detection system and the finite duration of the laser pulse could not be neglected. Therefore. a Wiener deconvolution was made. which corrected the measured curves for the response time of the detection 
system (see Fig. 7.4).

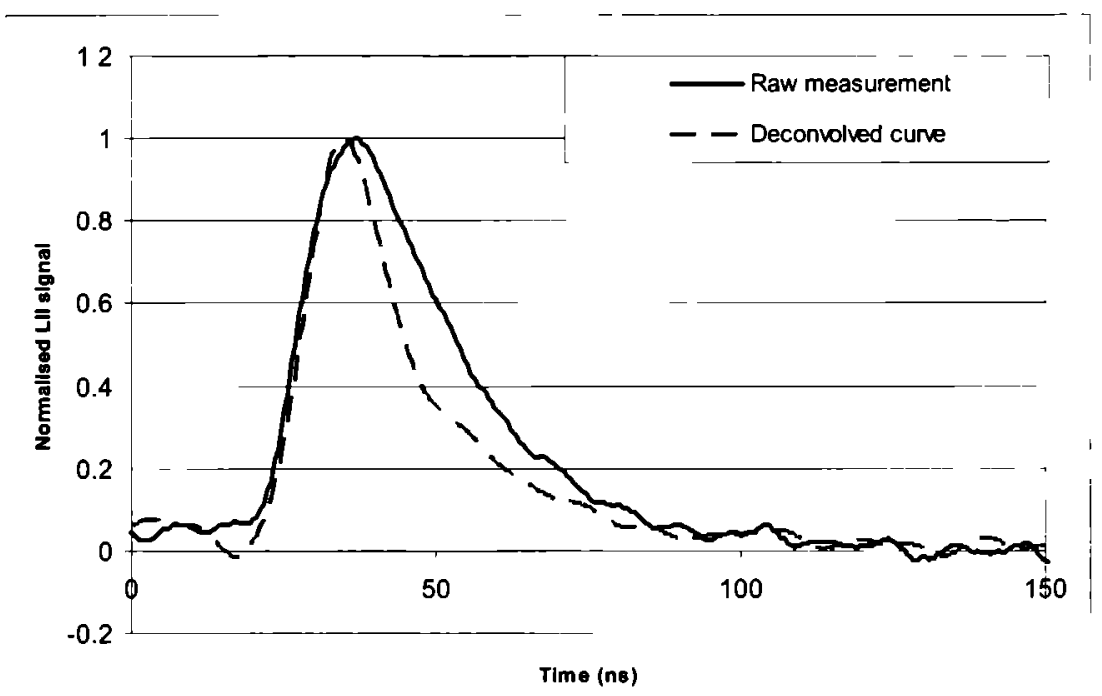

Figure 7.4: Example of the influence of the deconvolution on the measurement.

For each crank angle and each engine setting the measurement cylinder was fired 20 times. LII signal was observed for only part of the injections. Typically 2-6 injections out of 20 resulted in LII signal on both PMTs and on the spectrograph (Fig. 7.5). For the other injections no signal was observed, or, in rare cases, an LII-like signal was observed on only one of the PMTs and not on the spectrograph. These were regarded as spurious, and not included in the analysis. The relative paucity of useful LII data indicates that the soot formation in our engine is far from uniform and non-reproducible on the scale of our probe volume (estimated height $=10 \mathrm{~mm}$, diameter $=5 \mathrm{~mm}$ ).

In Fig. 7.6 the results of the radius as a function of the $\mathrm{CA}$ are presented for the different probe locations. Each data point corresponds to one instantaneous measurement (single laser pulse). In addition, the average value for the radius has been plotted together with the standard error of $r_{m}$ defined as

$$
S . E .=\frac{\sigma_{s t d}}{\sqrt{N}}
$$

in which $\sigma_{s t d}$ is the standard deviation of the $N$ measurements. The values for $\sigma_{m}$ were all found to fall in the range from $0.25-0.35$ (corresponding to a FWHM of the particle radius distribution of 10-35 nm, depending on the value of $r_{m}$ ). The fitted radii for the individual measurements have been plotted in the four different 


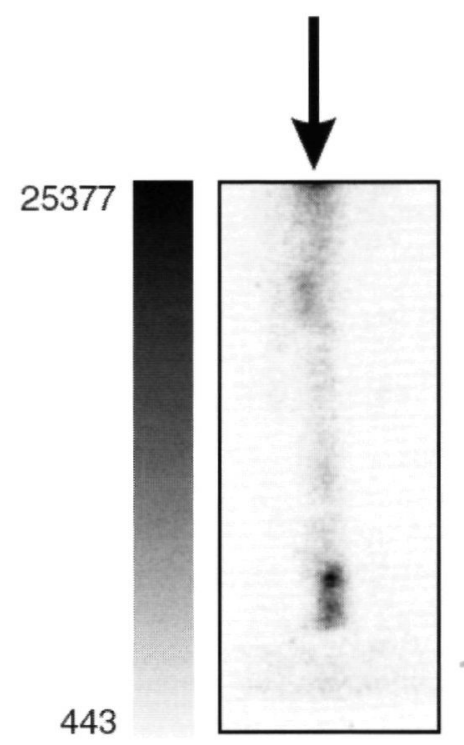

Figure 7.5: Image of line with glowing soot, which was hit by the laser, recorded through the side window. The gray scale indicates the intensity of the image, in arbitrary units. The arrow indicates the path of the laser beam.

graphs. An analysis of variance (ANOVA) showed that within a confidence interval of $95 \%$ the particle size cannot be considered to be constant as a function of crank angle for all engine conditions considered here.

The general trend in the mean particle size is shown by the trend lines in Fig. 7.6. It can be seen that the particle sizes increase during early stages of the combustion cycle and later on decrease again. Considering the $25 \%$ load case, it can be said that the particle size varies much more with crank angle for the 'through spray' than for the 'between sprays'location. Based on the trend lines in Fig. 7.6 it follows that in the 'through spray' location the maximum mean particle radius is a bit larger $(45 \mathrm{~nm})$ and reached a bit earlier in the stroke (at ca. $50^{\circ}$ aTDC) than in the 'between sprays' location (40 $\mathrm{nm}$ and ca. $70^{\circ}$ aTDC, respectively). The particle radii have not yet converged to the same limit at $100^{\circ}$ aTDC, indicating that the cylinder contents are not yet completely mixed by that time. For the $50 \%$ load case, maximum mean particle sizes and the crank angles at which they occur are similar, but the scatter in datapoints is larger than in the $25 \%$ load case. The latter is probably due to increased attenuation. (Although signal strength should not affect the decay times, there is of course a $\mathrm{S} / \mathrm{N}$ issue.)

Particle sizes could not be derived before $10^{\circ}$ aTDC in the $25 \%$ load case, and before $18^{\circ}$ aTDC in the $50 \%$ load case. Earlier in the stroke, the LII intensities were below 


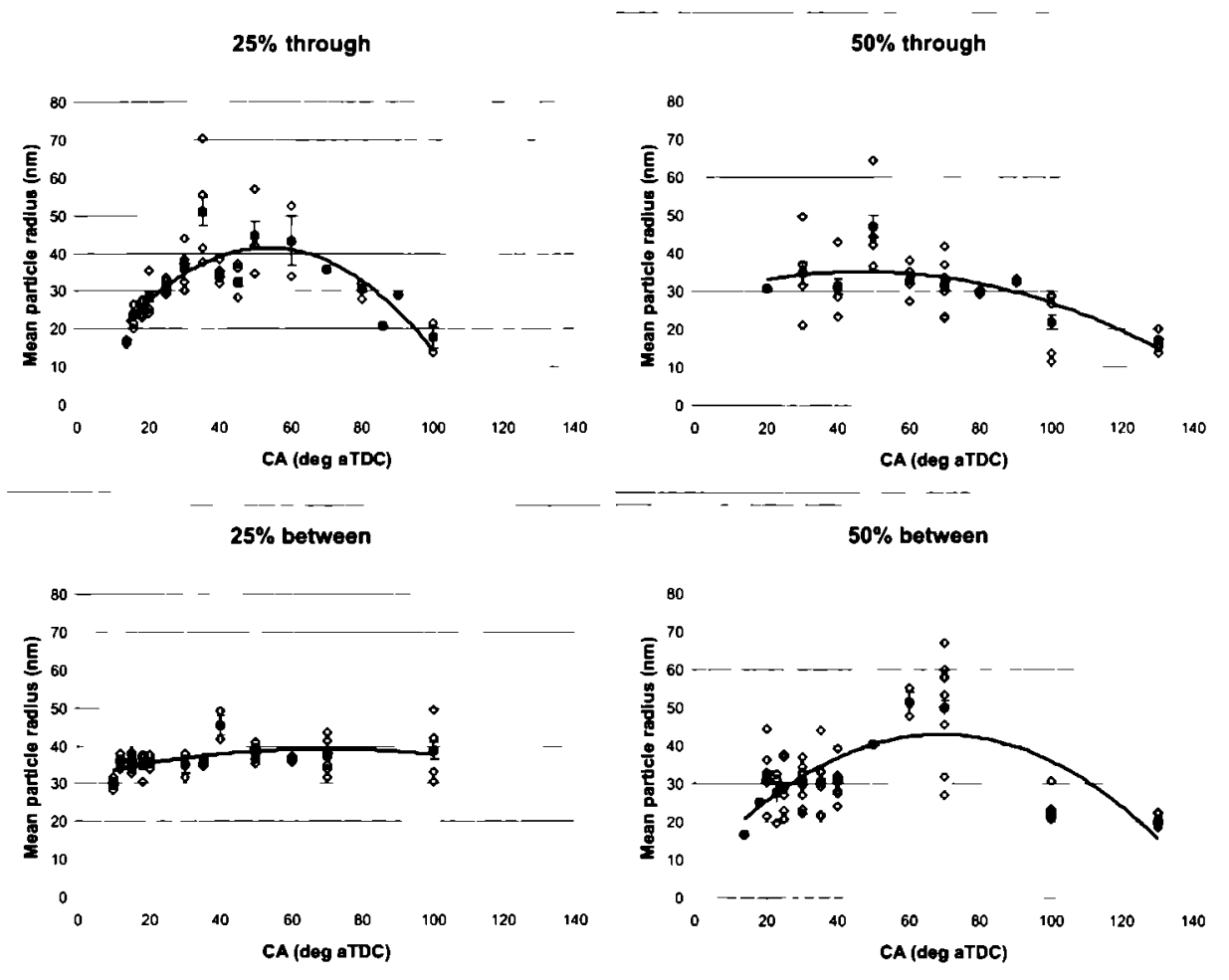

Figure 7.6: Mean particle sizc as a function of crank angle for the different engine loads and different probe locations. The open rhombi indicate the separate measurements, and the closed circles indicate the average values of the measurements during each cycle. The error bars around the latter indicate the standard crror in the measurements. Trend lines have been included for all graphs.

our detection limit. Late in the stroke (above ca. $100^{\circ}$ aTDC) the LII intensitics also declined, resulting in useful data only for the 50\% load case. From Fig. 7.3 it follows that combustion starts at about $1^{\circ}$ aTDC. and maximum heat release occurs at $5^{\circ}$ aTDC in the $25 \%$ load case and at $3^{\circ}$ aTDC in the $50 \%$ load case. The lower limits for the crank angle at which soot could be detected correspond closely to the maxima in the pressure curves.

The trend lines included in Fig. 7.6 show some variation for the four measurement series. In the $25 \%$ load 'through spray' and the $50 \%$ 'between sprays' cases the mean particle size $r_{m}$ starts small. goes through a maximum and declines again with increasing crank angle. For the other two cases. this behaviour is suggested. but much less evident. Several explanations are available for such a trend. Spcaking 
strictly in engine terms (see e.g. Heywood [15]), soot particles are expected to be formed from scratch, so to start small, then to grow in size and number as the combustion stroke proceeds, but to decrease in size (and number?) again later in the stroke, as the formation has stopped but the oxidation continues. This coursc of events is in agrcement with the trends observed in Fig. 7.6. There are, however, also some experimental issues, although these are more speculative. On the one hand, the contribution of individual laser-heated particles to the LII signal scales with the square of the radius (surface emitters). Thus, LII is predominantly sensitive to the larger particles. This is to some extent taken into account by the assumption of a particle size distribution, but it should be kept in mind that the actual shape of the distribution is not known. On the other hand, Diesel soot exists as agglomerates of morc-or-less spherical primary particles. Although LII is often claimed to yield information on only the primary particle size, the compactness of the particles is not irrelevant [16]. Loose, chain-like aggregates will be represented more accurately by the sum of the individual primary particles than do compact, ball-like agglomerates (sce the TEM pictures in Vanderwal [17] and Kock [5]). Thus, the curves in Fig. 7.6 are biased towards larger primary particles, and may also reflect the effect of agglomeration during the early combustion phase, rather than actual growth of primary particles. Similarly, the decline of the curves later in the stroke can indicate the oxidation of primary particles or agglomerates, but also the break-up of agglomerates into smaller and perhaps less compact fragments. There is some indication that at least later in the stroke (the exhaust valve opens at $130^{\circ}$ aTDC) the LII data do indecd represent primary particle sizes, as they compare well with TEM data on Diesel soot $[5,18]$.

The only other study of in-cylinder Dicsel soot particles known to us [5] has shown similar trends and size distributions, with relatively little variation as a function of crank anglc. Unfortunately, type of fucl and probe volume location relative to the sprays are not indicated in this paper.

\subsection{Conclusions}

Two-color time-resolved laser-induced incandescence (TR-LII) measurements have been performed in a production-type heavy duty Diesel engine running on lowsulphur 'city Diesel' fuel. The prompt LII signal measured in two disjunct wavelength bands was used to estimate the initial temperature of the Nd:YAG-laserheated soot particles. The finite duration of the laser pulse and the detection system have been taken into account explicitly by deconvolution. When interpreted in terms of primary particle sizes, the trends observed under conditions of different engine load and probe volume location indicate that the mean particle radius first grows to about $40 \mathrm{~nm}$, and then decreases with increasing crank anglc. 


\section{Acknowledgments}

The authors are very grateful for the help in the modeling part from B. Kock and P. Roth. This research is supported by the Technology Foundation STW. applied science division of NWO and the technology program of the Dutch Ministry of Economic Affairs. 


\section{Bibliography}

[1] D.B. Kittclson (1998): Engines and nanoparticles: A review. J. Aeros. Sci. 29 (5-6), 575-588.

[2] G. Bruncaux (2001): A studly of soot cloud structure in high pressure single hole common rail Diesel injection using multi-layered laser-induced incandescence. In: COMODIA, 622-630.

[3] D. Siebers and D. Higgins (2001): Flame lift-off on direct-injection Dicsel sprays under quiescent conditions. SAE Tech. Pap. Scrics 2001-01-0530.

[4] U. Mathis, M. Mohr, R. Kacgi, A. Bertola and K. Boulouchos (2005): Influence of diesel engine combustion parameters on primary soot particle diameter. Environ. Sci. Technol. 39 (6), 1887-1892.

[5] B.F. Kock, Th. Eckhardt and P. Roth (2002): In-cylinder sizing of Diesel particles by timc-rcsolved laser-induced incandescence (TR-LII). In: Proc. Combust. Inst. 29 (2), 2775-2781.

[6] S. Will, S. Schraml. K. Bader and A. Leipertz (1998): Performance characteristics of soot primary particle size measurements by time-resolved laser-induced incandescence. Appl. Opt. 37 (24). 5647-5658.

[7] G.J. Smallwood, D.R. Snelling, F. Liu and Ö.L. Gülder (2001): Clouds over soot evaporation: Errors in modeling laser-induced incandescence of soot. J. Heat Transfer 123 (4). 814-818.

[8] H. Bockhorn, H. Geitlinger. B. Jungfleisch, Th. Lehre. A. Schön. Th. Streibel and R. Suntz (2002): Progress in charactcrization of soot formation by optical methods. PCCP 4 (15). 3780-3793.

[9] H. Michelsen (2003): Understanding and predicting the temporal response of laser-induced incandescence from carbonaceous particles. JCP 118 (15). 70127045 .

[10] B.F. Kock and P. Roth (2003): Two-color TR-LII applied to in-cylinder diesel particle sizing. In: Proc. European Combustion Mecting. pap. (093. 
[11] B. Bougie, L.C. Ganippa, A.P. van Vliet, K. Verbiezen, N.J. Dam. W.L. Meerts and J.J. ter Meulen (2005): Soot characterization with lascr-induced incandescence in a heavy-duty Diesel engine. In: Proc. European Combustion Meeting, pap. 166.

[12] M.M.R. Williams and S.K. Loyalka (1991): Aerosol Science Theory and Practice, With Special Applications to the Nuclear Industry, Pergamon Press, Oxford.

[13] P. Roth and A.V. Filippov (1996): In situ ultrafine particle sizing by a combination of pulsed laser heatup and particle thermal emission. J. Acrosol Sci. 27 (1) 99-104.

[14] S. de Iuliis, M. Barbini, S. Benecchi, F. Cignoli and G. Zizak (1998): Determination of the soot volume fraction in an ethylene diffusion flame by multiwavelength analysis of soot radiation. Combust. Flame 115 (1-2), 253-261.

[15] J.B. Heywood (1988): Internal Combustion Engine Fundamentals. McGraw Hill. 1988.

[16] F. Liu. G.J. Smallwood and D.R. Snelling (2005): Effects of primary particle diameter and aggregate size distribution on the temperature of soot particles heated by pulsed lasers. J. Quant. Spec \& Rad. Trans. 93 (1-3), 301-312.

[17] R.L. Vanderwal, T.M. Ticich and A.B. Stephens (1999): Pulsed laser heating of soot: morphological changes. Combust. Flame 116 (1-2), 291-296.

[18] K. Park. D.B. Kittelson and P.H. McMurry (2004): Structural propertics of dicsel exhaust particles measured by transmission electron microscopy (TEM): Relationships to particle mass and mobility. Aerosol Sci. Technol. 38 (9). 881889 . 


\section{Chapter 8}

\section{TR-LII at high injection}

\section{pressure}

\subsection{Introduction}

The present chapter describes the results of particle size measurements which have been performed in the heavy-duty Diesel engine. equipped with a common-rail injection system. The advantage of a common-rail fuel system is that a permanent high injection pressure (1000-2000 bar) is present in the fucl line during the complete fuel injection period. (See also the monitored pressure trace in Fig. 4.5.) The injection pressure is built up with a separate fuel pump system. A higher injection pressure leads to a better atomization behavior of the Diesel fuel. which results in a better mixing behavior between fuel and air. and might result in the production of less soot [1] and smaller diameters of the soot particles.

Lepperhoff [2] investigated the in-cylinder soot particle size distribution and soot volume fraction in an engine equipped with a common-rail system. betwcen two fucl sprays by sampling part of the gas fuel mixture through a valve in the head of the cylinder and measured the soot particle size distribution with a scanning mobility particle sizer (SMPS). A disadvantage of this system is that this sampling technique is intrusive and that the measurement is not spatially resolved. In addition. the question is what the influence of the tubing between the sample valve and the particle sizer on the measurcd particle size distribution and the soot volume fraction is. The maximum soot volume fraction was found at about $20^{\circ}$. The maximum diameter which he measured was $105 \mathrm{~nm}$ at $25^{\circ}$ aTDC. It is not clear from the article how the $10^{\circ}$ sampling time is related to this moment. After $25^{\circ}$ a decrcasc in the particle size was found due to oxidation of the soot. in combination with a decrcase in the particle number. Measurements in the exhaust of the engine showed a particle size distribution that was similar to the in-cylinder particle sizc distribution in later phascs of the combustion cycle. Lepperhoff also measured the 
particle size distribution for different types of engines. An old type of engine with the so-called indirect injection systcm. which is an engine wit a pre-combustion chamber in which the Diesel gets the possibility to start the combustion after which it goes into the real combustion chamber and the more modern engines equipped with a common-rail systcm with a high injection pressure. He found that the more modern engines emit slightly approximately two times larger particles than the older engines. In addition, the more modern type of engines produce about $50 \%$ less particles.

Khatchigian [3] investigated the influence of the injection pressure on the soot concentration and particle size distribution in the exhaust of a 6 cylinder $3 \ell$ directinjected passenger car engine with a common-rail injection system. Part of the exhaust gases was diluted and guided through a SMPS. He found a log-normal shaped particle sice distribution in the exhaust of the engine. which was independent on the injection pressure in a range between $250 \quad 1600$ bar. The particle size decreased with increasing injection pressurc. The particle number density decreased with increasing injection pressure as well.

\subsection{Experimental setup}

The common-rail injector has becn mounted on a Bosch holder (type CR-12.8.1injector B2-sample). and has been provided with a needle displacement sensor (type: U05. constructed by Micro-Epsilon). TR-LII measurements have been performed for two cngine loads. The same values for the boost pressure have been used as for the line-pump measurcments: 1.4 bar and 1.7 bar and the same quantitics of fucl have been injected. The injection period for the first boost pressure was from $8^{\circ}$ bTDC until $2^{\circ}$ aTDC in the first case. corresponding to a $25 \%$ enginc load. The injection period was from $8^{\circ}$ bTDC until $12^{\circ}$ aTDC in the latter case corresponding to $50 \%$ load. In both measurement conditions the injetcd amount of fuel corresponds to the line-pump conditions (62 $\mathrm{mg}$ and $96 \mathrm{mg}$ per injection). The injection pressure was set to 1200 bar for both engine settings. Figurc 8.1 shows the pressure curves for the two engine loads. It can be seen that the peak pressure in the $50 \%$ load case is slightly lower in comparison with the peak pressure in the line-pump case (Fig. 7.3). The peak pressures for the lower load case are in both situations comparable. The optical arrangement of the experimental setup for the TR-LII measurements has been described elaborately in Chapter 6 and 7 and will not be repeated here. The measurements have been performed at two positions. like in the case with the linc-pump measurements: both at the extension of one of the fucl sprays and exactly in the middle between two fucl sprays.

\subsection{Results and discussion}

The measured TR-LII curves which have been measured for the two loads have becn analyzed in the way described in Chapter 6 . The signal was in general weaker than 


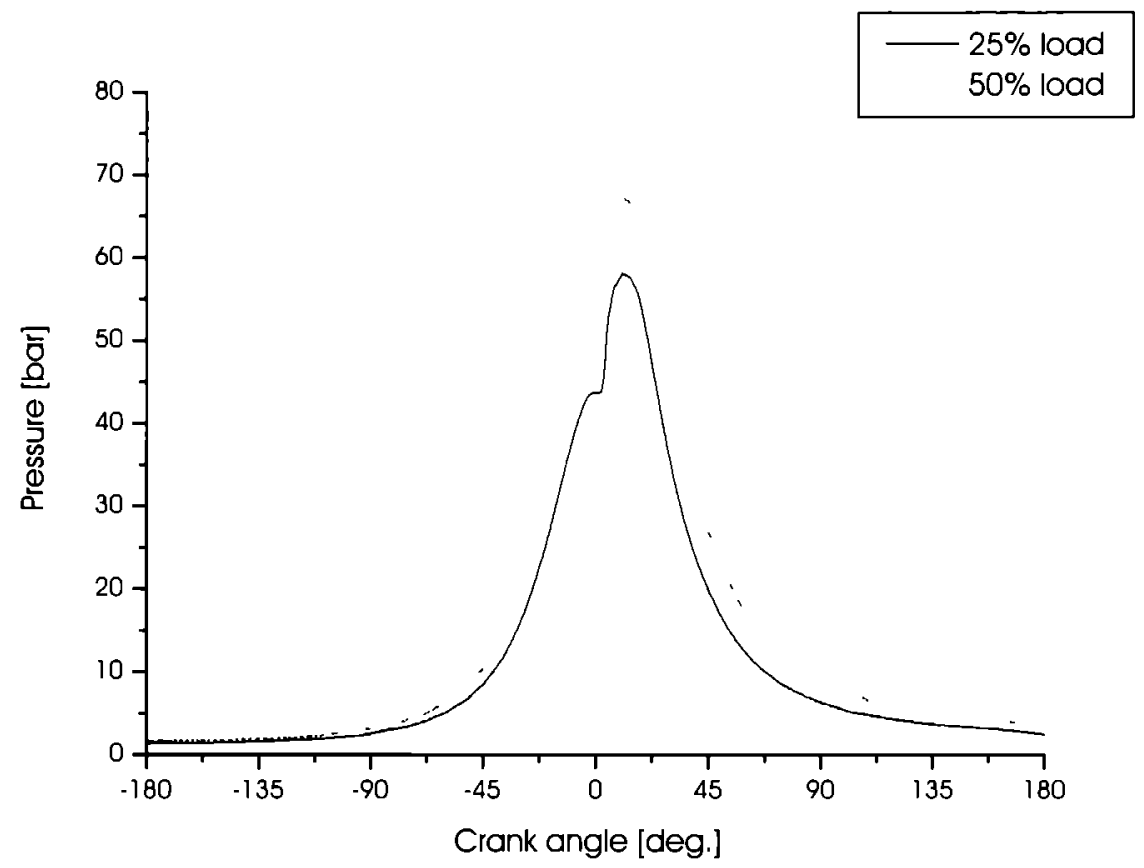

Figure 8.1: The pressure curves for the TR-LII measurements at the selected engine loads for the common-rail pump.

the signal measured with the line pump systcm indicating a smaller soot volume fraction. The obtained mean particle size as a function of the crank angle is plotted in Fig 8.2. The open symbols represent the rcsults of the individual measurements. showing the cycle-to-cycle fluctuations. For each crank angle the average valuc of the individual measurements is indicated with a closed symbol. Due to technical problems the " $25 \%$ through spray" case is only represented by a limited number of measurcment points. As a consequence, it is impossible to draw conclusions at that measurement condition. For the other measurement conditions, the trend-lines have been added in the graphs. For all three situations the trend is comparable to the trend. found with the line-pump system (Chapter 7). The first particles can be detected at around $10^{\circ}$ aTDC. An increase in particle size can be secn until about $40^{\circ}$ and afterwards a decrease in particle size. Also, the particle size is comparable for both injection systcms, with a maximum mean soot particle radius of about $40 \mathrm{~nm}$. although the $" 50 \%$ through spray case shows some bigger fluctuations. Apparently. independent of the injection pressure. the primary particle size does not change. using the line-pump or the common rail system. which confirms the measurements by Khatchigian [3]. However, as he measured the soot particle size distribution in 
the exhaust it is questionable whether the in-cylinder soot particle size distribution is the same as the soot particle size distribution in the exhaust. The explanation for the weaker signal is probably causcd by a smaller number of primary soot particles. present in the measurement volume.

Lepperhoff [2] found that the number of particles created in an engine with a higher injection pressure is smaller than the number of particles created in an engine with a lower injection pressure. Our measurements confirm that the number of the particles which is created with the line-pump system is bigger than with the common-rail pump system, because in general the TR-LII signal was weaker in the latter case but the primary particle size does not deviate that much within the statistical error of the mcasurements betwcen the two measurement conditions. However, the particle size created in an engine with a higher injection pressure measured by Lepperhoff is slightly smaller in comparison with the particle size created in an engine with a lower injection pressure. He investigated the shape of the agglomerates in the exhaust. by sampling exhaust gas and observing the soot samples in a transmission electron microscope. The primary particle size measured in the cylinder during later stages of the combustion cycle is the same as the particle size mcasured in the exhaust of the engine. Another finding was that the particles measured in the exhaust are chain-wise connected spherical primary particles. The outcome of our primary particle size measurements is slightly smaller than the results of Lepperhoff [2]. An explanation can be that Lepperhoff's measurements have not been performed $\imath n$-situ. The sampling tube can have influenced the measured particle sizc. The measurements performed in the exhaust are also an average of the complete combustion cycle which can also be an explanation for the size difference betwcen our results and his. An additional explanation for the deviation might be that he used a different type of Diesel. but unfortunately that is not indicated in his paper.

\subsection{Conclusions}

Our measurements show that within the statistical error of the measurements the primary particle size is not influenced by the injection pressure. Both the line-pump and the common-rail injection system show similar trend lines for the mean particle sizc. The first detection of soot takes place at about $10^{\circ}$ aTDC and an increase in particle size can be obscrved until about $40^{\circ}$ aTDC. After that moment a decrease in particle size has been measured. 


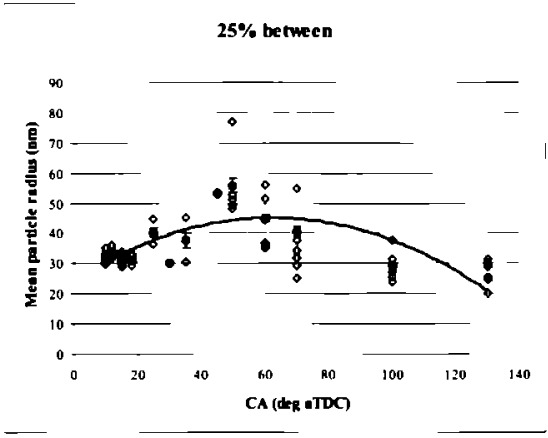

$50 \%$ through

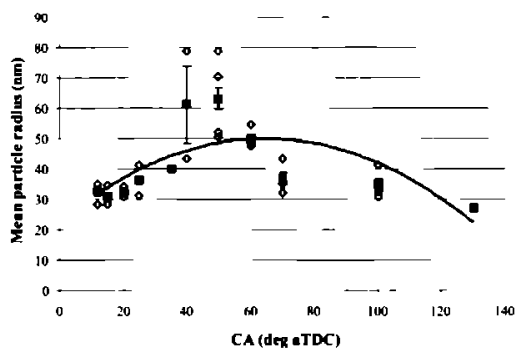

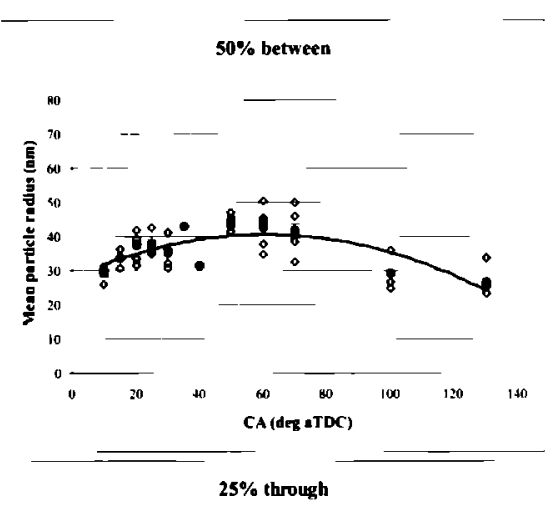

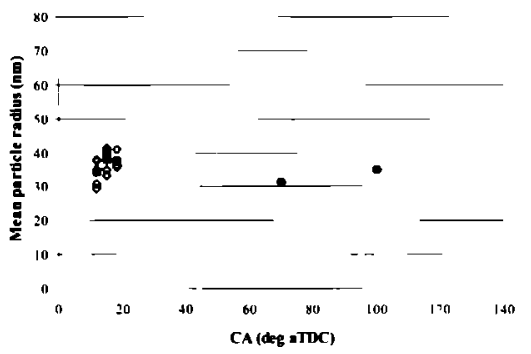

Figure 8.2: Measured particle radius as function of the crank angle for different engine loads. The two spray positions are indicated in the graphs. 


\section{Bibliography}

[1] A.H. Lefebvre (1989): Atomization and Sprays. Hemisphere Publishing Comp. New York.

[2] G. Lepperhoff (2001): Influcnces on the particle size distribution of dicsel particulatc cmissions. Topics in Catalysis 16-17 (1-4). 249-254.

[3] P. Khatchikian (2002): Dependence of particle size distribution on injection pressurc. Report Bosch. Germany.

[4] H. Bockhorn (1994): Soot Formation in Combustion. Springer Verlag. 


\section{Chapter 9}

\section{Conclusions and outlook}

The present disscrtation shows the results of timc-resolved laser-induced incandescence (TR-LII) measurements for the in-situ measurement of the soot particle size distribution in the combustion chamber of a heavy-duty Diesel engine. The results can be used by modelers in order to verify and improve their models on the soot formation mechanism in a heavy-duty Diesel engine. During early stages of the combustion cycle. first an increase in soot particlc size can be observed and a dccrease in diameter later on during the combustion cycle. This would point in the dircction of the correctness of the model proposed by Bockhorn [1]. described in Chapter 1: an incrcase in diameter due to agglomeration early in the combustion cycle and a decrease in diameter due to oxidation later on. The mean particle size is in good agrecment with what other researchers found during their measurements [2, 3]. Boiarciuc et al. [3], however, observed the soot however earlier during the combustion cycle (starting at $6^{\circ}$ aTDC), for similar engine conditions. They observed the maximum mean particle size at about $16^{\circ}$, which is earlier in comparison with our findings (about $40^{\circ}$ a TDC). The primary particle size does not depend drastically on the injection pressure. changing from the in-line pump system to the common-rail injection system. which is in agrcement with what other researchers found with in-cylinder measurements.

In the analysis of the measurements described in the present dissertation. the absumption has always been. that the TR-LII cooling behavior is dependent on the primary particle size and not on the agglomerate structure of the particles. because particles have been assumed to be chain-wise and point-wise connected to each othcr. Transmission electron microscopy images by Kock et al. [6] have shown that this is a correct approach for Diescl soot. The particles are point-wise connected with each other and not in a dense cloud. Furthermore, they showed [7] that the treatment of TR-LII signals on basis of spherical primary particles is a correct approach for particles which have such an aggregate structure.

However, the growth to bigger. more compact aggregate structures will result in a shielding effect of the primary particles. decelerating the cooling process of the 
individual primary particles. Liu et al. [8] introduced the fractal dimension of the particles in the model of the particle cooling mechanism. At atmospheric pressure they found a strong dependence of the particle temperature on both the primary particle size and the aggregate size distribution. They found that the temperature of particles which are more in the center of complex aggregates - which. consequently, have less contact with the ambient environment - cxhibit a different cooling behavior compared to the particles which are more at the outer side of the aggregate. The strong dependence can also be present at elevatcd pressures. However, as exhaust gas measurcments have shown that the primary particles are chain-wise and pointwise connected [5.6]. there is no necd to implement a complex aggregate structure in the TR-LII cooling model on Diesel soot [7]. and the approach, that the size of the spherical primary particles detcrmines the cooling behavior of the heated soot particles in the engine. seems to be a correct approach.

At this moment there are some other uncertainties in the TR-LII modeling which have to be clarified. A few of them are summarized here. A more elaborate description can be found in Chapter 3. First of all. there is a big uncertainty in the thermal accommodation coefficient. which plays a major role in the cooling term for conduction in most cooling models. Secondly, what is the matcrial bchavior of soot? Is soot mainly composed of carbon? Docs soot cvaporate or sublimate. if it is heated to high temperatures? What are relevant cooling processes [9]? And how can the cooling processes be described best [10]?

However. though there are still uncertainties in the TR-LII models. this dissertation shows that TR-LII is a powerful technique which can be applied $i n-s t u$ in a highpressure environment. like the Diesel engine. The applicd measurement approach for TR-LII can be used as well for in-situ investigation of the soot formation process in gasoline and newer type engines. like the homogencous charge compression ignition engine or in the rescarch for bio-fucls or other alternative fuels.

The present LII measurements were more or less point measurements. In the future the possibility of extending the measurement technique to a cross-scetion should be investigated. A first approach in this direction has been made by Boiarciuc et al. [3]. This group performed soot volume fraction measurements in a slice and measured simultaneously a local particle size distribution. With intelligent detection systems. a measurement of a $2 \mathrm{D}$ particle size distribution can perhaps be acquired. which will give more detailed information about the soot formation process in a Diescl flame. The power of (almost) simultaneous measurements (LII. shadowgraphy, elastic light scattering natural cmission) in the Diesel spray in a constant volume environment is shown in Chapter 4. A next step should be the application of a combination of the measurement techniques in the engine environment. This can lead to a better understanding of the soot formation and combustion process in the engine. in order to reduce the particulate cmission from engines. 


\section{Bibliography}

[1] H. Bockhorn (1994): Soot Formation in Combustion. Springer Verlag.

[2] B.F. Kock and P. Roth (2003): Two-color TR-LII applicd to in-cylinder Diesel particle sizing. In: Proc. European Combustion Meeting 2003. paper 093.

[3] A. Boiarciuc, F. Foucher and C. Mounaim-Rouselle (2006): Soot volume fractions and primary particle size estimate by means of the simultaneous twocolor-time-resolved and 2D laser-induced incandescence. Appl. Phys. B 83 (3), 413-421.

[4] T. Kim. S-M. Suh. S.L. Girshick. M.R. Zachariah, P.H. McMurrya, R.M. Rassel, Z. Shen and S.A. Campbell (2001): Particle formation during low-pressure chemical vapor deposition from silane and oxygen: Measurement, modeling, and film properties. J. Vac. Sci. Technol. A 20 (2), 413-423.

[5] R.L. Vanderwal. T.M. Ticich and A.B. Stephens (1999): Pulsed laser heating of soot: morphological changes. Combust. Flame 116 (1-2). 291-296.

[6] B.F. Kock, Th. Eckhardt and P. Roth (2002): In-cylinder sizing of Diesel particles by time-resolved laser-induced incandescence (TR-LII). In: Proc. Combust. Inst. 29 (2), 2775-2781.

[7] B.F. Kock. C. Kayan, J. Knipping. H.R. Orthner and P. Roth (2005): Comparison of LII and TEM sizing during synthesis of iron particle chains. In: Proc. Combust Inst. 30. 1689-1697.

[8] L. Liu. G.J. Smallwood and D.R. Snclling (2005): Effects of primary particle diameter and aggregate size on the temperature of soot particles heated by pulsed lasers. J. Quantum Spectrosc. Radiat. Transf. 93 (1-3), 301-312.

[9] H. Michelsen (2003): Understanding and predicting the temporal response of laser-induced incandescence from carbonaceous particles. JCP 118 (15). 70127045.

[10] C. Schulz, B.F. Kock, M. Hofmann, H. Michelsen, S. Will, B. Bougie, R. Suntz and G. Smallwood (2006): Lascr-induced incandescence: recent trends and current questions. Appl. Phys. B 83 (3). 333-354. 


\section{Appendix A}

\section{Annealing and oxidation}

This appendix describes the influence of the extra heat-transfer terms introduced by Michelsen [1]. in her LII model. which is the most elaborate one which is present. It introduces additional heat transfer terms for annealing and oxidation of the soot particles in comparison with the Melton model [2]. As a result the energy balance for the "Michelsen model" is defined as

$$
\frac{d\left(m_{p} C_{p} T_{p}\right)}{d t}=\dot{q}_{a b s}-\dot{q}_{c o n d}-\dot{q}_{s u b}-\dot{q}_{r a d}+\dot{q}_{a n n}+\dot{q}_{o x} .
$$

in which the latter two terms are the heat rise by annealing and oxidation succcssively. Annealing is an exothermic process which changes the structure of the soot particles to a more ordered phase [1]. The oxidation process is an additional cxothermic process. During the oxidation process it is assumed that $\mathrm{CO}$ is produced, exclusively. close to the surface of the soot particle, from the $\mathrm{C}$ which is present in the soot particle. In this appendix, an estimation of the influcnce of the extra terms on the heat transfer efficiency is given.

\section{A.1 Annealing}

The effect of annealing to a morc structured soot particle is considered in the model by [1]

$$
\dot{q}_{a n n}=-\frac{-\Delta H_{\imath m \imath g} k_{\imath m \imath g} N_{d}-\Delta H_{\imath^{\prime} m \imath q} k_{v \imath m g} N_{d}}{N_{a}} .
$$

in which $N_{a}$ is Avogadro's constant and $\Delta H_{\imath m \imath q}\left(=-1.9 \cdot 10^{4} \mathrm{~J} / \mathrm{mol}\right)$ is the estimated enthalpy for interstitial migration. This is the effect of crystallization of the soot particles [3]. $\Delta H_{v m \imath g}\left(=-1.4 \cdot 10^{5} \mathrm{~J} / \mathrm{mol}\right)$ is the enthalpy for vacancy migration. $k_{\imath m \imath g}$ is the rate constant for interstitial migration and $k_{\imath \text { mag }}$ is the rate constant 


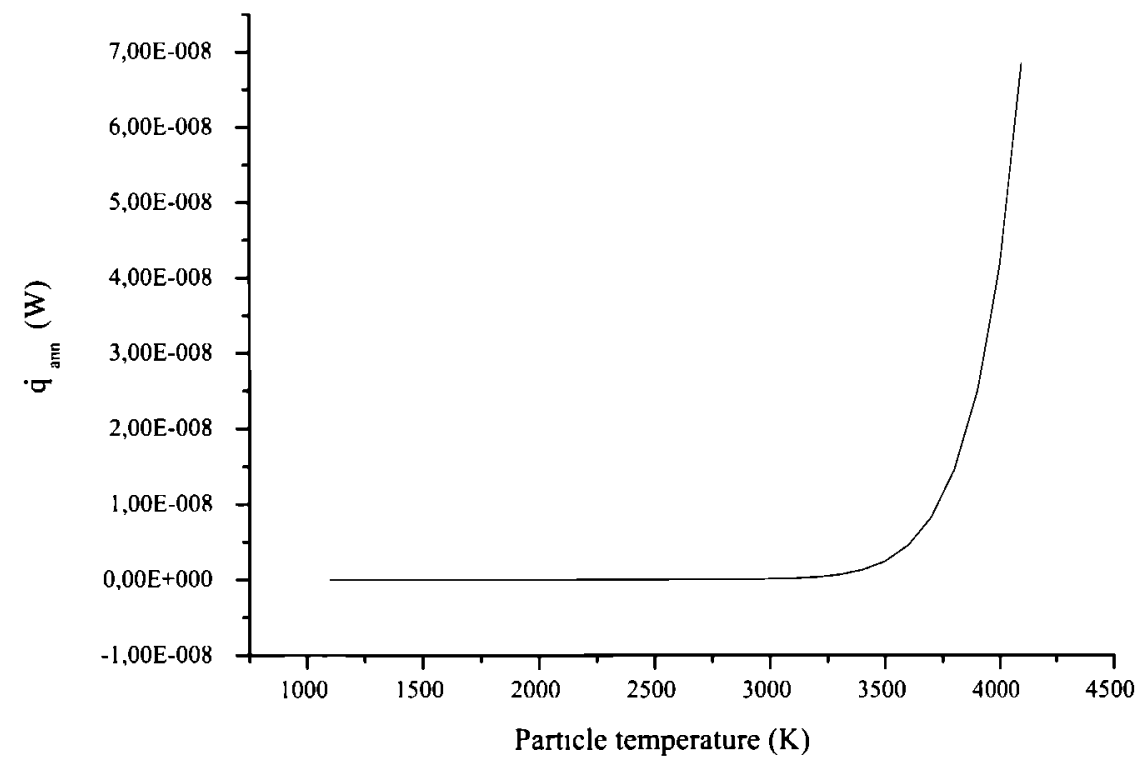

Figure A.1: Calculated heat increase rate by annealing according to Michclscn [1] as a function of the initial temperature for a particle with a radius of $25 \mathrm{~nm}$ at an ambient condition of $1000 \mathrm{~K}$.

for vacancy migration. Both are calculated from an Arrhenius relation [1]

$$
k_{r x n}=A_{r x n} \exp \left(\frac{-E_{r x n}}{R_{m} T}\right),
$$

of which the constants $A_{r x n}$ and $E_{r \times n}$ can be found in the list of symbols. $N_{d}$ is the number of lattice defects in the particle, which is solved by [1]

$$
\frac{d N_{d}}{d t}=X_{a n n} \frac{N_{C}}{2} k_{d \imath s,}-k_{\imath m \imath g} N_{d}-k_{v m \imath g} N_{d} .
$$

in which $k_{\text {drss }}$ is the rate constant for pyrolysis of the annealed particle, calculated with Eq. A.3. $X_{a n n}$ is the mass fraction annealed, which is calculated with [1]

$$
X_{a n n}=1-\frac{N_{d}}{X_{d} N_{C}} .
$$

in which $X_{d}$ is the initial defect fraction $\left(1 \cdot 10^{-2}\right.$ [4]. estimated from electron spin resonance measurements). $N_{C}$ is the number of C-atoms in the particle. calculated by

$$
N_{C}=\frac{M N_{a}}{W_{1}}
$$


in which $M$ is the soot particle mass and $W_{1}$ is the molecular wcight of C. Figure A.1 gives the calculated heat-flow as a function of the particle temperature for a particle with a radius of $25 \mathrm{~nm}$ at an ambient temperature condition of $1000 \mathrm{~K}$. It can be seen that the heat-change in comparison with the heat-flow by conduction is negligible. even at a particle temperature above $4000 \mathrm{~K}$.

\section{A.2 Oxidation}

The effect of oxidation considers

$$
\mathrm{C}(\mathrm{s})+\mathrm{O} \rightarrow \mathrm{CO}
$$

The heat-flow induced by this reaction is calculated by

$$
\dot{q}_{o x}=\left(-\Delta H_{o x}-2 \alpha_{T} C_{P}^{C O} T_{p}\right) \frac{4 \pi r_{p}^{2} k_{o x}}{N_{a}} .
$$

in which $\Delta H_{o x}$ is the enthalpy of reaction, $\alpha_{T}$ is the thermal accommodation coefficient. $C_{P}^{C O}$ is the molar heat capacity of $\mathrm{CO}$. The rate constant $k_{o x}$ is calculated from [1]

$$
k_{o x}=k_{o x, u n}+k_{o x, a n},
$$

in which $k_{o x, u n}$ is the rate constant for the unannealed fraction of the particle and $k_{o x, a n}$ is the rate constant for the annealed fraction of the particle. The rate constant for the unannealed part is calculated with

$$
k_{o x, u n}=12 P_{O_{2}}\left[\frac{k_{a} \chi_{A}}{1+k_{Z} P_{O_{2}}}+k_{l}\left(1-\chi_{A}\right)\right]\left(1-X_{a n n}\right) .
$$

in which $P_{\mathrm{O}_{2}}$ is the partial pressure of oxygen (0.209 bar at ambient condition), $k_{a}$ is the rate constant for oxidation at active sites (possibly a defect site for which the reaction probability is higher than on a perfect basal plane). given by [1]

$$
k_{a}=5.0 \cdot 10^{23} \operatorname{cxp} \frac{-1.255 \cdot 10^{5}}{R T_{p}}
$$

and $k_{l}$ the rate constant at less active sites (possibly a perfect basal plane sitc) [1]

$$
k_{l}=5.0 \cdot 10^{21} \exp \frac{-6.352 \cdot 10^{4}}{R T_{p}} .
$$

The latter one has a smaller effective surface, at which the reaction can take place [5]. $\chi_{a}$ is the fraction of available $a$-sites which is given by [1]

$$
\chi_{a}=\left(1+\frac{k_{T}}{k_{b} P_{O_{2}}}\right)^{-1}
$$




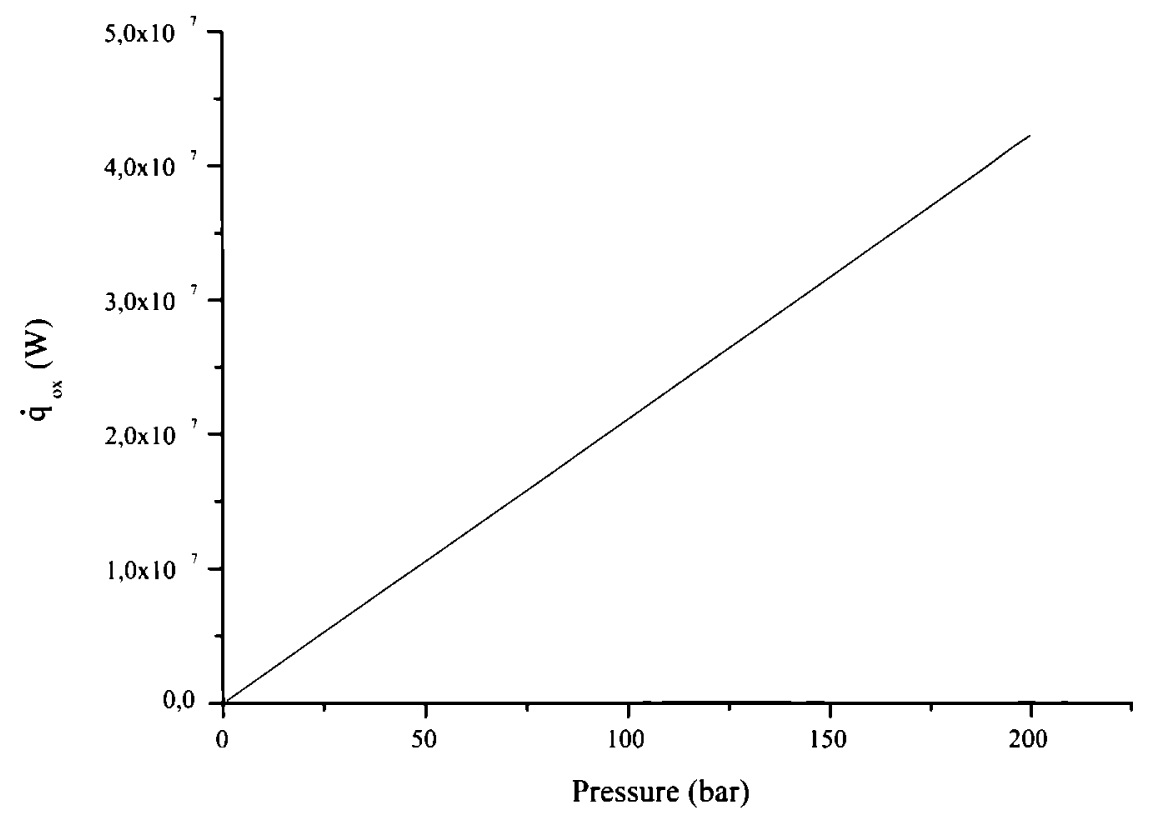

Figurc A.2: Calculated heat gain rate by oxidation according to Michelsen [1] as a function of the pressure for a particle with a radius of $25 \mathrm{~nm}$ with a temperature of $3500 \mathrm{~K}$ at an ambient temperature of $1000 \mathrm{~K}$.

in which $k_{T}$ is a rate constant which considers the effect of anncaling from $l$-sites into $a$-sites, given by [6]

$$
k_{T}=3.79 \cdot 10^{27} \exp \left(\frac{-4.06 \cdot 10^{5}}{R T_{p}}\right) .
$$

The rate constant for surface oxide formation $k_{Z}$ can be calculated using [1]

$$
k_{Z}=21.3 \exp \left(\frac{1.713 \cdot 10^{4}}{R T_{p}}\right)
$$

The oxidation rate for the annealed fraction of the particle $X_{a n n}$ is obtained from [1]

$$
k_{o x, a n}=\frac{2.8 Z_{o \alpha}}{\sqrt{T_{a}}} \exp \left(\frac{-1.4 \cdot 10^{5}}{R T_{p}}\right) X_{a n n} .
$$

in which $Z_{o x}$ is the collision rate of $\mathrm{O}_{2}$ with the surface. which is calculated by

$$
Z_{o x}=\frac{P_{a}}{k_{P} T_{a}} \sqrt{\frac{R_{m} T_{a}}{2 \pi W_{a}}}
$$




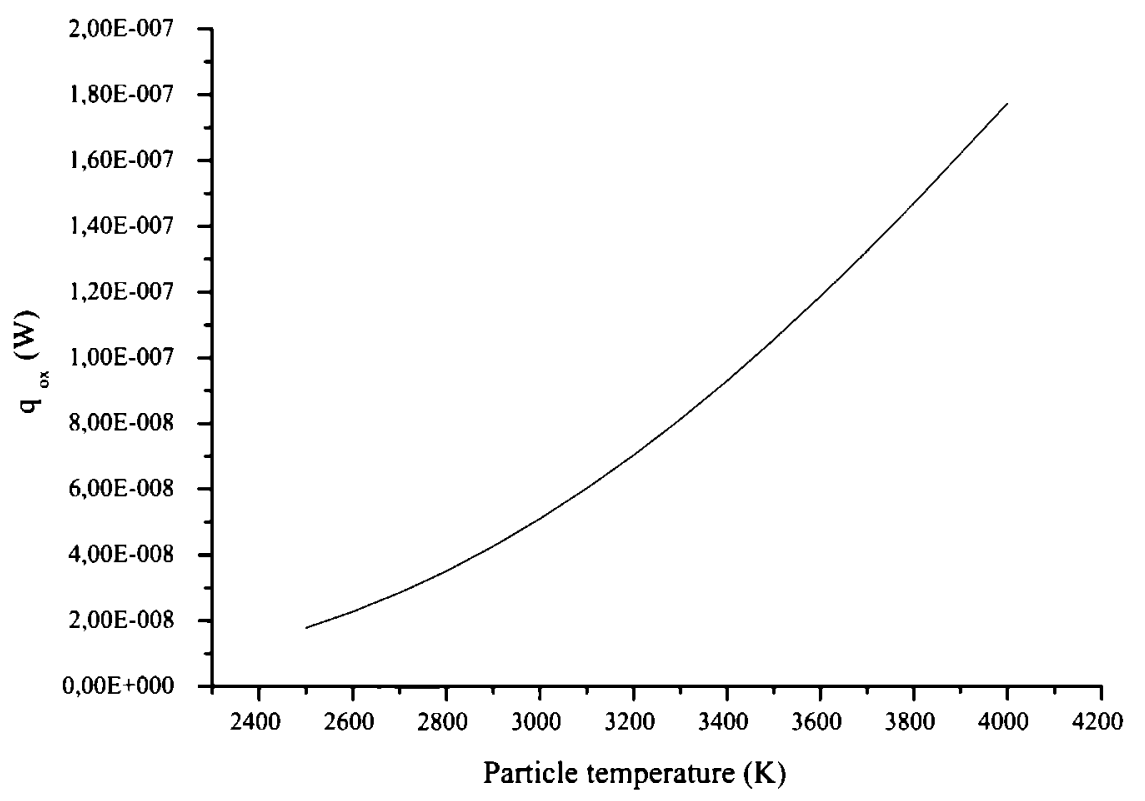

Figurc A.3: Calculated heat gain ratc by oxidation according to Michelsen [1] as a function of the particle temperature for a particle with a radius of $25 \mathrm{~nm}$ in an environment with a pressure of 50 bar at an ambient temperature of $1000 \mathrm{~K}$.

in which $k_{P}$ is the Boltzmann constant in effective pressure units. $R_{m}$ is the universal gas constant in effective mass units and $W_{a}$ is the averagc molecular weight of air. Figurc A.2 shows the heat exchange rate as a function of the pressurc for a particle at an ambient temperature of $1000 \mathrm{~K}$. It can be seen that the heat exchange rate is almost lincarly dependent on the pressure for the temperatures which are reached during typical LII experiments.

Figure A.3 shows the heat exchange rate as function of the particle temperature in an environment with a temperature of $1000 \mathrm{~K}$ in an atmosphere with a pressure of 50 bar. It can be seen that as the particle temperature increases. the oxidation rate increases dramatically. However, at the present pressures and tempcratures. the rate is much lower than the heat exchange rate by conduction.

Figure A.4 shows the heat exchange rate as a function of the ambient temperature for a soot particle with a radius of $25 \mathrm{~nm}$ with a temperature of $3500 \mathrm{~K}$ at a pressure of 50 bar. Again, it can be concluded that the heat loss by oxidation is negligible in comparison wit the heat loss mechanisms used in the model described in Chapter 3. 


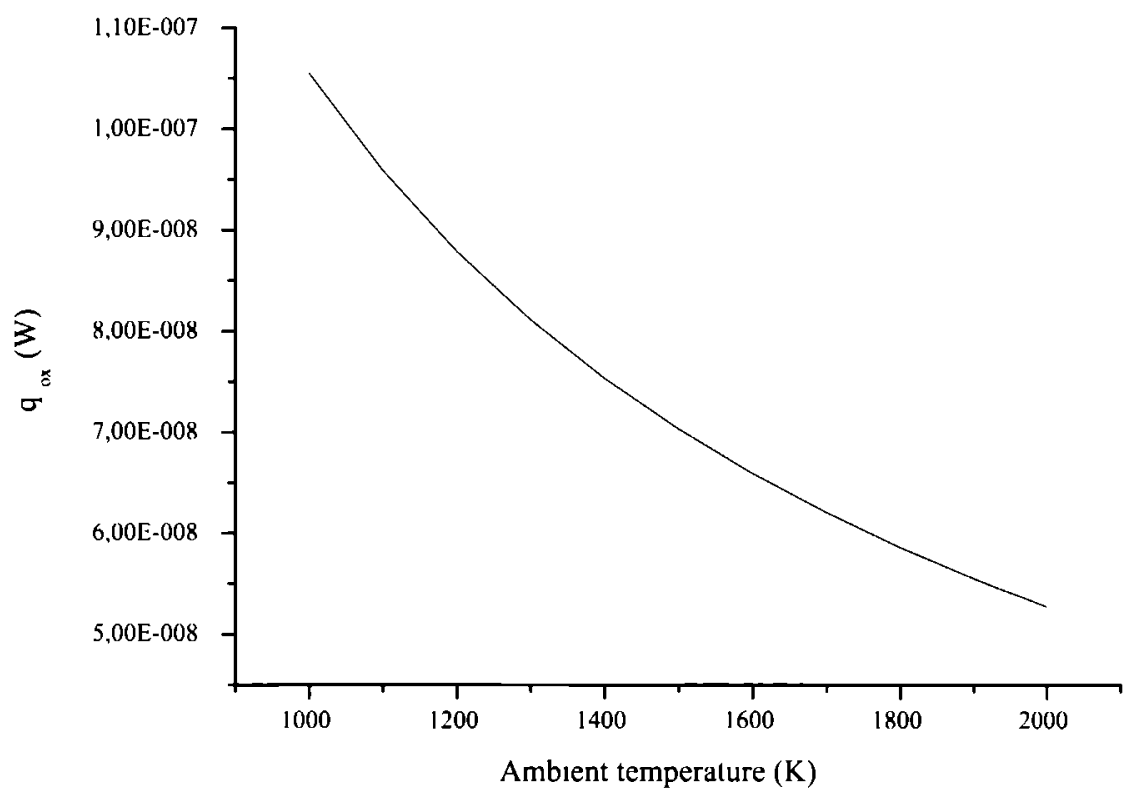

Figure A.4: Calculated heat gain rate by oxidation according to Michclsen [1] as a function of the ambient temperature for a particle with a radius of $25 \mathrm{~nm}$ with a temperature of $3500 \mathrm{~K}$ at a pressure of 50 bar. 


\section{Bibliography}

[1] H. Michelsen (2003): Understanding and predicting the temporal response of laser-induced incandescence from carbonaceous particles. JCP 118 (15). 70127045 .

[2] L.A. Melton (1984): Soot diagnostics based on laser heating. Appl. Opt. 23 (13), 2201-2208.

[3] T.J. Konno and R. Sinclair (1995): Crystallization of amorphous carbon in carbon-cobalt layered thin films. Acta metall. matcr. 43 (2). 471-484.

[4] L.J. Dunne, P.F. Nolan, J. Munn, M. Tcrrones, T. Jones, P. Kathirgamanathan. J. Fernandez and A.D. Hudson (1997): Experimental verification of the dominant influence of extended carbon networks on the structural. clectrical and magnetic properties of a common soot. J. Phys.: Condens. Matter 9 (48). 10661-10674.

[5] D.R. Olander. W. Sickhaus, R. Jones and J.A. Schwarz (1972): Reactions of modulated molecular beams with pyrolytic graphite. I. Oxidation of the basal plane. J. Chem. Phys. 57 (1), 408-420.

[6] J.R. Walls and R.F. Strickland-Constable (1964): Oxidation of carbon between 1000-degrees-C and 2400-degrees-C. Carbon 1 (3). 333-338. 


\section{Appendix B}

\section{Uniform particle temperature}

This appendix proves that it is correct to assume that the temperature of laserheated small soot particles can be supposed to be uniform. The driving mechanism bchind a heat flow is a tempcrature gradient. Conduction is the only possible heat transfer mechanism within a solid particle. Assuming an isotropic homogeneous medium for the soot particle. the conductive heat flux on a microscopic level can be described by [1]

$$
\dot{q}_{\text {ond }}=-\lambda_{\text {cond }}(T) \nabla T .
$$

in which $\lambda_{\text {cond }}$ is the thermal conductivity of the medium. In the engine environment the conductive heat losses are by far most significant (See Chapter 3). There are no additional heat sources at the interface betwecn the particle and the cnviromment. Assuming spherical symmetry of the temperature distribution within the particle. the energy balance at the interface between the particle and the cnvironment can be rewritten in [1]

$$
-\frac{\partial}{\partial r} \lambda_{\text {cond.a }}\left(T_{a}\right) \frac{1}{r} \frac{\partial T_{a}}{\partial r}=-\frac{\partial}{\partial r} \lambda_{\text {cond }, s}\left(T_{s}\right) \frac{1}{r} \frac{\partial T_{s}}{\partial r} .
$$

in which $r$ is the distance from the center of the soot particle. $\lambda_{\text {cond } a}$ is the thermal conductivity of the ambient environment (air). $\lambda_{\text {cond.s }}$ is the thermal conductivity

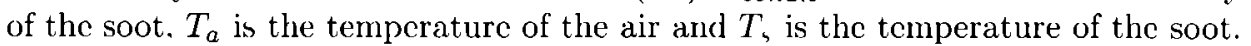
Using the kinetic theory of gases the thermal conductivity for air can be written as [2]

$$
\lambda_{\text {cond } a}=\frac{1}{3} \lambda_{m f p a} c_{t g} C_{v, a} \frac{P_{a}}{R_{m} T_{a}}=\frac{1}{3} \lambda_{m f p a} c_{t g} C_{v, a} \rho_{a} .
$$

in which $\lambda_{m f p . a}$ is the mean free path of the air. $C_{v a}$ is the molar specific heat capacity of the air at constant volume. $P_{a}$ is the ambient pressurc. $R_{m}$ is the 
universal gas constant and $c_{t g}$ is the thermal velocity of the gas molccules which is defined as [2]

$$
c_{t g}=\sqrt{\frac{8 k_{B} T_{a}}{\pi \frac{M_{a}}{N_{A}}}},
$$

in which $k_{B}$ is Bolzmann's constant, $M_{a}$ is the molar mass of air and $N_{A}$ is Avagadro's constant. The ratio $\frac{M_{a}}{N_{A}}$ gives the molecular mass. The specific heat capacity of the ambient gas is a function of the temperature and is calculated with [3]

$$
C_{v, a}=a_{\jmath, a}+b_{\jmath, a} T_{a}+\frac{c_{\jmath, a}}{T_{a}^{2}}-R_{m}
$$

in which $a_{\jmath, a}, b_{\jmath, a}$ and $c_{\jmath, a}$ are material constants, for which the properties of $\mathrm{N}_{2}$ have been assumed. Calculating $\lambda_{c o n d, a}$ at a pressure of 70 bar (which is the highest pressure in our engine conditions) and ambient temperature of $1000 \mathrm{~K}$ results in

$$
\lambda_{\text {cond, } a}=0.019 \mathrm{Wm}^{-1} \mathrm{~K}^{-1} \text {. }
$$

Michelsen [4] calculated the thermal conductivity for soot up to $2000 \mathrm{~K}$. Extrapolating these values it varies between $0.13 \mathrm{~W} \mathrm{~m}^{-1} \mathrm{~K}^{-1}$ and $1 \mathrm{~W} \mathrm{~m}^{-1} \mathrm{~K}^{-1}$ for the temperature range between $1000 \mathrm{~K}$ and $4000 \mathrm{~K}$. If Eq. B.2 has to be fulfilled and as $\lambda_{\text {cond,a }}<<\lambda_{\text {cond,s }}$ it can be concluded that $\frac{d T_{s}}{d r}<<\frac{d T_{u}}{d r}$ at the interface. Hence. it can be concluded that the temperature gradicnt in the soot particle can be neglected and as a consequence the soot particles can be supposed to be uniform in temperature for small particles. 


\section{Bibliography}

[1] J. Taine and J.-P. Pctit (1993): Heat transfer. Prentice Hall.

[2] E.H. Kennard (1938): Kinetic Theory of Gases, McGraw-Hill Book Company.

[3] P.W. Atkins (1998): Physical Chemistry $6^{\text {th }}$ ed. Oxford University Press.

[4] H. Michelsen (2003): Understanding and predicting the temporal response of laser-induced incandescence from carbonaceous particles. JCP 118 (15). 70127045 . 


\section{Appendix $\mathrm{C}$}

\section{Hyperbolic behavior}

The chi-square error maps as a function of initial temperature and particle radius of a mono-disperse size distribution (Fig. 6.7) show only little initial temperature dependence in comparison with the radius dependence. This section shows why this is the case.

Conduction is the most important cooling mechanism in high-pressure cnvironments. It can be described in the transition regime [1] in the following way

$$
\dot{q}_{\text {cond }, t r}=\pi \cdot 4 r_{p} \lambda_{\text {cond }}\left(T_{p}-T_{a}\right) \cdot f\left(K n_{h}\right) .
$$

in which

$$
f\left(K n_{h}\right)=\left[1+K n_{h} \frac{\frac{\dot{q}_{c o n t}}{\dot{q}_{f m}} \cdot \xi_{h}+\zeta_{h}}{K n_{h} \xi_{h}+1}\right]^{-1}
$$

and $\xi_{h}$ and $\zeta_{h}$ arc cmpirically determined interpolation constants.

The proportion between the free-molecular and the continuum regime in Eq. (C.2) is given by [1]

$$
\frac{\dot{q}_{\text {cont }}}{\dot{q}_{f m}}=\frac{5}{4} \pi K n_{h} .
$$

The Knudsen number for conduction is given by [1]

$$
K n_{h}=\frac{I_{g a s}}{r_{p}}=\frac{1}{\sqrt{2} \cdot \sigma_{c o l l}} \cdot \frac{k_{B} T_{a}}{p_{a}} \cdot \frac{1}{r} .
$$

Since all other parameters in this equation do not depend on particle properties. but only on the enviromment (which is stationary on the time scale of a LII measurement). it follows that

$$
\lim _{p_{a} \rightarrow \infty} \dot{q}_{\text {cond }} \propto \sqrt{p_{a}} \Delta T r
$$

in which $\Delta T=T_{p}-T_{a}$. Eq. C.5 shows a hyperbolic rclation between $\Delta T$ and $r$. given a certain conduction heat loss rate (that is determined by the cxperimentally found decay rate). This is reflected in the shape of the chi-square plots of Fig. 6.7. 


\section{Bibliography}

[1] M.M.R. Williams and S.K. Loyalka (1991): Acrosol Science Theory and Practice, With Special Applications to the Nuclear Industry. Pergamon Press. 


\section{List of symbols}

Symbol Meaning

$c_{t v}$

$d_{0}$

$f$

$h$

$k_{0}$

$m_{p}$

$\dot{q}_{a b s}$

$\dot{q}_{\text {cond }}$

$\dot{q}_{\text {rad }}$

$\dot{q}_{v a p}$

$r_{p}$

$r_{m}$

$t$

$t_{b, H}$

$B_{\jmath}$

$C_{p}$

$C_{p}$

$C_{v}$

$\mathbb{D}$

$E_{\text {tnt }}$

$G$

$\Delta H_{s}$

$\Delta H_{v}$

$K n$

$K n_{\mathrm{c}}$

$K n_{v}$

$M_{a}$

$N_{p}$

$p_{a}$

$P_{f}$

Time
Thermal velocity of vaporised soot

Geometric nozzle diameter

Eucken factor

Heat-transfer coefficient

Reference thermal conductivity

Soot particle mass

Absorbed heat

Heat-flow rate by conduction

Heat-flow rate by radiation

Heat-flow rate by vaporization

Soot particle radius

Mean soot particle radius

Spray break-up time

according to Hiroyasu

Proportionality constant considering convective contributions during sublimation for species $\mathrm{C}_{\mathrm{j}}[3]$

Hcat capacity of gas at constant pressure

Heat capacity of solid soot particle

Heat capacity of gas at constant volume

Diffusion coefficient

Internal energy of soot particle

Geometry dependent heat transfer factor

Specific sublimation enthalpy of carbon

Specific vaporisation enthalpy of carbon

Knudsen number

Knudsen number for conduction

Knudsen number for vaporisation

Molar mass of ambient gas

Particle density

Ambicnt pressure

Injection pressure of fuel
Unit

$\mathrm{m} \mathrm{s}^{-1}$

$\mathrm{m}$

$\mathrm{W} \mathrm{m}^{-2} \mathrm{~K}^{-1}$

$\mathrm{W} \mathrm{m}{ }^{-1} \mathrm{~K}^{-1}$

$\mathrm{kg}$

W

W

W

W

m

III

S

s

$\mathrm{J} \mathrm{kg}^{-1} \mathrm{~K}^{-1}$

$\mathrm{J} \mathrm{kg}^{-1} \mathrm{~K}^{-1}$

J kg ${ }^{-1} \mathrm{~K}^{-1}$

$\mathrm{m}^{2} \mathrm{~s}^{-1}$

J

$\mathrm{W} \mathrm{kg}^{-1}$

$\mathrm{W} \mathrm{kg^{-1 }}$

-

$\mathrm{kg} \mathrm{mol}^{-1}$

$\mathrm{m}^{-3}$

$\mathrm{N} \mathrm{m}^{-2}$

$\mathrm{N} \mathrm{m}^{-2}$ 
$\begin{array}{lll}P\left(r_{p}\right) & \text { Particle size distribution } & \mathrm{m}^{-2} \\ Q_{a b s} & \text { Mie absorption efficiency } & - \\ Q_{\imath n} & \text { Energy absorbed by soot particle } & \mathrm{J} \\ Q_{o u t} & \text { Energy released by soot particle } & \mathrm{J} \\ S_{H} & \text { Modeled penetration length } & \mathrm{m}\end{array}$ according to Hiroyasu

$S_{k} \quad$ Sutherland constant for $\quad$ K thermal conductivity

$S_{L I I} \quad$ Intensity of LII radiation

$T \quad$ Temperature

$T_{a} \quad$ Ambient temperature

$T_{b b} \quad$ Black-body temperature

$T_{k 0} \quad$ Reference temperaturc

$\mathrm{X} \quad$ Fraction of soot particle

$T_{p} \quad$ Temperature of soot particle

$U_{b b} \quad$ Black-body power-density spectrum

$U_{3} \quad$ Thermal velocity of species $\mathrm{C}_{\mathrm{J}}$

$\mathrm{W} \mathrm{m}^{-2}$

$\mathrm{K}$

$\mathrm{K}$

$\mathrm{K}$

$\mathrm{K}$

$U_{m} \quad$ Measured black-body power-density spectrum

$W_{3} \quad$ Molar mass of species $\mathrm{C}_{\mathrm{J}}$

$\alpha_{T} \quad$ Thermal accommodation coefficient

$\alpha_{\jmath} \quad$ Mass accommodation coefficient for species $\mathrm{C}_{\mathrm{J}}$

$\beta \quad$ Mass accommodation coefficient

$\gamma \quad$ Heat capacity ratio

$\varepsilon \quad$ Emissivity

$\varepsilon_{1} \quad$ Emissivity at $\lambda_{1}$

$\varepsilon_{2} \quad$ Emissivity at $\lambda_{2}$

$\lambda$ Wavelength

$\lambda_{a} \quad$ Thermal conductivity of air

$\lambda_{\text {det }} \quad$ Detection wavelength

$\lambda_{1} \quad$ Detection wavelength 1

$\lambda_{2} \quad$ Detection wavelength 2

$\mathrm{K}$

$\mathrm{W} \mathrm{m}^{-3}$

$\mathrm{m} \mathrm{s}^{-1}$

$\mathrm{W} \mathrm{m} \mathrm{m}^{-3}$

$\mathrm{kg} \mathrm{mol}-1$

$\lambda_{m f p, a}$ Ambient mean-free path

$\rho_{f} \quad$ Density of the fuel

$\rho_{v} \quad$ Density of vaporised soot

$\tilde{\rho} \quad$ Dimensionless density

$\sigma_{m} \quad$ Geometric width of the

m

$\mathrm{W} \mathrm{m}^{-1} K^{-1}$

In

$\mathrm{m}$

$\mathrm{m}$

$\mathrm{m}$

$\mathrm{kg} \mathrm{m}^{-3}$

$\mathrm{kg} \mathrm{m}{ }^{-3}$

particle size distribution

$\sigma_{\text {coll }} \quad$ Collisional cross-section

$\tau$ Detection efficiency of optical system

m 


\section{Sub- and superscripts}

\begin{tabular}{|c|c|}
\hline Symbol & Meaning \\
\hline abs & Absorbed \\
\hline ann & Annihilation \\
\hline cond & Conduction \\
\hline $\mathrm{fm}$ & free molccular \\
\hline int & Internal \\
\hline 1 & liquid \\
\hline melt & Melting \\
\hline $\mathrm{rad}$ & Radiation \\
\hline $\mathrm{p}$ & Particle \\
\hline s & Solid \\
\hline $\mathrm{v}$ & vaporised soot or vapor phase \\
\hline sub & Sublimation \\
\hline vap & Vaporization \\
\hline $\mathrm{L}$ & Lamp \\
\hline
\end{tabular}

\section{Material constants}

Symbol Meaning

$a_{\jmath, a} \quad$ Constant needed to calculate heat-capacity of air

$b_{\jmath, a} \quad$ Constant needed to calculate heat-capacity of air

$c_{j, a} \quad$ Constant needed to calculate heat-capacity of air

$a_{\jmath, p} \quad$ Constant needed to calculate heat-capacity of soot

$b_{\jmath, p} \quad$ Constant needed to calculate heat-capacity of soot

$c_{\jmath, p} \quad$ Constant needed to calculate heat-capacity of soot

$A_{d \imath s s} \quad$ Factor for calculation rate constant $k_{d r s s}$ $A_{\imath m \imath g} \quad$ Factor for calculation rate constant $k_{\imath m \imath g}$ $A_{v m i g} \quad$ Factor for calculation rate constant $k_{v m i g}$ $\Delta H_{2 m \imath g} \quad$ Interstitial migration enthalpy $\Delta H_{v} \quad$ Specific Vaporisation heat of carbon

$\Delta H_{v m \imath g} \quad$ Vacancy migration enthalpy $\zeta_{c} \quad$ Constant for conduction interpolation function

$\zeta_{v} \quad$ Constant for vaporization interpolation function
Value

$28.58 \mathrm{~J} \mathrm{~mol}^{-1} \mathrm{~K}^{-1}$

$3.77 \cdot 10^{-3} \mathrm{~J} \mathrm{~mol}^{-1} \mathrm{~K}^{-2}$

$-50000 \mathrm{~J} \mathrm{~K} \mathrm{~mol}^{-1}$

$16.86 \mathrm{~J} \mathrm{~mol}^{-1} \mathrm{~K}^{-1}$

$4.77 \cdot 10^{-3} \mathrm{~J} \mathrm{~mol}^{-1} \mathrm{~K}^{-2}$

$-8.54 \cdot 10^{5} \mathrm{~J} \mathrm{~K} \mathrm{~mol}^{-1}$

$1 \cdot 10^{18} \mathrm{~s}^{-1}[3]$

$1 \cdot 10^{8} \mathrm{~s}^{-1}[3]$

$1.5 \cdot 10^{17} \mathrm{~s}^{-1}[3]$

$-1.9 \cdot 10^{4} \mathrm{~J} \mathrm{~mol}^{-1}$

$21.946 \mathrm{~kJ} \mathrm{~kg}^{-1}$ follows

from (Eq. 3.10) Clausius-

Clapeyron

$-1.4 \cdot 10^{5} \mathrm{~J} \mathrm{~mol}^{-1}$

$1.1759 \cdot 5 / 8 \cdot \sqrt{\pi}[6]$

$1.0161[6]$ 
$\xi_{c} \quad$ Constant for conduction $\quad 1.9243$ [6] interpolation function

$\xi_{v} \quad$ Constant for vaporization $1.3333[6]$ interpolation function

$\rho_{p} \quad$ Density of solid soot $\quad 1860 \mathrm{~kg} \mathrm{~m}^{-3}[1]$

$\sigma_{\text {coll }}$ Collisional cross-section $\quad 0.43 \cdot 10^{-18} \mathrm{~m}^{2}[4]$

\section{Physical constants}

\section{Symbol Meaning}

$c$

$h \quad$ Planck's constant

$k_{B} \quad$ Boltzmann`s constant

$M_{a}$

$M_{v}$

$N_{A}$

$R_{m}$

$R_{p}$

$\sigma_{S B}$

$\left(p^{*} \cdot T^{*}\right)$
Molar mass of ambient environment

Molar mass of vaporised soot

Avogadro 's constant

Molar universal gas constant

Universal gas constant in

effective pressure units

Stefan-Boltzmann constant

Corresponding states at the vapor

pressure curve
Value

$2.9979 \cdot 10^{8} \mathrm{~m} \mathrm{~s}^{-1}[2]$

$6.62608 \cdot 10^{-34} \mathrm{~J} \mathrm{~s}[2]$

$1.38\left(07 \cdot 10^{-23} \mathrm{~J} \mathrm{~K}^{-1}[2]\right.$

$0.031058 \mathrm{~kg} \mathrm{~mol}^{-1}$

$0.036 \mathrm{~kg} \mathrm{~mol}^{-1}$

$6.022 \cdot 10^{23} \mathrm{~mol}^{-1}$

$8.3145 \mathrm{~J} \mathrm{~mol}^{-1} \mathrm{~K}^{-1}[2]$

$82.058 \mathrm{~atm} \mathrm{~cm}^{3} \mathrm{~mol}^{-1} \mathrm{~K}^{-1}$

$5.6705 \cdot 10^{-8} \mathrm{~W} \mathrm{~m}^{-2} \mathrm{~K}^{-4}[2]$

(61.5 Pa. $3000 \mathrm{~K}$ ) calculated from all species $\mathrm{C}_{1}$ to $\mathrm{C}_{7}[5]$ 


\section{Bibliography}

[1] S.C. Graham, J.B. Homer and J.L.J. Rosenfeld (1975): The formation and coagulation of soot aerosols generated by the pyrolysis of aromatic hydrocarbons. Proc. Roy. Soc. 344 (1637). 259-285.

[2] D.R. Lide (2001): CRC Handbook of Chemistry and Physics. CRC Press. Florida.

[3] H.A. Michelsen. (2003): Understanding and predicting the temporal rcsponse of laser-induced incandescence from carbonaceous particles. J. Chem. Phys. 118 (15), 7012-7045.

[4] P.W. Atkins (1998): Physical Chemistry $6^{\text {th }}$ ed.. Oxford University Press. U.K.

[5] H.R. Leider, O.H. Krikorian and D.A. Young (1973): Thermodynamic properties of carbon up to the critical point. Carbon $11(5), 555-563$.

[6] M.M.R. Williams and S.K. Loyalka (1991): Aerosol Science Theory and Practice. With Special Applications to the Nuclear Industry. Pergamon Prcss. 


\section{Summary}

\section{Soot characterization during combustion in a Diesel engine}

This dissertation describes the results of soot medsurements acquired in the combustion chamber of an optically accessible heavy-duty Diesel engine The Diesel engine is the most efficient internal combustion engine Pollutant cmissions from the engine, such as soot and NOx, however, form a tremendous problem Soot is mainly formed during an inefficient combustion process and plays a role in climate change and affects human health $\mathrm{NO}_{\mathrm{x}}$, however, is mainly produced during an efficient combustion process and is formed in a high temperature environment It is one of the substances that contributes to the formation of acid rain and plays a role in the destruction of ozone As a consequence, authorities are posing stricter regulations for the emissions from engines

The smallest and probably most harmful soot particles are not trapped by soot particulate filters Consequently, the formation of soot has to be reduced in the combustion chamber The formation process of soot has not yet been fully understood This dissertation describes the devclopment of laser-induced incandescence (LII) as a measurement techmque enabling the investigation of the soot formation process $i n$-situ In this technıque soot is heated to temperatures at which its the mal radiation is visible, by a shift of the Planck's emission curve The intensity of the soot emission is dependent on the soot volume fraction and on the temperature of the soot After the laser pulse the soot particles cool down, causing a gradual dccrease in LII intensity, that can be measurcd with a photo-multiplier tube (PMT) a light-sensor with a high temporal resolution This so-called time-resolved LII (TRLII) signal is dependent on the particulate size A smaller particulate cools down faster than a bigger one With TR-LII and the assumption of a physical cooling model, the soot particle size can be determined by fitting the model to the measured TR-LII curve In the model used in this dissertation cooling effects by conduction, vaporization and radiation are taken into account

Soot is a composition of unburned carbon molecules It is formed mannly at the location in the engine where the fuel-dir mixture is too rich The alr-flow in an internal combustion engine is highly turbulent Besides that the Diesel fucl is 
injected into the cylinder at such high pressures that the brcak-up bchavior of the fuel spray is also influcnced by turbulence. making it difficult to reproduce an expcriment. Consequently, it is necessary to use simultaneously as many optical measurement techniques as possible, in order to extract reliable information about the Diescl combustion process. In order to find out more about the influence of one physical process on anothcr onc, part of the measurements has been performed in a constant volume high pressure high temperature combustion cell, which had easier optical access. This is a combustion chamber in which the Diesel combustion process can be investigated without the moving piston. improving the reproducibility of the cxperiments.

The dissertation describes the issues which should be considered during LII measurements in an engine environment. One of the conclusions is that the time resolution of the detection system is crucial in the interpretation of the measurements and that the available measurement systems are not able to measure the signal in an engine environment in a correct way. A tool to extract the correct information from the mcasurements is given. Measurements have been performed for several engine loads. No influence of the engine load or injection pressure on the primary particle size has been observed. During the engine cycle, first. an increase of the primary particle size has been obscrved and later on during the combustion cycle a decrease of the primary particle size.

A correct application of LII in an engine can be used to improve the efficiency of engines and as a consequence the reduction of soot in the exhaust. In addition, LII can be applied on engines. powered by different types of fuels. The combination of both can lead to the optimal engine design. with a minimum production of soot. In addition. the results of this dissertation can be used in order to improve combustion models. which will contribute to clcancr Diesel engines. 


\section{Samenvatting}

\section{Roetkarakterisatie tijdens verbranding in een diesel- motor}

Deze dissertatie beschrijft de resultaten van roetmetingen. verkregen met behulp van een optische meettechniek, in de verbrandingskamer van een optisch toegankelijke vrachtwagenmotor. De dicsclmotor is de zuinigste interne verbrandingsmotor die bestaat. Een groot nadeel van de motor is de uitstoot van de schadelijke stoffen roet en $\mathrm{NO}_{\mathrm{x}}$. Roet wordt met name gevormd tijdens een inefficiënt verbrandingsproces en heeft invloed op het klimaat en een schadelijk effect op de menselijke gezondheid. $\mathrm{NO}_{\mathbf{x}}$, daarentegen, wordt met name gevormd bij hoge temperaturen. wat een gevolg is van ccn efficiënt verbrandingsproces en draagt bij tot de vorming van zure regen en leidt tot de afbraak van ozon. Derhalve stellen overheden regels op waaraan motorfabrikanten zich moeten houden om zowel de uitstoot van roet als van NO tegen te gaan.

De kleinste en waarschijnlijk gevaarlijkste roetdeeltjes kunnen niet worden afgevangen door cen roetfilter en daarom zal de vorming van roet in de motor moeten worden tegengegaan. Over het roctvormingsmechanisme bestaat op het moment nog vecl onduidelijkheid en dit proefschrift reikt handvatten aan waarmee de aanwezigheid en de eigenschappen van roet in de verbrandingsruimte van een dieselmotor onderzocht kunnen worden met behulp van laser geïnduceerde incandescentie (LII). Deze meettechniek gebruikt ecn laser om roetdeeltjes op te warmen in een heel korte periode. wat een verschuiving veroorzaakt in het Planckse stralingsspectrum. De intensiteit van de straling. dic wordt afgegeven door de roetdeeltjes. is afhankelijk van de roctconcentratie en de temperatuur. Na de lascrpuls zullen de roctdecltjes afkoelen, wat een geleidelijke afname van het LII-signaal tot gevolg heeft. die gemeten kan worden met behulp van een zogenaamde photo-multiplicr tube (PMT). een lichtdetector met een hoge tijdsresolutie. Dit zogenaamde tijdsopgeloste LII (TR-LII) signaal is afhankelijk van de grootte van de roctdeeltjes. Een klciner deeltje zal sneller op z'n oorspronkelijke temperatuur terug zijn dan een groter deeltje. Door het TR-LII signaal te meten kan bij de aanname van een fysisch afkoclmodel de grootte van de roetdecltjes worden bepaald door het model te fitten aan de meetcurve. In het model dat beschreven staat in dit proefschrift zijn 
afkoelbijdragen meegenomen voor geleiding, verdamping en straling van het roet. Roet bestaat voornamelijk uit grote moleculen van koolstofbindingen. Het wordt, naar men nu aanneemt, met name gevormd op die plekken in de motor waar het mengsel diesel-lucht te rijk is. De omgeving in de verbrandingscilinder van een dieselmotor is turbulent. Daarbij komt dat het inspuiten van de brandstof in de cilinder onder een zodanige druk plaatsvindt dat ook het opbreken van de brandstofstraal aan turbulentic onderhevig is met als gevolg dat de metingen moeilijk te reproduccren zijn. Het is daarom nodig zo veel mogelijk verschillende optische meettechnieken te combineren tijdens het onderzoek in een motor, zodat uit de interpretatic van simultaan uitgevocrde meettechnieken meer geconcludeerd kan worden over het verbrandingsproces. Om de afhankelijkheid van de rol die verscheidene processen spelen tijdens een verbrandingscyclus te onderzoeken, zijn er combinaties van meettechnieken uitgevoerd in een hoge-druk hoge-temperatuur verbrandingscel met een constant volume. Dit is een verbrandingscel waarin dieselverbranding bekeken kan worden zonder bewegende zuiger, zoals die in een motor wel aanwezig is, wat de reproduceerbaarheid van metingen vergroot.

Deze dissertatic beschrijft problemen die kunnen optreden tijdens het uitvoeren van LII metingen in een motoromgeving. Een van de conclusies is dat de tijdsresolutie van het detectiesysteem van cruciaal belang is in de interpretatie van de metingen cn dat de meetsystemen die nu bestaan niet snel genoeg zijn om het LII signaal te meten in een motoromgeving. Een manier om wel de juiste informatie uit do metingen te herleiden wordt beschreven. Metingen zijn uitgevoerd voor verscheidene motorbclastingen. Invloed van de belasting op de primaire deeltjesgrootte is niet waargenomen. Gedurende de motorcyclus wordt eerst een groei van de primaire deeltjesgrootte waargenomen, cn daarna weer een gedeeltelijke afname.

LII kan worden toegepast in verscheidene type motoren, als ook op vlammen die ontstaan als gevolg van de toepassing van verscheidene typen brandstoffen. Bij de toepassing van LII in een dergelijke omgeving is het mogelijk om optimale motorcondities te onderzoeken om zo de uitstoot van roet uit de motor te minimaliseren. De resultaten kunnen verder gebruikt worden bij het verbeteren van huidige verbrandingsmodellen, wat zal bijdragen tot schonere dieselmotoren. 


\section{Acknowledgments}

De resultaten die in dit proefschrift beschreven staan, waren niet mogelijk geweest zonder de hulp van velen, van wie ik er hicr graag enkelen wil nocmen.

Allereerst prof. dr. J.J. ter Meulen, omdat je me het vertrouwen hebt gegeven deze klus te kunnen klaren. Je hebt altijd met een opbouwend kritische blik naar de resultaten gekeken en bij het schrijven van het proefschrift altijd de juiste vragen gesteld ter verduidelijking van de tekst. Hans, bedankt voor de positieve input en de vrijheid die je me hebt gegeven in het uitvoeren van het onderzoek. Daarnaast heb je me de ruimte gegeven een bijdrage te leveren aan de organisatie van de eerste LII workshop en conferentie in 2005 te Duisburg.

Als mede-promotor wil ik bedanken prof. dr. ir. R.S.G. Baert. Tijdens de discussies die we hebben gevoerd over de materie heb ik veel van jou, Rik, kunnen leren over het verbrandingsproces in een dieselmotor.

Vervolgens wil ik jou, dr. N.J. Dam bedanken. Als directe begeleider te Nijmegen en co-promotor was jij, Nico, altijd nauw betrokken bij mijn onderzoek, hetzij bij het werk in het lab - dat voor jou nooit af was - hetzij in het modelleren. Je wist me scherp te houden met je vaak humoristische, kritische opmerkingen.

Ich möchte dir, dr. T. Gerber als co-promotor, auch ganz herzlich danken, für die Arbeit die ich in deiner Gruppe machen konnte. Die HTDZ ist ein konzeptucl erfinderisches Messsystem, das viele Möglichkeiten geboten hat gute Messungen zu machen. Diese Periode hat mir auch viele Lehrmomenten gegeben, wic du öfter erwähnt hast, Thomas.

Daarnaast wil ik jou. prof. dr. W.L. Meerts, bedanken voor de waardevolle input tijdens de maandagochtendbesprekingen over het dieselonderzoek. Daarnaast wil ik je, Leo, bedanken voor het aanvaarden van het voorzitterschap in de manuscriptcommissie.

Dann möchte ich dir danken. dr. T. Dreier, Forscher am PSI und Mitglied der Manuskriptkommission. Ich habe viel gelernt von deinem Wissen im Bereich von LII, Thomas, und wir haben eine erfolchreiche Zusammenarbeit gehabt.

Après. je vous remercie. prof. dr. C. Mounaïm-Rousselle. pour votrc participation à la commission de manuscrit. Les discussions avec vous. Christine. pendant quclqucs conférences ont été très stimulants pour la recherche.

I would like to thank you. dr. M. Tulej, researcher at the PSI. I learned a lot from your expertise, Marck, in the ficld of laser diagnostics and thank you as well for the 
technical support in the HTDZ.

Ik wil jou bedanken. ing. A.P. van Vliet, voor jouw "stuurmanskunsten" van de motor. Zonder jouw technisch inzicht en hulp tijdens de metingen in Nijmegen, Arjan. had de motor helemaal niet gedraaid. Je aanhoudend goed humeur droeg positicf bij tot de werksfeer in de Graalburcht. It was a plcasure for me to work together with you dr. L.C. Ganippa as well, the postdoc on the Diesel project in Nijmegen. It was a great experience for me to learn from your knowledge and expertise in engine measurcments, Lionel. Daarnaast wil ik dr. K. Verbiezen bedanken, de andere promovendus op het Dieselproject. Kasper, het was een aangename ervaring met je samen te werken. Dan wil ik graag de technici en andere mensen "van boven" bedanken voor de hulp en gezellige werksfeer en niet te vergeten de secretaresses, van wic ik Ine Meijer met name wil noemen. Bedankt, voor de gocde service en gezelligheid gedurende mijn verblijf in de Graalburcht.

Ein Dankwort auch an dr.-ing. B.F. Kock und prof. dr.-ing. P. Roth. Ich möchte euch auch gerne Dank sagen für die Hilfe in der Modellierung von LII und die Gastfreundschaft während meines Besuchs zu euerem Institut.

De andere (voormalige) bewoners van de Graalburcht mogen hier natuurlijk niet ontbreken, omdat ze hebben bijgedragen tot een aangename werksfeer. Natürlich möchte ich meine andere Arbeitsgruppekollegen am PSI Dank sagen für die angenähme Atmosphäre. Eveneens wil ik jullie. collega's van de TU Eindhoven, bcdanken voor de prettige samenwerking. Evenals de huidige collega's aan de TU Delft voor de interesse die ze hadden in de afronding van mijn onderzoek.

Ik wil graag Wybe en Agnes bedanken voor de gastvrijhcid die ik altijd bij jullie heb mogen ervaren. Het was echt hocl bijzonder. Als laatste. maar zeker nict het minst, wil ik mijn ouders met Maud en Rob bedanken voor de interesse die jullie hebben getoond in het onderzoek en voor de steun die jullie me hebben gegeven tijdens het uitvoeren daarvan.

Bas 


\section{About Bas Bougie}

June 30, 1976

$1988-1994$

1994 - Scpt 2000

Jan 2000 - Mar 2000

Oct $2000 \quad$ Jan 2001

Mar $2001 \quad J a n 2006$

May 2001 - April 2003

Feb 2006
Born in Sittard, The Netherlands.

Secondary school at the Gymmasium of the College Sittard.

M.Sc. study in Applied Physics, Delft University of Technology, The Netherlands. Graduated at the section of Transport Phenomena. Thesis title: On the reconstruction of given objects with electrical capacitance tomography.

Traineeship at the Elcctronic and Electrical Eng. dept., University of Leeds. United Kingdom.

Temporary rescarch position at the Particle Technology section, Chemical Enginecring Fac.. Delft University of Technology. The Netherlands.

PhD student in the Applied Molecular Physics Group. Radboud University Nijmegen, The Netherlands.

Guest researcher in the Rcaction Analysis Group. Paul Scherrer Institute. Villigen. Switzerland.

Postdoctoral research associate at the dept. of Multi-Scale Physics. Fac. of Applicd Sciences. Delft University of Technology. The Netherlands. 


\section{List of publications}

\section{Peer-reviewed papers}

- G. Knopp, P. Beaud, P. Radi, M. Tulej, B. Bougie, D. Cannavo and T. Gcrber (2002): Pressure-dependent $\mathrm{N}_{2} \mathrm{Q}$-branch fs-CARS measurements. Journal of Raman Spectroscopy, 33 (11-12), 861-865.

- B. Bougie, M. Tulej, T. Dreicr, N.J. Dam. J.J. ter Mculen. T. Gerber (2005): Optical diagnostics of Diesel spray injections and combustion in a high-pressure high-temperature cell. Appl. Phys. B 80 (8), 1039-1045.

- B. Bougic. L.C. Ganippa. A.P. van Vliet, W.L. Meerts. N.J. Dam. J.J. ter Meulen (2006): Laser-induced incandescence particle size measurements in a heavy-duty Diesel engine. Combust. Flame. 145 (3). 635-637.

- C. Schulz, B. Kock, M. Hofmann. H. Michclsen, S. Will. B. Bougic. R. Suntz and G. Smallwood (2006): Laser-induced incandescence: Recent trends and current questions. Appl. Phys. B 83 (3). 333-354.

- T. Drcicr. B. Bougic, N. Dam and T. Gerber (2006): Modeling of time-resolved laser-induced incandescence (TIRE-LII) transients for particle sizing in highpressure spray combustion environments. Appl. Phys. B 83 (3). 403-411.

- B. Bougie, L.C. Ganippa. N.J. Dam and J.J. ter Meulen (2006): On particulate characterization in a heavy-duty Dicsel engine by timc-rcsolved laserinduced incandescence. Appl. Phys. B 83 (3). 477-485.

- B. Bougie. L.C. Ganippa. A.P. van Vlict. W.L. Mecrts. N.J. Dam and J.J. ter Mculcn (2007): Soot particulate size characterization in a heavy-duty Dicsel engine for different engine loads by laser-induced incandescence. Proc. Combust. Inst. 31 (1). 685-691. 


\section{Conference proceedings}

- B. Bougic, M. Tulej, T. Drcier, P. Beaud, G. Knopp, P.P. Radi, T. Gerber and N.J. Dam: Investigation of Diesel spray injections under non-reactive and reactive conditions using a high-pressure high-temperature test rig. $4^{\text {th }}$ Towards Clean Diesel Engines symposium. June 5-6. 2003. Micrlo. The Netherlands.

- B. Bougie. M. Tulej. T. Drcicr. G. Knopp. P. Beaud. P. Radi and T. Gerber: A general setup to study soot development by combining different techniques. $4^{\text {th }}$ Towards Clcan Diesel Engines symposium. Junc 5-6. 2003. Mierlo. The Netherlands.

- M. Tulej. B. Bougie. T. Dreier, P. Beaud. G. Knopp, D. Cannavo. N. Dam and $\mathrm{T}$. Gerber: Investigations of diesel spray combustion by using hightemperature high-pressure test rig. XVIII International Symposium on Combustion Processes. September 2-5. 2003 Ustroń. Poland.

- M. Tulej. T. Dreier. B. Bougie. T. Gerber and K. Boulouchos: Investigation of Diescl spray injection in a high-pressure high-temperature test rig. $25^{\text {th }}$ task leaders meeting of the Intcrnational Encrgy Agcncy implementing agreement on energy conservation and emissions reduction in combustion. Septemper 7-10. 2003. Faringdon. Unitcd Kingdom.

- B. Bougie. M. Tulej. T. Dreier. N. Dam. T. Gerber and J.J. ter Meulen: Investigations of Diesel spray injections under non-reactive and reactive conditions using a high pressure high temperature constant volume combustion cell. Europcan Combustion Mecting. October 25-28. 2003. Orléans. France.

- L.C. Ganippa. B. Bougic. A.P. van Vliet. K. Verbiezen. N.J. Dam. W.L. Meerts and J.J. ter Meulen: Soot formation and oxidation process in a heavy-duty Dicscl engine using laser-induced incandescence. Combura symposium, STW meeting of the Dutch section of the combustion institute, March 3-4, 2004. Nicuwegein. The Netherlands.

- B. Bougie. L.C. Ganippa. A.P. van Vliet. N. Dam. W.L. Meerts and J.J. ter Mculen: Soot characterization with laser-induced incandescence in a heavyduty Diesel engine. European Combustion Meeting. April 3-6. 2005. Louvainla-Ncuve. Belgium.

- K. Verbiezen. A.P. van Vliet. R.J.H. Klein-Douwel. L.C. Ganippa. H.J.T. Bougic. W.L. Mecrts. N.J. Dam and J.J. ter Meulen: Quantitative nitric oxide measurements by means of laser-induced fluorescence in a heavy-duty Dicscl engine. European Combustion Meeting. April 3-6. 2005. Louvain-la-Neuve. Belgium.

- T. Dreier. B. Bougie. N. Dam. T. Gerber and J.J. ter Mculen: Modelling of timc-resolved laser-induced incandescence (TIRE-LII) transients for particle 
sizing in high-pressurc spray combustion environments. $5^{\text {th }}$ Towards Clean Diesel Engines symposium. June 1-3. 2005. Lund. Sweden.

- B. Bougic. L. Ganippa. A.P. van Vliet. N. Dam. W.L. Meerts and J.J. ter Meulen: Particulate characterization in a heavy-duty Diesel engine. $5^{\text {th }}$ Towards Clcan Diesel Engines symposium, June 1-3. 2005. Lund. Swederı.

- B. Bougie. L.C. Ganippa. A.P. van Vlict. N.J. Dam, W.L. Mcerts and J.J. ter Mculen: Soot particulate size measurements in a heavy-duty Diesel engine. International Bunsen discussion meeting on laser-induced incandescencc: Quantitative interpretation modeling and application. September 25-28. 2005. Duisburg. Germany.

- T. Dreicr, B. Bougic, L. Ganippa, N. Dam, T. Gerber and J.J. ter Meulen: Modeling of time-resolved laser-induced incandescence (TIRE-LII) transients for particle sizing in high-pressure spray combustion environments. Intcrnational Bunsen discussion mecting on laser-induced incandescence: Quantitative interpretation modeling and application. September 25-28. 2005. Duisburg. Germany.

- B. Bougie. L.C. Ganippa. A.P. van Vliet. N.J. Dam. W.L. Meerts and J.J. ter Meulen: Soot particulate size measurements in a heavy-duty Diesel engine. Combura symposium, STW meeting of the Dutch section of the Combustion Institute. October 14, 2005. Nieuwegcin, The Netherlands.

- B. Bougie, L.C. Ganippa. A.P. van Vliet. W.L. Mecrts. N.J. Dam and J.J. ter Meulen: In-cylinder particulate sizing with combined TR-LII/2C pyrometry. $2^{\text {nd }}$ International Bunsen discussion meeting on laser-induced incandescence: Quantitative interpretation, modeling and application, August 3-5. 2006. BadHerrenalb. Germany.

- B. Bougic. L.C. Ganippa. A.P. van Vliet. W.L. Meerts. N.J. Dam and J.J. ter Meulen: In-cylinder particulate size measurcmonts with laser-induced incandescencc. Combura symposium, STW meeting of the Dutch section of the Combustion Institute, October 6, 2006, Nicuwegein, The Netherlands. 





Stellingen behorende bij het proefschrift van Bas Bougie

"On particulate characterization in a heavy-duty Diesel engine by time-resolved laser-induced incandescence"

1. Het meenemen van de druk in het modelleren van LII is noodzakelijk in het berekenen van deeltjesgroottes onder motorcondities.

Dit proefschrift.

2. Een PMT is eigenlijk te traag voor TR-LII onder motorcondities.

Dit proefschrift.

3. Interpretatie van een meting leidt alleen maar tot het juiste resultaat als het fysisch model correct is.

C. Schulz, B.F. Kock, M. Hofmann, H. Michelsen, S. Will, B. Bougie, R. Suntz and G. Smallwood (2006): Laser-induced incandescence: recent trends and current questions. Appl. Phys. B 83 (3), 333-354.

4. Onderzoek naar LII moet doorgaan, want het is de enige meettechniek, die toepasbaar is voor deeltjesgroottemetingen over een zo groot bereik.

5. Het versnellen van het toerental van een Dieselmotor leidt tot een hogere roetuitstoot in vergelijking met het draaien van een motor op constant toerental [1]: Met de aanleg van verkeersdrempels haalt de overheid een sluipmoordenaar in huis. [1] W.E. Bechtold, J.S. Dutcher, B.V. Mokler, J.L. Pez, I. Wolf, A.P. Li, T.R. Henderson and R.O. McClellan (1984): Chemical and brological properties of Diesel exhaust particles collected during selected segments of a simulated driving cycle. Fund. Appl. Toxicol. 4 (31), 370-377. 
6. Benzinemotoren met directe inspuiting stoten meer zeer fijne deeltjes uit dan moderne dieselmotoren [1]. De dieselmotor staat ten onrechte in een kwaad daglicht.

[1] A. Schrauwers (2005): Fijnstofmeter pikt supervervuilers zo uit het verkeer. Delft Integraal 2005 (4), 3-5.

7. De resultaten van de huidige door de overheid gehanteerde meetmethodes voor het meten van luchtvervuiling representeren niet volledig luchtvervuiling.

E. Buringh and A. Opperhuizen textit (eds.) (2002): On health risks of ambient PM in the Netherlands, Executive summary, RIVM-rapportnr. 650010 033, ISBN 90-6960-100-1.

8. Er zou meer interactie moeten bestaan tussen de verschillende gebieden van wetenschap.

9. Het experiment heeft de toekomst.

10. Als de badkuipcurves van experimentele apparatuur niet op elkaar zijn afgestemd, verandert het lab in een groot zwembad. 

